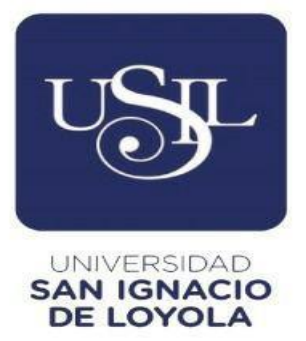

ESCUELA DE POSTGRADO

Maestría en Educación con Mención en Gestión de la Educación

\title{
RÚBRICA PEDAGÓGICA PARA DESARROLLAR LA EVALUACIÓN FORMATIVA EN LOS ESTUDIANTES DEL NIVEL SECUNDARIA DE UNA INSTITUCIÓN EDUCATIVA PARTICULAR EN EL DISTRITO DE SAN MIGUEL
}

Tesis para optar el grado de Maestro en Educación con Mención en Gestión de la Educación

ROSA MARIEL ASCURRA LOZADA Asesor:

Mag. Hernán Gerardo Flores Valdiviezo

LIMA - PERÚ 


\section{Dedicatoria}

A mis amados hijos, Mya Alejandra y Matias

Alejandro, porque me dan las fuerzas necesarias para seguir avanzando en mi vida familiar y profesional. 


\section{Agradecimiento}

A la Universidad San Ignacio de Loyola por abrirme las puertas hacia el conocimiento de la investigación, por tener una excelente plana profesional que han sabido guiarme. También a mi asesor Mgtr. Hernán Flores Valdiviezo que me apoyó, enseñó y tuvo paciencia al acompañarme mientras realizaba cada una de las asesorías hasta culminar la tesis. 


\section{Índice}

Pág.

Dedicatoria

Agradecimiento

Índice de tablas

Índice de figuras

Resumen

Abstract

Introducción $\quad 1$

Planteamiento del problema $\quad 3$

Formulación del problema $\quad 6$

$\begin{array}{lr}\text { Objetivos de la investigación } & 6\end{array}$

Población y muestra, técnica de muestreo cualitativo no probabilístico: unidad de análisis

$\begin{array}{ll}\text { Población } & 7\end{array}$

Muestra y muestreo no probabilístico $\quad 7$

$\begin{array}{lr}\text { Justificación de la investigación } & 8\end{array}$

$\begin{array}{ll}\text { Teórica } & 8\end{array}$

Metodológica 99

$\begin{array}{ll}\text { Práctica } & 9\end{array}$

Social 9

Metodología de la investigación 10

Diseño de investigación 13

Métodos de la investigación 13 
Técnicas e instrumentos

\section{Capítulo I}

Marco teórico

Antecedentes de la investigación

Antecedentes internacionales

Antecedentes nacionales

Fundamentación teórica sobre la categoría de la evaluación formativa

Subcategorías de la evaluación formativa 25

$\begin{array}{ll}\text { Dimensión cognitiva } & 25\end{array}$

$\begin{array}{ll}\text { Dimensión procedimental } & 26\end{array}$

$\begin{array}{ll}\text { Dimensión actitudinal } & 26\end{array}$

$\begin{array}{ll}\text { La metacognición en la evaluación formativa } & 27\end{array}$

La retroalimentación en la evaluación formativa $\quad 28$

Fundamentación teórica sobre la categoría de la rúbrica pedagógica 29

Subcategorías de la rúbrica pedagógica 30

$\begin{array}{ll}\text { Desempeño del estudiante } & 30\end{array}$

Rol del docente $\quad 31$

Niveles de dominio del uso de las rúbricas 32

$\begin{array}{ll}\text { Características de las rúbricas } & 34\end{array}$

$\begin{array}{ll}\text { Importancia de las rúbricas } & 35\end{array}$

$\begin{array}{ll}\text { Evaluación con rúbricas } & 35\end{array}$ 


\section{Capítulo II}

Trabajo de campo

$\begin{array}{ll}\text { Diagnóstico } & 37\end{array}$

Análisis, interpretación y discusión de los resultados 37

Presentación de resultados por técnicas e instrumentos 38

Observación del proceso de enseñanza aprendizaje $\quad 38$

$\begin{array}{ll}\text { Entrevista a los docentes } & 40\end{array}$

$\begin{array}{ll}\text { Cuestionario a estudiantes } & 47\end{array}$

Análisis e interpretación de las categorías apriorísticas y emergentes 53

$\begin{array}{ll}\text { Conclusiones } & 63\end{array}$

\section{Capítulo III}

$\begin{array}{ll}\text { Propósito de la propuesta metodológica } & 67\end{array}$

$\begin{array}{ll}\text { Fundamentación de la propuesta } & 67\end{array}$

$\begin{array}{ll}\text { Diseño de la propuesta metodológica } & 75\end{array}$

$\begin{array}{ll}\text { Desarrollo o implementación } & 77\end{array}$

Orientaciones para la aplicación de la propuesta 106

Validación de la propuesta metodológica por criterio de expertos 108

$\begin{array}{ll}\text { Conclusiones } & 114\end{array}$

$\begin{array}{ll}\text { Recomendaciones } & 116\end{array}$

$\begin{array}{ll}\text { Referencias } & 118\end{array}$

Anexos 


\section{Índice de tablas}

\section{Pág.}

Tabla 1. Categorías y subcategorías 11

Tabla 2. Áreas curriculares, competencias, niveles educativos de Educación 79

Básica regular.

Tabla 3. Indicadores de niveles de dominio. $\quad 82$

Tabla 4. Rúbrica para la comunicación oral $\quad 84$

Tabla 5. Rúbrica para la producción de textos 86

Tabla 6. Rúbrica para la comprensión de textos $\quad 89$

$\begin{array}{ll}\text { Tabla 7. Datos de expertos } & 108\end{array}$

Tabla 8. Tabla de valoración 109

Tabla 9. Criterio de validación interna de la propuesta 110

Tabla 10. Criterio de validación externa de la propuesta 111

Tabla 11. Puntuación y promedio 112

Tabla 12. Resultado y consolidado de la valoración interna y externa 115 


\section{Índice de figuras}

Pág.

Figura 1. Categorías apriorísticas y emergentes $\quad 54$

Figura 2. Dimensión cognitiva $\quad 55$

$\begin{array}{lll}\text { Figura 3. Dimensión procedimental } & 57\end{array}$

$\begin{array}{llr}\text { Figura 4. Dimensión actitudinal } & 58\end{array}$

Figura 5. Desempeño del estudiante 59

$\begin{array}{lll}\text { Figura 6. Niveles de dominio } & 60\end{array}$

$\begin{array}{lll}\text { Figura 7. Rol del docente } & 61\end{array}$

Figura 8. Motivación en el proceso de enseñanza y aprendizaje 63

$\begin{array}{lll}\text { Figura 9. Estrategias evaluativas } & 64\end{array}$

Figura 10. Desarrollo de competencias en el área de comunicación 65

Figura 11. Categorías apriorísticas y emergentes 66

Figura 12. Esquema teórico funcional que representa propuesta 76

Figura 13. Conceptualización de competencias, capacidades, estándares y desempeños 78

$\begin{array}{lc}\text { Figura 14. Indicadores de niveles de dominio } & 81\end{array}$ 


\section{Resumen}

La investigación propone la rúbrica pedagógica para contribuir en el desarrollo de la evaluación formativa en los estudiantes de Educación Secundaria de una institución educativa privada para la mejora del proceso de aprendizaje. Por su naturaleza, metodológicamente, el tipo de investigación es aplicada educacional, con un enfoque cualitativo dentro del paradigma interpretativo. La muestra de estudio está conformada por 20 estudiantes y 3 docentes del área de Comunicación, seleccionados mediante la técnica del muestreo no probabilístico, a través de entrevistas, encuestas, observación y análisis. En el diagnóstico pedagógico se emplean diferentes técnicas e instrumentos que brindan información objetiva acerca de las potencialidades y las carencias que presentan en el proceso de enseñanza- aprendizaje en el uso de la evaluación formativa. Así, el resultado más importante está en que los docentes desarrollen la evaluación formativa para poder formar integralmente a sus estudiantes, donde puedan regular su aprendizaje en el proceso educacional con la planificación, monitoreo, evaluación de aprendizajes, el trabajo colaborativo y logren aprendizajes significativos con una adecuada mediación docente. Dado el fundamento científico de diferentes ciencias que inciden en el objeto de investigación, la rúbrica pedagógica se convierte en una herramienta de un valor extraordinario para que el docente dirija el proceso enseñanza - aprendizaje desde perspectivas flexibles y abiertas, en donde se involucra a los estudiantes en su propio proceso evaluativo para contribuir en la mejora de sus aprendizajes y por ende en su formación integral.

Palabras clave: Rúbrica pedagógica, evaluación formativa, planificación, evaluación, monitoreo, trabajo colaborativo, aprendizaje significativo. 


\begin{abstract}
The research proposes the pedagogical rubric to contribute in the development of the formative evaluation in the students of Secondary Education in a private Educational Institution to improve their learning process. Due to its methodological nature, its design is applied projectively, with a qualitative approach within the interpretive paradigm. The study sample is made up of twenty students and three teachers from the communication area, selected through the sampling technique, through interviews, surveys, observation and analysis. In the pedagogical diagnosis, different techniques and instruments are used to provide objective information about the potentialities and deficiencies that they present in the teaching-learning process in the use of formative assessment. Thus, the most important result is that teachers use formative evaluation to be able to develop their students comprehensively, where they can regulate their learning in the process with planning, monitoring, evaluation of learning, collaborative work and achieve significant learning with adequate teacher mediation. Given the scientific foundation of different sciences that affect the research object, the pedagogical rubric becomes a tool of extraordinary value for teachers to direct the teaching-learning process from flexible and open perspectives where students are involved in their own evaluation process to contribute to the improvement of their learning and therefore in their comprehensive training.
\end{abstract}

Keywords: Pedagogical rubric, formative evaluation, planning, evaluation, monitoring, collaborative work, meaningful learning. 


\section{Introducción}

Las nuevas tendencias educativas en el siglo XXI y la necesidad de potencializar el proceso de enseñanza aprendizaje a través de la evaluación formativa en los estudiantes para la mejora del aprendizaje son vitales para el rendimiento en el proceso de aprender a aprender. En lo que respecta la escuela peruana necesita adecuarse a cambios para que los futuros ciudadanos den respuestas efectivas a las características y demandas de la sociedad actual. El rol del docente en el aula debe ser el requerido por la demanda de la sociedad actual, cambiando su enfoque evaluativo tradicional a uno formativo. Al respecto, Casanova (2012): "la sociedad avanza y la educación no puede ni debe quedarse atrás si pretende preparar para la vida a las jóvenes generaciones" (p. 9). Si la educación quiere satisfacer las demandas de la sociedad actual, sus metas esenciales deben dirigirse al fomento en los estudiantes de las "capacidades de gestión del conocimiento, o de gestión metacognitiva, ya que solo así, más allá de la adquisición de conocimientos concretos, podrán enfrentarse a las tareas y a los retos que les esperan en la sociedad del conocimiento" (Pozo, 2006).

Por lo que se refiere, los docentes ponen los escenarios para que los alumnos logren aprender mediante su propia actividad pudiendo evaluar su propio proceso de aprendizaje con guía del profesor; siendo el conocimiento construido por el propio sujeto, asimilándolo y acomodándose a él. Entonces, el profesor facilita el aprendizaje evaluando el proceso de sus estudiantes formativamente, creando las situaciones en las cuales el alumno aprenda a partir de su propia actividad utilizando herramientas que permitan saber qué es lo que se espera de él. Hoy el conocimiento ya no es aplicable solo al ser sino más bien al hacer.

Por ello, se plantea una rúbrica que permita la evaluación formativa para el estudiante que por medio del aprender a aprender (metacognición) en sus actividades en clases, sus 
conocimientos y competencias sean construidas. Valverde (2014) refiere que durante el proceso de utilización de las rúbricas, como parte de la evaluación formativa del estudiante se progresan y forman competencias; menciona también que las rúbricas no sólo evalúan, si no también enseñan durante el proceso centrado en el aprendizaje.

En lo que respecta las rúbricas se utilizan en todas las áreas de conocimiento y para todo tipo de actividades de evaluación, en este caso se utiliza para el desarrollo de la evaluación formativa en el proceso de aprender a aprender. Las rúbricas se utilizan, para profundizar en una evaluación para el aprendizaje, donde interesa la calidad del feedback que recibe el estudiante durante el proceso de evaluación y las repercusiones que tiene en la mejora de los aprendizajes, y otros docentes las usan como instrumento para evaluar el trabajo del estudiante como nos menciona Andrade (2000).

Por ello el docente debe reflexionar sobre los procesos de enseñanza - aprendizajes, cuya prioridad consiste en el fomento de un aprendizaje autónomo, autorregulado y continuo, que permita orientarse en la gran cantidad de información disponible, convirtiéndola en conocimiento. La propuesta de aplicación de las rúbricas dentro de una evaluación formativa permite a los estudiantes adquirir herramientas necesarias para el fomento del aprendizaje.

El papel del profesor para apoyar este proceso siendo mediador, orientador y retroalimentador para el logro de los aprendizajes a través de una evaluación permanente. Por lo expuesto, es muy importante que los sujetos al generar conocimiento, conozcan su propio funcionamiento cognitivo para autorregularse, planificarse y organizarse en las actividades académicas; que los cambios o ajustes que se hagan durante su trabajo se instruyan, monitoreen; que sean capaces de evaluarse a sí mismos en sus tareas, permitiendo mejorar su trabajo y hacer 
las revisiones necesarias durante y después de finalizar las diferentes etapas del aprendizaje (Flavell, 1981; Brown, 1987).

\section{Planteamiento del problema}

Actualmente, la pedagogía ha tenido diversos cambios, ahora en pleno siglo XXI, muchos estudios informan de metodologías, estrategias, desempeños, didácticas, estándares, modelos de evaluación, entre otros. El triunfo de la educación se basa en formación de competencias básicas, insertando nuevos enfoques y estrategias en el aula que generen aprendizajes significativos. Siendo una de las finalidades educativas, garantizar el desarrollo metacognitivo de los estudiantes, estimular el desarrollo afectivo, creativo y formación en valores para ser buenos ciudadanos como nos informa la Unesco (2005).

Al respecto, consideramos a Trahtemger (2006) quien refiere que la pedagogía parte del interés de los estudiantes. El docente del sigo XXI, investiga, analiza las características de sus alumnos, lo que quieren aprender y cómo lo lograrán, cuáles son las formas de aprendizaje que lo motiva, qué estrategias podría usar en el aula o qué tipo de evaluación utilizará para los procesos de la clase. El profesor no es ahora un impartidor de conocimientos, sino que debe adecuarse a los intereses y motivaciones de sus estudiantes para lograr que ellos aprendan. Por lo planteado, los docentes tienen que observar que despierta en sus alumnos ese interés, buscando alternativas concretas para efectivizar el aprendizaje.

El Ministerio de Educación del Perú (Minedu, 2015) refiere sobre la comunicación, la cognición y la metacognición; estableciendo que los alumnos con mayor eficacia son conscientes de sus saberes y sus procesos, de lo que les falta para lograr sus aprendizajes; asimismo, los estudiantes que se encuentren frente a una dificultad o situación acuden a una ejecutar diversas estrategias para lograr la meta planteada, el resultado esperado o el objetivo. 
Cabe señalar que existen teorías del aprendizaje que amplían el conocimiento respecto a las formas de aprendizaje de los estudiantes. Ausbel (1976) en su teoría sobre el aprendizaje significativo enfatizo la conexión de los nuevos conocimientos a partir de la integración de los saberes previos; también habla del proceso de enseñanza y aprendizaje, según la parte cognitiva dándole importancia a la comprensión, almacenamiento, transformación y de cómo se usa la información.

En la escuela los docentes deben hacer partícipes a los estudiantes, involucrándolos para que puedan construir y ampliar sus conocimientos, trabajando durante el proceso con la evaluación formativa; esto es fundamental para su desarrollo cognitivo; por lo tanto la pedagogía tradicionalista queda ya desfasada de la práctica educativa por los avances científicos y teóricos; la memorización, la escucha pasiva, el docente que solo impartía conocimientos, el docente que y no desarrollaba procesos de trabajos con los estudiantes, entre otros.

En el Plan Nacional Educación para Todos (2005) se sostiene que una de las metas primordiales del plan es optimizar la calidad educativa, por ende el mejoramiento de la educación, ya que los resultados de logro que se dan el marco nacional y regional son deficientes, escasos y desiguales. En este documento también se describen políticas educativas, una de ellas y de vital importancia referida al desempeño del docente para el mejoramiento continuo, reforzando las competencias pedagógicas que le permitan insertar en el aula estrategias para el logro de aprendizajes de sus estudiantes.

De aquí la importancia de fomentar en la escuela un lugar vital para construcción de conocimientos de los estudiantes, donde el docente enseña a sus estudiantes a autorregular y construir sus aprendizajes, motivándolo y enseñándoles a evaluar sus procesos durante las clases para su mejora continua o la de su equipo en el trabajo colaborativo. 
Cabe mencionar que el estado peruano sostiene nuevas políticas y mecanismos para una educación de calidad hacia todos los educandos, por ello es importante la eficacia del trabajo docente donde este sea guía y el estudiante participe de su propio aprendizaje. En las aulas el generador de aprendizaje y motivación en los educandos, son los profesores; por ello la importancia de que siempre se encuentren actualizados y capacitados en miras de su mejor desenvolvimiento en el aula con sus estudiantes buscando las mejores estrategias para lograr el aprendizaje en cada uno de ellos por ejemplo usando la evaluación formativa.

Muchos de los docentes de ahora aún se encuentran inmersos en prácticas educativas tradicionales y desfasadas, donde no se hace protagonista de su aprendizaje al estudiante, esto hace que no utilicen todo su potencial en las sesiones de clase, ya que no existen estrategias evaluativas donde el docente y el estudiante evalúen sus procesos para el mejoramiento continuo de sus actividades utilizando la retroalimentación.

El trabajo de investigación tiene la visión de implementar mejoras en el proceso de enseñanza-aprendizaje, donde los actores principales sean los estudiantes, a través de una rúbrica pedagógica que será utilizada como retroalimentación del proceso de planificación, autorregulación, monitoreo y evaluación como objetivo fundamental mejorar el aprendizaje en el aula desarrollando la evaluación formativa, siendo este un pilar fundamental.

En la actualidad, en que la sociedad avanza y se ve enriquecida de valiosos aportes a nivel educativo, ya sea en lo internacional o nacional, expuesta la realidad del mundo, nuestro país y la realidad de la problemática presentada, motiva a realizar la investigación titulada sobre la rúbrica pedagógica para el desarrollo de la evaluación formativa en los estudiantes de Educación Secundaria de una institución educativa particular del distrito de San Miguel. 


\section{Formulación del problema}

\section{Pregunta científica general.}

¿Cómo desarrollar la evaluación formativa en los estudiantes de segundo de Secundaria de una institución educativa particular en el distrito de San Miguel?

\section{Preguntas científicas específicas.}

¿Cuál es el estado actual de la evaluación formativa en los estudiantes de segundo de Secundaria de una institución educativa particular en el distrito de San Miguel?

¿Cuáles son los fundamentos teóricos de la propuesta de rúbricas pedagógicas para contribuir al desarrollo de la evaluación formativa en los estudiantes de segundo de Secundaria de una institución educativa particular en el distrito de San Miguel?

¿Qué criterios se tendrán en cuenta en la modelación de la propuesta de rubrica pedagógica para contribuir al desarrollo de la evaluación formativa en los estudiantes de segundo de Secundaria de una institución educativa particular en el distrito de San Miguel?

¿Cuáles son las potencialidades curriculares de la rúbrica pedagógica para contribuir en el desarrollo de la evaluación formativa en los estudiantes de segundo de Secundaria de una institución educativa particular en el distrito de San Miguel?

\section{Objetivo general.}

Proponer la rúbrica pedagógica para desarrollar la evaluación formativa en los estudiantes de segundo de Secundaria de una institución educativa particular en el distrito de San Miguel. 


\section{Objetivos específicos o tareas científicas.}

Diagnosticar el estado actual de la evaluación formativa de los estudiantes de segundo de Secundaria de una institución educativa particular en el distrito de San Miguel.

Sistematizar los fundamentos teóricos de una rúbrica pedagógica para el desarrollo de la evaluación formativa de los estudiantes de segundo de Secundaria de una institución educativa particular en el distrito de San Miguel.

Determinar los criterios teóricos y metodológicos para la modelación de la propuesta de una rúbrica pedagógica para desarrollar la evaluación formativa en los estudiantes de segundo de Secundaria de una institución educativa particular en el distrito de San Miguel.

Identificar las potencialidades curriculares de validez de la rúbrica pedagógica para el desarrollo de la evaluación formativa de los estudiantes de segundo de Secundaria de una institución educativa particular en el distrito de San Miguel.

\section{Población y muestra, técnica de muestreo cualitativo no probabilístico}

\section{Población, muestra y muestreo no probabilístico.}

En la investigación cualitativa, la lógica que sitúa a este tipo de muestreo reside en lograr que en los casos elegidos se proporcione una mayor riqueza de información posible para estudiar en profundidad la pregunta de investigación como lo explica Patton (2002). La población la forman 285 estudiantes de una institución educativa donde se realizó el diagnóstico y los docentes de las áreas escolares.

La muestra se integra por 20 estudiantes que estudian en el segundo grado de Secundaria quienes se observa en el proceso de enseñanza-aprendizaje durante sus clases; se aplicaron 3 entrevistas a las profesoras y a los 20 estudiantes un cuestionario semiestructurado para 
determinar si se está trabajando la evaluación formativa, para lograr aprendizajes óptimos. Para validación de la rúbrica pedagógica se seleccionan tres expertos que cumplen con los siguientes criterios una especialista gestora de la educación y dos docentes con el grado de doctor.

\section{Unidades de análisis en la investigación}

El objeto de estudio está constituido por unidades de análisis que son las docentes del área de Comunicación y los estudiantes del segundo de Secundaria, respecto a las categorías y subcategorías identificadas en el desarrollo de la evaluación formativa.

\section{Justificación de la investigación}

Considerando que la evaluación formativa es una parte elemental de la práctica docente para la generación de aprendizajes significativos en los estudiantes de la institución educativa particular, la propuesta de la rúbrica pedagógica como resultado de la investigación, contribuirá notablemente en la mejora de los aprendizajes y así elevaremos la calidad de la educación, por lo que se asume la necesidad del desarrollo de los criterios pedagógicos que permiten la justificación de la investigación en los siguientes aspectos.

\section{Teórica.}

Teóricamente, se examinaron y sistematizaron los antecedentes referidos al tema investigado a nivel internacional y nacional. Las tendencias, enfoques y teorías nos permitieron estudiar y lograr los objetivos planteados, las categorías de estudio nos ayudaron a comprender desde el método científico y los diferentes procedimientos conceptuales desarrollaron un marco teórico de acuerdo con los requerimientos científicos.

\section{Metodológica.}


Con respecto a lo metodológico, para lograr el objetivo de estudio, se realizó la elaboración de la rúbrica pedagógica, dándose su aplicación mediante la observación y monitoreo de las actividades de aprendizaje en el aula con los estudiantes, que buscan desarrollar la evaluación formativa para que ellos puedan ponerlo en práctica en su proceso de enseñanza - aprendizaje; con la finalidad de la mejora de los aprendizajes, siendo el estudiante participe de estos. Las rúbricas demuestran en esta investigación su validez y confiabilidad pudiendo ser utilizadas en otros trabajos de investigación y en otras instituciones educativas.

\section{Práctica.}

En el aspecto práctico, la investigación será útil para todas las personas que conforman el proceso educativo, a los docentes en beneficio de los estudiantes; igualmente para los directivos que van a guiar y acompañar el proceso de enseñanza- aprendizaje, para la mejora de su práctica pedagógica mediante el desarrollo de la evaluación formativa de los educandos a través de la aplicación de la rúbrica pedagógica.

\section{Social.}

En el ámbito social, la investigación hará reflexionar sobre la evaluación formativa que se promueve en el aula, los instrumentos aplicados para la mejora de aprendizaje, que aportan significativamente a potenciar el desarrollo personal y la socialización conjunta de saberes, donde la construcción del conocimiento sea primordial, por medio de la planificación, regulación y evaluación, dentro del proceso de enseñanza. La educación escolar tiene una evidente función socializadora, cuando las prácticas educativas en el aula son formativas y centradas en los estudiantes estableciendo metas u objetivas comunes, los estudiantes aprenden a relacionarse los unos a los otros, formándose habilidades comunicativas y de liderazgo educativo. 


\section{Metodología de la investigación}

La investigación presenta a la rúbrica pedagógica que permitirá a los docentes contar con un apoyo orientativo y estructural en el desarrollo de la evaluación formativa de sus estudiantes para que contribuyan en el fortalecimiento del aprendizaje. La metodología de la investigación permite tener la información necesaria y conocimientos sobre la evaluación formativa donde se deben tener en cuenta en los procesos de planificación, regulación o monitoreo y evaluación de los aprendizajes en el contexto educacional, insertando una herramienta que será capaz de enseñar a los estudiantes mediante la retroalimentación constante del docente en el proceso enseñanza-aprendizaje.

Por ello, la investigación permitirá proponer conclusiones para fortalecer los aprendizajes de los estudiantes y mejorar el rendimiento escolar, implementando herramientas evaluativas que permitan fortalecer los procesos para dar un nuevo enfoque en las sesiones de aprendizaje en donde se desarrollen las competencias estudiantiles en el desarrollo de los procesos educativos mediante la rúbrica pedagógica.

En tal sentido, considerando las nuevas metodologías innovadoras en clase, el docente logra transmitir saberes empleando la evaluación formativa y la rúbrica pedagógica de la investigación. Los resultados del trabajo investigativo podrán ser útiles a diversas instituciones educativas de nivel básico regular ya sea en colegios privados o públicos del país. 


\section{Categorías apriorísticas y subcategorías de investigación}

García (2010) define que las categorías representan un concepto que se usa en el proceso investigativo para ir explicando o respondiendo el problema planteado inicialmente, partiendo de los propósitos y marco teórico; el investigador define las categorías y luego de la conceptuación de cada categoría, se operacionalizan mediante un resultante conceptual de subcategorías. Las subcategorías son atributos o características de las categorías, representan el detalle de la información que desea investigar. Cada categoría tiene un grupo de subcategorías que delimitan qué y cómo se va a investigar.

Tabla 1.

Categorías y subcategorías.

\section{CATEGORIAS}

Montalván (2016) refiere que la evaluación formativa es parte intrínseca del proceso de enseñanza- aprendizaje, en la cual, el profesor considera el avance y las dificultades con el objetivo de corregir, mejorar o reajustar, comunicando oportunamente a los estudiantes acerca de los resultados. El docente aplica estrategias y usa instrumentos de evaluación que le permite observar el progreso de los aprendizajes, los estudiantes reflexionan a través de la metacognición sobre sus aciertos o desaciertos con la finalidad de que en lo sucesivo puedan mejorar.

\section{Rúbrica pedagógica:}

Las rúbricas o matrices de valoración son guías o escalas de evaluación donde se establecen niveles progresivos de dominio o pericia relativos al desempeño que una persona muestra un amplio rango de criterios que cualifican el modo progresivo el tránsito de un desempeño incipiente o novato al grado del experto. Son escalas ordinales que destacan una evaluación del desempeño centrada en aspectos cualitativos, aunque es posible el establecimiento de puntuaciones numéricas. Díaz y De la Cruz (2011).
- Dimensión cognitiva

- Dimensión procedimental

- Dimensión actitudinal

Fuente: Elaboración propia. 
Las subcategorías apriorísticas se consideran dentro de la matriz metodológica de la tesis y de categorización; cuando se aborda la discusión de los resultados después del complejo proceso de la codificación y triangulación, se verifico su validez conceptual con las categorías emergentes, que se definen en el marco teórico en el diagnóstico o trabajo de campo y en la modelación de la propuesta.

\section{Tipo de investigación}

La investigación cualitativa está ubicada en el paradigma socio crítico e interpretativo, argumentativo y narrativo, que responde a una investigación educacional de tipo aplicada, que busca la aplicación o uso de conocimientos, mientras se adquieren otros, luego de la implementación y sistematización de la práctica de la investigación educacional. Esta investigación educacional también se caracteriza por tratar el problema científico desde un punto de vista epistemológico crítico social en el que dialécticamente se integran los diferentes métodos como refiere Murillo (2008).

Según Schuster et al. (2013). El paradigma interpretativo intenta interpretar y comprender la conducta humana desde los significados e intenciones de los sujetos que intervienen en la escena educativa, acentúan la comprensión y estudian sus intenciones, creencias, motivaciones y otras características no directamente manifiestas (p. 109).

La autora identificó el problema desde su mirada de gestor educacional y resultados de rendimiento escolar del proceso en la práctica pedagógica, a través de la fundamentación teórica se realizó el análisis de la problemática, analizando las causas y consecuencias; por ello, realiza la propuesta de investigación implementando una rúbrica pedagógica para el desarrollo de la evaluación formativa que se dispone a la transformación del proceso de enseñanza-aprendizaje 
de los estudiantes del segundo grado de Educación Secundaria de una institución educativa particular.

\section{Diseño de investigación}

El diseño de investigación es descriptivo e interpretativo porque buscará recolectar la información, evaluarla y valorarla sobre aspectos, dimensiones del campo o categorías de estudio. Hernández, Fernández y Baptista, (2014) mencionan que "los estudios descriptivos pretenden medir o recoger información de manera independiente o conjunta sobre los conceptos o las variables a los que se refieren”, (p. 118). También se puede aseverar que los estudios descriptivos buscan analizar las propiedades, características y faces de fenómenos u objeto que se estudian.

\section{Métodos}

Tomando en consideración de la organización de los métodos de investigación, en cuanto al nivel teórico y empírico propusimos lo siguiente:

\section{Métodos de nivel teórico}

Para sintetizar lo objetivos planteados en la presente investigación se utilizaron un conjunto de métodos científicos del nivel teórico y empírico, como:

\section{Método histórico- lógico.}

Según Torres (2016) este método se basa en datos históricos para descubrir leyes que rigen el desarrollo del objeto de investigación y lo histórico no se limita a la explicación de los hechos o descripción, sino que requiere una mayor ilustración partiendo de la lógica del objeto definido (p.10).

Este método nos permitirá conocer el desarrollo histórico lógico de la evaluación formativa y de la rúbrica pedagógica. Empleándose los antecedentes históricos, origen, 
evolución y estado actual del estudio. También como el diseño propuesto contribuye al desarrollo de las estrategias en los estudiantes.

Método de análisis- síntesis.

Según Cerezal y Fiallo (2016), indican que los métodos son importantes, en el análisis se estudian los factores de la investigación individualmente, descomponiendo y estudiando el todo en partes y en la síntesis se estudia las relaciones e interrelaciones de los factores, integrándolos y buscando relaciones.

Con este método se analizaron los documentos y resultados alcanzados de los instrumentos aplicados, esto nos dio una visión para enriquecer los fundamentos teóricos y contribuir a desarrollar la evaluación formativa de los estudiantes.

\section{Método de la Modelación.}

Cerezal y Fiallo (2016), señalan que es el método donde se construye una representación para estudiar la realidad permitiendo lograr hacer abstracciones, con detalles, características y conexiones del objeto de estudio, obteniendo explicaciones y orientando las hipótesis teóricas.

Se utiliza para diseñar la rúbrica pedagógica que caracteriza los fundamentos teóricos y metodológicos para el desarrollo de la evaluación formativa en los estudiantes del segundo grado de educación secundaria.

\section{Método de inducción- deducción}

El método inductivo se fundamenta en la lógica con sucesos particulares entonces los conocimientos pasan de lo particular a lo general, por otro lado el método deductivo va del conocimiento general a lo especifico como lo menciona Bernal (2010).

Se utilizó en la investigación para plantear deducciones lógicas, organizando categorías, subcategorías e indicadores en el marco teórico apriorístico y emergente después del proceso de 
triangulación y la estructura metodológica.

\section{Método de lo abstracto a lo concreto}

El método de lo abstracto a lo concreto parte de una percepción concreta identificándola en la realidad con algunas características detectables fácilmente, dando una cierta explicación al investigador, mediante el conocimiento abstracto podemos conocer cualidades primordiales del objeto de investigación como lo sostiene Cerezal y Fiallo (2016).

En la investigación primero se han recopilado datos concretos de los miembros de la comunidad educativa a través de los instrumentos aplicados y posteriormente el análisis de la información nos permite estructurarla.

\section{Métodos empíricos}

Cerezal y Fiallo (2016), sustentan que los métodos empíricos permiten obtener datos en la práctica realizada y obtener características propias del estudio, para analizarlas y buscar respuestas a las preguntas científicas; formando así el conocimiento.

En la investigación este método se usa al recolectar la información mediante las entrevistas, respuestas al cuestionario y la observación de clases, los resultados de los datos, permitió analizar el estado actual de los estudiantes y docentes respecto al desarrollo de la evaluación formativa en clase, logrando emplear las rúbricas para la mejora del rendimiento.

\section{Método matemático o estadístico}

Los métodos matemáticos y estadísticos son importantes, como lo señalan Cerezal y Fiallo (2016), porque al establecer la muestra se tabulan y procesan datos empíricos.

En la investigación se empleó para realizar los análisis con porcentajes y procesamiento datos obtenidos de los instrumentos aplicados, a través de la estadística descriptiva, sirvió para procesar la información obtenida del diagnóstico y así realizar el análisis correspondiente. 


\section{Técnicas e instrumentos}

Durante la investigación se emplearon varios métodos del nivel empírico, conocidos también como técnicas y fueron los siguientes:

\section{Observación del proceso de enseñanza aprendizaje.}

Se trabajó con el propósito de observar al docente en el proceso de enseñanza-aprendizaje, evidenciando el fortalecimiento de la evaluación formativa para sus estudiantes, se empleó una guía de observación de las clases. También se observaron a los estudiantes en el proceso pedagógico, la interiorización de las diferentes formas de evaluativas y se verificará el nivel de aprendizaje.

Encuestas a estudiantes.

Se aplicó a los estudiantes del segundo de secundaria para conocer el nivel de uso de la evaluación formativa en su aprendizaje, para este fin se elaboró un cuestionario.

\section{Criterio de expertos.}

Los expertos son los especialistas seleccionados con el objetivo de que emitan sus criterios científicos acerca de la validez y pertinencia de la rúbrica pedagógica para el desarrollo de la evaluación formativa.

\section{Entrevistas.}

Se realizó entrevistas a la muestra de docentes del área de Comunicación de la institución educativa, que permitió conocer el estado actual de su trabajo en el aula referente a la evaluación formativa y uso de herramientas evaluativas generadoras de aprendizaje. 


\section{Validación de instrumentos}

La validación de instrumentos se realizó a través de juicio de expertos, los instrumentos de recolección fueron entregados a dos expertos metodólogos y un temático, con grado de doctores y magister, emitiendo a sus juicios, la validez, para la aplicación. Cada experto recibió la ficha para la validación, los instrumentos y la matriz de categorías. Los expertos validaron de manera independiente la relevancia, pertinencia y construcción gramatical de los ítems de cada uno de los instrumentos (ver anexo 3).

\section{Estructura de la tesis}

El trabajo se desarrolla mediante la sección de la introducción y tres capítulos.

Capítulo I: Marco teórico. En este capítulo se dan a conocer los antecedentes de la investigación a nivel internacional y nacional, los fundamentos teóricos que sustentan las categorías de investigación: Evaluación formativa y rúbrica pedagógica. Por ello, se ha realizado la sistematización de la información a partir de su análisis crítico y reflexivo.

Capítulo II: Diagnóstico o trabajo de campo. El capítulo está dedicado a conocer el estado actual del objeto investigado. Para desarrollar las tareas empleadas en esta investigación se trabajó con una población de 265 estudiantes y 3 docentes del área curricular de comunicación integral de una institución educativa particular en el distrito de san miguel. La muestra se conformó por 40 estudiantes del segundo año de educación secundaria y docentes del curso en mención. En la práctica pedagógica del proceso de enseñanza aprendizaje los docentes fueron observados, seguidamente fueron entrevistados para determinar sus conocimientos teóricos y metodológicos en la aplicación de la evaluación formativa hacia el logro metacognitivo y por ende del aprendizaje. Por su parte, a los estudiantes se les aplicó un cuestionario para determinar 
si el docente promueve la evaluación formativa en el desarrollo de sus sesiones de clase. Para la aplicación de instrumentos se realizó la validación de tres docentes expertos, cuando se obtuvieron los resultados se analizó y se trabajó la triangulación de toda la información recabada, estas servirán para plantear las conclusiones de la elaboración de la propuesta de investigación del capítulo tres de la tesis, llamado modelación.

Capítulo III: Modelación y Validación de la propuesta metodológica. En capitulo consta de la modelación de la propuesta de rúbricas pedagógicas para el desarrollo de la evaluación formativa en el proceso de enseñanza aprendizaje del área de comunicación de los estudiantes de segundo de secundaria de Educación Básica Regular. A partir de la modelación se realiza la propuesta, como resultado de la triangulación del análisis a nivel metodológico y teórico. El diseño de rúbrica pedagógica tiene como objetivo ser un apoyo para la práctica docente en el proceso de enseñanza aprendizaje en educación secundaria, este sirve para orientar su práctica hacia el nuevo tipo de evaluación formativa que se debe insertar en las escuelas. 


\section{Capítulo I}

\section{Marco teórico}

\section{Fundamentación teórica de la investigación}

\section{Antecedentes de la investigación.}

Antecedentes de las investigaciones realizadas en el ámbito internacional y nacional sobre la evaluación formativa y rúbrica. Diversos autores han investigado sobre el desarrollo de la evaluación formativa y la utilización de la rúbrica como herramienta en el proceso enseñanzaaprendizaje.

\section{Antecedentes internacionales.}

Guajardo (2011) en su tesis para obtener su grado de magíster realizó una investigación en la que tenía como objetivo la implementación de la evaluación formativa en una institución educativa, esta influencio en el rendimiento escolar de los estudiantes; de tal modo, en esta investigación se realizaron dos estudios con base en métodos mixtos, es decir, los datos se recolectaron a partir de técnicas cuantitativas, esta metodología permitirá contribuir al conocer la realidad del ejercicio docente facilitando información de las fortalezas y debilidades. De tal manera, una de las conclusiones es que la evaluación formativa tiene como principal objetivo conocer en qué grado los estudiantes han desarrollado las capacidades o competencias establecidas, detectando posibles errores o carencias en la adquisición de los conocimientos, ofrecer al profesor información valiosa que los oriente en el proceso de aprendizaje de sus alumnos, ayudándolos a conocerse a sí mismos y a desarrollar su propia autoestima, valorar los métodos y procedimientos empleados, re direccionar el rumbo sobre las prácticas educativas, determinar el adecuado contenido de los programas y seleccionarlo de acuerdo a su valor formativo. 
Sironi (2014) en su investigación para obtener su grado de magister abordo el tema de la evaluación formativa, siendo una investigación cualitativa - descriptiva; una de las conclusiones fueron que el cambio de la forma de evaluación en el aula propició una clase constructivista otorgando importancia al diálogo, al trabajo en equipo y a la retroalimentación entre pares; estos cambios permitieron un avance en el aprendizaje de los estudiantes y desarrollaron habilidades de comunicación.

Ninabanda (2014) realizó su tesis respecto a la rúbrica como herramienta pedagógica en la evidencia de resultados de aprendizaje para obtener su grado de magister en Gerencia Educativa; fue una investigación cualitativa aplicada correlacional, donde se realizaron una serie de encuestas y entrevistas, la población y la muestra estuvo conformada por treinta y cuatro estudiantes y diez docentes del área de ciencias naturales para determinar la eficacia de la rúbrica en función a los aprendizajes de los estudiantes. Una de las conclusiones que llegó el autor fue que la aplicación de la rúbrica hizo que mejorará en un $80 \%$ la motivación de los estudiantes hacia el aprendizaje y los beneficios de la aplicación de las rúbricas como instrumentos adecuados para lograr el desarrollo y la formación de criterios adecuados durante el proceso de enseñanza-aprendizaje.

Ruiz (2014) elaboró una tesis para obtener el grado de doctora en Educación referida al análisis de las rúbricas para la evaluación de la expresión oral y escrita en los estudiantes de su muestra. Fue una investigación de tipo cuantitativa experimental, de tal manera que nos manifiestan la conclusión de que la rúbrica es un instrumento que unifica criterios de evaluación entre docentes, y a la vez permite que el estudiante se implique en el proceso evaluador cuando conoce la herramienta con qué será evaluado, los estudiantes y docentes consideran útiles las rubricas como instrumentos útiles para la evaluación oral y escrita. 
Cruz (2008) realizó una investigación donde se analiza y profundiza la evaluación formativa y autorregulación, esta investigación fue de tipo cualitativo descriptivo y los hallazgos fueron variados, en general mostraron que la aplicación de la evaluación formativa trajo efectos positivos en cuanto a promover el desarrollo de la autorregulación en el estudiante a través de los procesos metacognitivos; sin embargo, este tipo de evaluación requiere un proceso largo, sistematizado y planificado para que sea eficaz.

\section{Antecedentes nacionales.}

Tarazona (2011) trabajo su tesis para obtener el grado de magister en Educación referida a la evaluación formativa y llegó a la conclusión que dicha evaluación debe comprender todo el proceso educativo y no sólo tome en cuenta los resultados; permitiendo el seguimiento continuo de aquellos estudiantes que presentan mayores dificultades de aprendizaje; siendo esta propuesta importante para elevar el rendimiento escolar, a través de la reflexión continua, sistemática e integrada sobre la acción educativa, implementando las acciones que son necesarias para obtener mejores resultados en la valoración del desarrollo cognitivo. La investigación fue un estudio explicativo, por tanto, también está dentro del método cuantitativo.

Quintana (2018) realizó su tesis sobre el desarrollo de la evaluación formativa de los aprendizajes en el segundo ciclo de Educación Básica Regular en una institución educativa nacional del distrito de Ate. La investigación es de enfoque cualitativo, empírico y de nivel descriptivo. Durante el análisis de la investigación se observó la ausencia de la retroalimentación en el proceso de enseñanza, la regulación y el registro continuo de las observaciones en clase de los estudiantes; elementos que son claves en la evaluación formativa. Una de las conclusiones de la investigación es que los profesores deben de reflexionar sobre la finalidad de la evaluación formativa y de buscar estrategias de cómo impartirla en las aulas para poder desarrollarla de una 
adecuada manera; esta debe permitir al estudiante alcanzar los objetivos de aprendizaje autorregulándose, y construyendo una cultura de formación autónoma. De tal forma, es importante que el docente cree situaciones en donde se propicie la evaluación y retroalimentación, para brindar al estudiante orientaciones, planteamientos, explicaciones y motivaciones, con la finalidad de sentirse apoyado para la mejora de su desempeño.

Pumacayo (2017) realizó su tesis para obtener su grado de maestría, teniendo como objetivo determinar la relación de la evaluación formativa y las habilidades matemáticas desarrolladas en los estudiantes de la carrera de Administración de Empresas de la Universidad Privada SISE. Respecto a la metodología, el enfoque de la investigación fue cuantitativo; el tipo de investigación no experimental y el diseño metodológico es correlacional. La población y muestra total conformada por 173 estudiantes del primer ciclo de las carreras de Administración de Empresas. Una de las conclusiones de la investigación es que se deben priorizar metodologías y estrategias evaluativas en los procesos de enseñanza y aprendizaje como recurso didáctico basados en el trabajo cooperativo y participativo para mejorar en el desarrollo de las habilidades matemáticas en los alumnos.

Urrutia (2015) realizó su tesis para obtener el título de segunda especialidad, el objetivo de su investigación fue aplicar rúbricas en las clases para evaluar los aprendizajes significativos dentro del enfoque por competencias del área de Matemática. La investigación se realiza dentro del paradigma socio crítico, el tipo de investigación es cualitativa, denominada investigación acción en la modalidad investigación de aula. Las conclusiones de la investigación fueron que la rúbrica es un instrumento útil y necesario para el alumno, ya que se evidencia la evaluación más real, acorde al logro de las capacidades y potencialidades de los estudiantes. La aplicación de rúbricas como instrumento de evaluación incrementaron positivamente la frecuencia de 
participación en el aula, el nivel de reflexión y la capacidad de organización de la información; a su vez ayuda a descubrir las potencialidades y limitaciones del estudiante, obteniendo una información sistematizada y científica, permitiendo desarrollar un proceso de enseñanza aprendizaje más acorde a la realidad.

Siccha (2015) en su investigación para obtener el grado de magister en Gestión Educacional propone una guía de procedimiento de rúbrica para mejorar la evaluación de competencias de estudiantes del tercer grado de secundaria en el área de Historia. La metodología que utilizó es aplicada proyectiva con un enfoque cualitativo dentro del paradigma interpretativo. La muestra poblacional fueron 95 estudiantes, un docente y sub director; los instrumentos utilizados fueron encuestas, análisis documental y entrevistas. Una de las conclusiones más importantes es que la rúbrica como instrumento de evaluación va a permitir mejorar las competencias de los estudiantes, de manera objetiva, contribuyendo en su preparación de forma integral, regulando y efectivizando su aprendizaje; también ayuda a los docentes al logro de una intervención evaluativa más efectiva en el proceso pedagógico. 


\section{Bases teóricas}

\section{Fundamentos teóricos sobre la categoría conceptual: Evaluación formativa}

Como indica Popham (2009) la evaluación formativa es un proceso planificado en el que la evidencia de la situación del alumno, obtenida a través de la evaluación, si es utilizada bien por los profesores para ajustar sus procedimientos de enseñanza en curso, o bien por los alumnos para ajustar para ajustar sus procedimientos de enseñanza en curso, o bien por los alumnos para ajustar sus técnicas de aprendizaje habituales.

Montalván (2016) refiere que la evaluación formativa es parte intrínseca del proceso de enseñanza- aprendizaje, en la cual, el profesor considera el avance y las dificultades con el objetivo de corregir, mejorar o reajustar, comunicando oportunamente a los estudiantes acerca de los resultados. El docente aplica estrategias y usa instrumentos de evaluación que le permite observar el progreso de los aprendizajes, los estudiantes reflexionan a través de la metacognición sobre sus aciertos o desaciertos con la finalidad de que en lo sucesivo puedan mejorar.

Ortega (2015) señala que la evaluación formativa es un proceso permanente, sistemático e interactivo, cuyo objetivo es acompañar, observar, comprender y analizar la conducta del estudiante, a través del recojo de información en el durante con el fin de regular y procesar el aprendizaje de forma innovadora y continua, usando la retroalimentación con el propósito de asegurar en el estudiante la capacidad de pensar y aprender; propiciando la reflexión, creatividad y sentido crítico; para adaptar, modificar y enfrentar autónomamente una situación. De tal manera, Tobón (2006) señala que la evaluación formativa es un proceso que fija el nivel de logro de una competencia basada en criterios planeados y en el desempeño del estudiante como evidencia de sus logros progresivos; buscando siempre superar los obstáculos para consolidar aprendizajes en el trabajo escolar. 
Lamas (2018) afirma que la evaluación formativa es reconocida por cambiar el panorama tanto al docente como al estudiante sobre sus ideas respecto a la evaluación. Durante su proceso, brinda oportunidades de retroalimentación al estudiante en base a las evidencias de sus aprendizajes para la mejora de su desempeño. Se caracteriza por ser sistemática y estructurada, y a través de sus pasos, promueve la reflexión del estudiante sobre su forma de aprender y al docente en su forma de enseñar. Por el aporte brindado a los actores del proceso educativo, promueve también un clima favorable para el aprendizaje entre el estudiante y docente. Al respecto, Mc Millan (2007) conceptualiza a la evaluación formativa como la retroalimentación que se le da al alumno en el proceso de enseñanza-aprendizaje para que este tome acciones correctivas sobre su desempeño, encaminadas hacia el mejoramiento continuo, de tal modo que incentiva la motivación y el aprendizaje, ya que estos se dan según sus necesidades.

\section{Sub-categorías apriorísticas de la categoría: Evaluación formativa}

\section{Dimensión cognitiva.}

Parra (2016) sostiene que la evaluación debe señalar los aciertos y debilidades del estudiante en el uso preciso de nociones, conceptos, categorías y relaciones dentro del marco referencial que va construyendo, en la articulación adecuada de los mismos, en las transferencias que realice con los conocimientos aprehendidos y en el proceso de análisis que lo lleven a proponer y argumentar sus puntos de vista. Podemos decir que la dimensión cognitiva de la evaluación es la forma en que se desarrollan las estructuras del conocimiento, incluyendo los conceptos vinculados a disciplinas específicas, los procedimientos de razonamiento y la resolución de problemas. En tal sentido, cómo el conocimiento es encodificado, almacenado, organizado en redes complejas y recuperado. Reconoce que a medida que se avanza en el aprendizaje se crean 
diferentes tipos de representaciones en dominios de conocimiento específico (construcción del conocimiento). La evaluación no solo busca determinar qué conocimientos se han adquirido, sino cómo, cuándo se usan estos conocimientos.

\section{Dimensión procedimental.}

Parra (2016) refiere que, durante el proceso de aprender, es importante el uso de instrumentos y operaciones en diferentes contextos. La dimensión procedimental es la manifestación práctica de las habilidades desarrolladas en el proceso de aprendizaje en las áreas del conocimiento en diferentes contextos. El aprendizaje de procedimientos hace referencia a la ejecución y la elaboración o construcción de soluciones. Para su evaluación se debe considerar el tipo de contenido procedimental: Algorítmico, Heurístico. Por consiguiente, podemos afirmar que la finalidad de esta evaluación es que el alumno tome conciencia de su aprendizaje y se dedique de manera más eficaz y experta a él.

\section{Dimensión actitudinal.}

De igual forma, Parra (2016) refiere que esta enseñanza se tendrá en cuenta la formación y consolidación en valores, haciendo énfasis en la responsabilidad, honestidad, respeto, cumplimiento, interés, participación y dedicación al estudio en cada una de las áreas, teniendo en cuenta las competencias ciudadanas y de convivencia desde cada asignatura, para fortalecer su práctica. Lo actitudinal se refiere a la formación de un accionar positivo según las valoraciones de la sociedad en la que se vive, motivando al alumno a moldear una personalidad que opte o prefiera por ejercer conductas deseables que sean provechosas para sí mismo y para la sociedad.

En cuanto en esta dimensión encontramos tres componentes: Cognitivo, afectivo, conductual; por lo tanto, se deben evaluar en forma conjunta con todas las otras dimensiones. 


\section{La metacognición en la evaluación formativa}

Flavel (1996) expone que "la metacognición se refiere a «cualquier conocimiento o actividad cognitiva que tiene como objeto, o regula, cualquier aspecto de cualquier empresa cognitiva" (p. 157). El Ministerio de Educación (2013) sostiene que la metacognición es la capacidad que tenemos de autorregular el propio aprendizaje, es decir de planificar qué estrategias permiten aprender, procesar ideas, conocer e identificar estilos de aprendizaje, controlar el proceso, evaluarlo para detectar posibles fallos, y como consecuencia transferir todo ello a un nuevo proceso. Es aprender a razonar sobre el propio razonamiento, aplicación del pensamiento al acto de pensar, aprender a aprender, es mejorar las actividades y las tareas intelectuales que uno lleva a cabo, usando la reflexión para orientarlas y asegurarse una buena ejecución (p.28).

Ahora podemos mencionar que la metacognición y la autorregulación son dos vocablos de profundo interés cuando los docentes reconocen cómo favorecer en los estudiantes los procesos cognitivos, en vistas a ayudar a que se desplieguen mejores procesos comprensivos. La metacognción se refieren a dos dominios específicos que presentan los individuos: conocimiento de los procesos cognitivos y regulación, como indica Flavel (1976). Estos procesos cognitivos van a ser procesos mentales que se encargan de todo el procesamiento de la información; por el mismo modo, el docente debe de trabajar la cognición en el aula dando paso a las interacciones entre sus estudiantes permitiendo también el trabajo de la autonomía, planificación y la autoregulación en el proceso de enseñanza-aprendizaje a través de una evaluación formativa permanente para la formación de competencias.

Cabe mencionar que el Ministerio de Educación del Perú (Minedu), expone que es importante que se promueva el aprender a aprender, donde el estudiante toma consciencia de las diferentes formas de aprendizaje que puede tomar y reflexionar sobre ello realizando 
valoraciones respecto al proceso mediante la evaluación formativa. Así mismo, indica que el aprendiz cuando utiliza sus estrategias en la escuela debe usar la planificación, regulación y evaluación de las técnicas, del cuándo, del cómo, del por qué y el para qué, estas se aplican con la meta de aprender, esto hace que el estudiante se vuelva estratega. Por lo expuesto, el profesor debe estimular las capacidades cognitivas del estudiante, pero también las capacidades metacognitivas.

\section{La retroalimentación en la evaluación formativa}

El Minedu en el Currículo Nacional (2016) sobre la evaluación, señala que la conceptualización de este término ha ido cambiando de forma significativa a lo largo del tiempo pues antes se entendía como la praxis que se centró en la enseñanza que categoriza lo correcto y lo incorrecto, arrojando resultados calificativos solo al término de todo el proceso, por el contrario hoy está focalizada en el aprendizaje del estudiante que es retroalimentado de forma oportuna en función a sus progresos en el transcurso de todas la tarea pedagógica.

La evaluación, entonces, diagnostica, retroalimenta y posibilita las acciones para el progreso del aprendizaje de los estudiantes. El estudiante, cuando recibe la información de los aciertos y desaciertos de lo que realizó, será capaz de superar las deficiencias que le imposibilitan avanzar e irá en busca de los objetivos o metas; el docente debe manejar con tino estas informaciones, para crear condiciones psicológicas adecuadas para retroalimentar el aprendizaje, esto le dará mayor seguridad, fortaleza y motivación, buscando se involucre las acciones del conocimiento como refiere Delgado y Oliver (2006).

Según Ruiz (2009), considera la retroalimentación como proceso metodológico que realiza el profesor con el estudiante, para que la información almacenada en la memoria se active y el estudiante la emplee en diferentes situaciones nuevas que requiera. Como menciona 
también, García (2011), el docente debe informar a los estudiantes los objetivos, metas o criterios que desea lograr en ellos; la retroalimentación será constante e individual para alcanzar un nivel autónomo, siendo dirigida y monitoreada, haciendo que el estudiante participe y poniendo su empeño considerando que es parte fundamental.

\section{Fundamentación teórica de la categoría rúbrica pedagógica}

Las rúbricas pedagógicas permiten establecer valoraciones respecto al desempeño del trabajo en el aula de clases. Según Simón (2001) "las rubricas son un descriptor cualitativo que establece la naturaleza de un desempeño, la rúbrica o matriz de valoración proporciona la calificación del desempeño de los alumnos, en áreas subjetivas, complejas e imprecisas, a través de un conjunto de criterios que nos permiten hacer una valoración del aprendizaje, las competencias y/o conocimientos logrados por el estudiante" (p. 23).

Las rúbricas son una de las mejores herramientas para los procesos evaluativos por competencias y evaluación continua; por ende, son los instrumentos de excelencia que deben aplicarse en los procesos de aprendizaje asentados en el enfoque de competencias como lo refiere Blanco (2008). Roblyer y Wiencke (2003) coinciden en conceptualizar a la rúbrica como una herramienta objetiva y versátil que puede utilizarse diferentes formas para la evaluación y tutorización de los trabajos de los estudiantes; por una parte, brinda al alumno un feedback relativo para mejorar su trabajo, por otro lado, provee al docente la posibilidad de informar a sus estudiantes de sus expectativas sobre las metas u objetivos de aprendizaje que se fijaron.

Una rúbrica es una descripción de criterios empleados para la valoración o emisión de un juicio sobre las acciones y desenvolvimiento de un alumno en un proyecto o trabajo; dicho de otra forma, una rúbrica es una matriz que se explica con un conjunto de criterios fundamentales 
y específicos que permiten apreciar el aprendizaje, las competencias o conocimientos alcanzados por el alumno en una materia particular o trabajo como sostienen Díaz (2005), Stevens, y Levi, (2012) que una rúbrica de evaluación es una herramienta de puntuación que divide una misión en sus partes componentes y objetivos, que permite proporcionar una descripción detallada de lo que constituye niveles de rendimiento para cada parte aceptable e inaceptable. Las rúbricas se pueden utilizar para cualquier grado de asignación o tarea como por ejemplo, papeles, reseñas de libros, participación en debates, trabajo de laboratorio, portafolios, presentaciones orales, trabajos en grupo y más.

Las rúbricas son guías de valoración usadas en la evaluación del desempeño de los educandos que narran las características de forma específicas de un proyecto o tarea, producto en diferentes niveles de rendimiento, con la finalidad de ser claros de lo que esperamos del trabajo del estudiante, de apreciar su realización y de facilitar el feedback como nos refiere Andrade (2005). Desde la socioformación, las rúbricas se definen como instrumentos de evaluación que permiten determinar el nivel de logro o desempeño en la resolución de problemas del contexto, relacionando una serie de indicadores con descriptores de niveles de dominio (Tobón, 2013b).

\section{Subcategorías apriorísticas de la categoría: Rúbrica pedagógica}

\section{Desempeño del estudiante en el uso de las rúbricas.}

En lo que respecta al papel del estudiante en el uso de las rúbricas, le permitirá conocer los criterios con el que será evaluado pudiendo observar las pautas de lo que se requiere, para alcanzar el éxito de su trabajo; utilizará la rúbrica como guía antes de entregar el trabajo al profesor, esto le permitirá hacer una evaluación de su trabajo identificando sus fortalezas o debilidades para implementar las mejoras necesarias; se autoevaluará y evaluará el trabajo de sus 
compañeros, tomando conciencia de su propio proceso construyendo su aprendizaje en equipo como lo refiere Urrutia (2015).

La rúbrica permite que el estudiante se evalúe y revise los criterios de calificación con qué será evaluado su trabajo, antes de entregarlo al profesor; también la rúbrica hace notar al estudiante con claridad las áreas débiles que debe mejorar y con esto planea con el profesor las estrategias a desarrollar para que pueda mejorar. De lo mencionado, se afirma que la rúbrica permite que los educandos reconozcan los criterios con los que serán evaluados en su práctica, les proporcionará a los estudiantes realimentación sobre sus fortalezas y debilidades, les brinda criterios para documentar y medir el progreso del estudiante, siendo la rúbrica de fácil uso y explicación.

\section{Rol del docente en el uso de las rúbricas}

En cuanto al docente, este debe conocer las habilidades que los estudiantes desarrollan para mejorar los procesos y compartir información para una futura retroalimentación, también implementar criterios de una evaluación integral; es decir, es necesario que el docente considere aspectos tanto cuantitativos como cualitativos para evaluar a los estudiantes. Así pues, para que estos parámetros tengan un sustento de objetividad, se debe recurrir a una herramienta que garantice dicho proceso: la "rúbrica". Conceptualmente, "es un instrumento de evaluación basado en una escala cuantitativa y/o cualitativa asociada a unos criterios preestablecidos que miden las acciones del alumnado sobre los aspectos de la tarea o actividad que serán evaluados para realizar las mejoras respectivas como lo sostienen Torres y Pereira (2010).

Ante lo mencionado, los docentes deben formarse para entender el rol de la evaluación en el proceso de aprendizaje, es decir, para usar las evaluaciones como mecanismos de 
retroalimentación, para interpretar los resultados de las evaluaciones y para tomar acciones adecuadas que conduzcan al mejoramiento como lo refiere López (2008).

\section{Niveles de dominio de la rúbrica}

Hernández et al (2016) refieren que las rúbricas son instrumentos de evaluación que tienen por objetivo determinar el nivel de desempeño del estudiante, relacionando indicadores con descriptores de niveles de dominio. Tobón (2013) sostiene que las rúbricas no se enfocan en evaluar los contenidos, este instrumento de evaluación permite reconocer los avances del estudiante y así mejorar en el desempeño a nivel personal o grupal, los niveles de dominio abordan los problemas del contexto considerando la pertinencia, ética, idoneidad y la mejora continua, la rúbrica genera una evaluación integral del desempeño porque no solo valora la ausencia o presencia de indicadores en una acción o evidencia, ya que también permite identificar la calidad del desempeño del estudiante.

Los niveles de dominio son los grados a través de los cuales se forman las competencias mediante el abordaje de problemas del contexto, desde lo más sencillo a lo más complejo, ya sea en procesos cortos o largos de la formación. La socioformación propone cinco niveles de dominio para la evaluación del trabajo o actividad que realiza el estudiante: Nivel preformal contiene algunos elementos pero no están relacionados con el desempeño esperado, Nivel receptivo tiene recepción de información, el desempeño es operativo. En el nivel resolutivo se tienen elementos técnicos de los procesos implicados y se poseen conceptos básicos. Por su parte, en el nivel autónomo se gestionan recursos, hay argumentación sólida y profunda y en el nivel estratégico donde se plantean estrategias de cambio en la realidad, hay creatividad e innovación, se muestran altos niveles de impacto, se hacen análisis evolutivos y prospectivos y 
se consideran las consecuencias de diferentes opciones de resolución de los problemas en el contexto como lo refieren Hernández \& Vizcarra, (2015), Tobón, (2013).

De tal manera, fortaleciendo el uso de las rúbricas los estudiantes identifican logros, aspectos que debe optimizar y nivel de dominio que logró (retroalimentación), siendo este aspecto de la metodología más significativos durante el proceso de implementación de rúbricas de socioformación. Por ende, es importante que el estudiante sepa sus logros, en que debe mejorar y el nivel de dominio alcanzado en su actividad o evidencia e involucrar al estudiante en su propio proceso de mejora continua.

Para Torres y Perera (2010). La rúbrica como instrumento pedagógico para la evaluación de los aprendizajes. Revista de Medios y Educación, 36, 141-149, nos menciona que las rúbricas son tablas de doble entrada que buscan determinar el nivel de dominio que posee un estudiante respecto a la resolución de un problema y sugerir acciones para lograr el mayor desempeño posible. El uso de las rúbricas en el proceso de evaluación de evidencias facilita la retroalimentación, permite señalar los retos progresivos a ser alcanzados por los estudiantes en las evidencias y miden las acciones del alumnado sobre los aspectos de la actividad que serán evaluados (Torres y Perera, 2010).

Por otro lado, García (2011) es del planteamiento que se evalúa es el nivel de dominio de una o varias competencias con base en criterios y evidencias diversas. Cuando una persona no posee los niveles mínimos de dominio de una competencia, que sean los requeridos para desempeñar una determinada actividad o resolver una gama de problemas, se indica que la persona "aún no es competente" para esas funciones específicas, ofreciéndole la posibilidad de que lo pueda ser en el futuro o bajo los parámetros de otro contexto. Esto, porque desde el enfoque de las competencias la actuación idónea siempre se valora a partir de unos determinados 
desempeños y no en términos del ser (García, Tobón y López, 2010). Ahora, respecto a los niveles de dominio para cada criterio y evidencia habrán de formularse indicadores que hagan patente el grado de dominio que se tiene de una competencia. Esto, para poder medir claramente los niveles de logro de los estudiantes, a medida que se lleven a cabo las actividades de aprendizaje, de debe establecer indicadores que permitan valorar los avances en un determinado periodo de tiempo, por ejemplo: durante un módulo o a la mitad y al final de un programa.

Los niveles de dominio de la rúbrica son en el Nivel Inicial donde el desempeño del estudiante es muy básico, operativo, tiene baja autonomía y se tienen nociones sobre la realidad, Nivel Básico el estudiante resuelve problemas sencillos del contexto, hay labores de asistencia a otras personas, se tienen algunos elementos técnicos de los procesos implicados en la competencia y se poseen algunos conceptos básicos. Así se encuentran el nivel autónomo en donde el estudiante no requiere asesoría de otras personas, gestiona proyectos, recursos, hay argumentación científica, se resuelven problemas de diversa índole con los elementos necesarios y el nivel estratégico donde el estudiante planea estrategias de cambio en la realidad, creatividad e innovación, hay altos niveles de impacto en la realidad, se resuelven problemas con análisis como mencionan Tobón, Pimienta y García (2010).

\section{Características de las rúbricas}

Las rúbricas son guías con puntuaciones que describen el nivel en el cual un aprendiente ejecuta un producto o un proceso, estas tienen las siguientes características: Se establecen en criterios de desempeño coherentes y claros, su uso es para evaluar el avance y productos de los estudiantes, describe claramente lo que se debe aprender, son descriptivas, rara vez numéricas, ayudan a los alumnos a supervisar su propio trabajo, eliminan la subjetividad en la evaluación y ubica por niveles de los educandos como nos refieren Díaz y Hernández (2007). 


\section{Importancia del uso de las rúbricas}

Las rúbricas ayudan a los profesores a ser específicos con los criterios de la evaluación estudiantil aumentando su consistencia y contando con argumentos para la evaluación debido a niveles de desempeños claros, también para que el padre de familia este informado ya que provee descripciones del desempeño del alumno; por el mismo modo ayudan a los estudiantes a determinar lo que es importante en su producto y proceso, colabora a la autorregulación de sus aprendizajes motivando a la propia evaluación de sus desempeños, favorece la coevaluación y brinda descripciones de su desempeño como refiere Airasian (2001).

\section{Evaluación con rúbricas}

El emplear protocolos de evaluación o rúbricas, hace que la evaluación sea de mayor calidad, teniendo un carácter cualitativo y permitiendo evaluar los procesos, esto hace que el docente obtenga una evaluación sistematizada; por ello, las rúbricas son una herramienta con mucho valor para desarrollar competencias de autoevaluación, monitorización y coevaluación, por ende va a contribuir en el proceso de aprendizaje, obteniendo un mayor entendimiento, autonomía y autoregulación del educando como nos informan Stevens y Levi (2005). Según Torres y Pereira (2010) sostienen que la evaluación educativa es fundamental en la formación de los estudiantes, por ello se deben conocer sus habilidades para mejorar los procesos por medio de la retroalimentación.

Desde la visión constructivista se deben considerar aspectos cuantitativos como cualitativos para evaluarlos, por lo cual la rúbrica es un instrumento de evaluación basado en una escala cuantitativa y/o cualitativa asociada a criterios preestablecidos que miden las acciones de los estudiantes sobre sus tareas o actividades evaluadas. 
Por lo expuesto, podemos decir que, insertando la rúbrica como herramienta evaluadora, no buscamos que el docente deje de lado otros instrumentos que conoce; podría trabajarlos a la par de la rúbrica, fortaleciendo el proceso evaluativo; igualmente las rúbricas se usarán para evaluar evaluaciones, lecciones o cualquier distinta actividad en concordancia a las necesidades que el profesor vaya desarrollando en su quehacer educativo.

La rúbrica pedagógica tiene un gran valor cuando se trabaja en práctica docente; de una parte, es una herramienta de evaluación que se debe entender diferente a una evaluación tradicional; de tal modo, la rúbrica no sólo evalúa los conocimientos de los estudiantes, sino que esta debe servir como un instrumento de reflexión que les permita tomar concientización de lo aprendido durante el proceso de enseñanza aprendizaje; de otro lado, sirve a los estudiantes como guía para cumplir las partes de la estructura de una actividad, ayudando también en la acción tutorial del docente. 


\section{Capítulo II}

\section{Diagnóstico o trabajo de campo}

En el este capítulo se describen los hallazgos encontrado al aplicar los diferentes técnicas e instrumentos de recolección de datos. Se aplicaron cuestionarios a los estudiantes con la finalidad de determinar si el docente promueve la evaluación formativa en sus estudiantes en el desarrollo de sus sesiones de enseñanza - aprendizaje.

\section{Análisis, interpretación y discusión de los resultados}

Con la finalidad del conocimiento del estado actual del desarrollo de la evaluación formativa, dentro del proceso de enseñanza-aprendizaje, en el curso de comunicación en los estudiantes del segundo de Secundaria de un colegio privado del distrito de San Miguel, se realizó un diagnostico en la aplicación de tres instrumentos de investigación, los mismos que nos dieron a conocer información objetiva y veraz de la muestra del estudio aplicado. El diagnostico de campo se llevó a cabo con estudiantes entre 12 y 13 años.. Se diseñó y se validó tres instrumentos que se aplicaron a 20 estudiantes y tres docentes del área de Comunicación Integral.

Así mismo, se emplearon una guía de entrevista semiestructurada a los docentes con la finalidad de conocer su experiencia en el proceso de enseñanza -aprendizaje en el desarrollo de la evaluación formativa de sus estudiantes, constatando también los conocimientos teóricos y estrategias evaluativas que poseen los docentes y finalmente, se realizó las observaciones de clase durante el proceso de enseñanza-aprendizaje, con la finalidad de Identificar si el docente utiliza las rúbricas pedagógicas para desarrollar la evaluación formativa en sus estudiantes. Una vez diseñado los instrumentos se procedió a la evaluación de la efectividad por medio del método criterio de expertos, quienes después de analizarlos y aportar sus sugerencias en los 
casos requeridos y al final dictaminaron su pertinencia para su aplicación en la práctica. Según Miles y Huberman (1994) en el análisis cualitativo concurren tareas de la reducción de datos, presentación de datos o extracción y verificación de conclusiones.

A continuación, se presentan los resultados del estado actual del desarrollo de la evaluación formativa con los datos regidos por tres instrumentos, durante el proceso se realizó la reducción, codificación, categorización, triangulación, análisis e interpretación tanto en procesos estadísticos como cualitativos.

\section{Presentación de resultados por técnicas e instrumentos}

\section{Análisis de los datos codificados de las observaciones de clases.}

Las docentes observadas en segundo grado de Secundaria tienen experiencia en el ámbito profesional, la docente A cuenta con maestría y la docente B cuenta con diplomado, ambas en su especialidad profesional, los instrumentos utilizados para esta investigación, se da en el contexto del proceso de enseñanza-aprendizaje, las observaciones se realizaron a las dos, en las que se evidencio que en el inicio de la clase la docente A no tomó en cuenta las nociones, conceptos, saberes previos de sus estudiantes dentro de la construcción de los aprendizajes, mientras que la docente B lo hizo de manera oportuna, eficiente y acertada. En otro momento la docente A si propicia y construye con sus estudiantes competencias ciudadanas y de convivencia, fomentando un clima de aprendizaje basado en valores, mientras que la docente B solo lo hace en algunas ocasiones.

Durante el desarrollo de la clase se evidenció que la docente A propicia que los estudiantes pongan en práctica sus habilidades, siendo capaces de organizar, planificar, regular y evaluar su aprendizaje mientras que la docente B no lo hace. Asimismo, se observó que a veces en ambas sesiones de clases los estudiantes demuestran autonomía gestionando sus proyectos, 
actividades o trabajos realizados en el ambiente de trabajo. Cabe mencionar que en ninguna de las dos sesiones se observa una retroalimentación por parte de los maestros, es decir que no realizaron el feedback en base a criterios de éxito con rúbricas de evaluación.

También ninguna de las dos docentes enseña la utilización de la rúbrica como herramienta midiendo las acciones del alumnado respecto a su tarea o actividad realizada para obtener un resultado e implementar las mejoras necesarias. Además, es importante recalcar que para el caso de la docente B no se observó que los estudiantes proponen o argumentan sus puntos de vista para construir aprendizajes significativos, mientras que en el caso de la docente A solo a veces sucede esto. De manera general los estudiantes no utilizan como herramienta la rúbrica como guía, ni identifican sus fortalezas o debilidades para implementar planes de mejora a su trabajo y no conoce los criterios de la rúbrica con la que es evaluado.

Paralelamente, en ninguna de las sesiones las docentes miden los niveles de logro de sus estudiantes mediante el uso de las rúbricas, no retroalimentan el proceso, no conocen los lineamientos establecidos en la rúbrica por ello no valoran su aprendizaje. Por otro lado, fue posible observar que en ambos casos si evalúan teniendo en cuenta los valores durante las actividades ya sea individualmente o en equipo.

Al finalizar la sesión de clases se evidenció que la docente B a veces fomentó que el estudiante se autoevalúe tomando conciencia de sus propios procesos, mientras que la docente A si lo hizo eficientemente. Se atestiguó que durante la primera sesión de clases a veces se propició que el estudiante coevalúe a sus compañeros contribuyendo su aprendizaje colaborativamente, mientras que durante la segunda sesión observada si se hacía con bastante regularidad. Por último, se evidenció que la docente B no empleó estrategias de cierre de clase para la evaluación 
respectiva, utilizando la metacognición (preguntas u otro), mientras que en el otro caso se observó que si se hizo.

\section{Análisis de los datos codificados de las entrevistas a los docentes}

Dentro del proceso de investigación, se realizaron entrevistas a tres docentes que desarrollan el área de comunicación de la institución educativa particular con el objetivo de conocer la experiencia docente en el proceso de enseñanza aprendizaje en el desarrollo de la evaluación formativa en sus estudiantes y constatar sus conocimientos teóricos y metodológicos al respecto en dicha área académica.

A continuación, se indican los resultados, durante la entrevista, los docentes revelan que los métodos utilizados en clase son muy importantes para desarrollar las habilidades de los estudiantes durante las clases de comunicación. Estos métodos se utilizan para indicar sus aciertos y debilidades durante las actividades de construcción de los conocimientos. Los docentes utilizan mucho la observación y escucha activa, encaminando y orientando a sus estudiantes. La docente B nos explica sobre la retroalimentación para fomentar el desarrollo de habilidades, contenidos durante el proceso. La docente $\mathrm{C}$ con más experiencia en el colegio y metodología de trabajo, igualmente nos explica al respecto, donde destaca la reflexión de los indicadores de la rúbrica, motivando a sus estudiantes ya sea cuando trabajan de forma individual o colaborativa para la construcción de sus aprendizajes.

Respecto a los procesos cognitivos, estos permiten agrupar e identificar información del medio que rodea, permitiendo al estudiante explorar el mundo a través del análisis y la adaptación del conocimiento, siendo una de las particularidades que a través del conocimiento existente se generan nuevos conocimientos. De esta forma las docentes hacen hincapié de los análisis de los procesos cognitivos de sus estudiantes a través de rubricas, anecdotarios y 
monitoreo. La docente A proporciona ejemplos que le permiten sus estudiantes realizar textos argumentativos, planteando ejemplos y contraejemplos.

Por otro lado, la docente $\mathrm{B}$ fortalece los procesos cognitivos realizando preguntas y repreguntas, observando el desempeño de sus estudiantes y orientándolos siempre argumentando muy bien sus puntos de vista hasta que vayan consolidando los aprendizajes esperados. La docente C busca la asimilación de conceptos, procedimientos, valores construyendo representaciones mentales significativas y así lo puedan aplicar a diferentes contextos, lográndolo con la retroalimentación; destacando la importancia de formar un triángulo interactivo alumno, profesor y contenido, buscando la mejora de los procesos mediante la interacción para la formación de estos procesos.

En cuanto a las estrategias evaluativas, los docentes entrevistados transmitieron que estas permiten evaluar integralmente, posibilitando una evaluación en procesos, teniéndose en cuenta sus fortalezas en lugar de sus debilidades. Los docentes indicaron tener en cuenta los criterios de éxito fundamentalmente y saber que desempeños son los esperados, trabajando la evaluación formativa con instrumentos a diario.

De otro modo, la docente $\mathrm{C}$ utiliza la estrategia del trabajo colaborativo utilizando el instrumento del check list y destaca la importancia de utilizar las rúbricas pedagógicas que contienen las competencias específicas que se quiere el estudiante logre. En lo que respecta a la importancia del desarrollo de habilidades en el proceso de aprendizaje y la capacidad de planificación, regulación y evaluación de los estudiantes, las tres docentes indicaron que usan retroalimentación haciendo repreguntas de tal manera que ellos descubran que lo más importante fue la habilidad desarrollada. Por ello, la importancia de la observación siendo el docente guía 
del proceso de trabajo, motivándolos al desarrollo de sus habilidades tanto académicas como competencias valorativas y de buena convivencia para que el trabajo sea óptimo; realizando preguntas metacognitivas para que ellos mismos aprendan a regular su aprendizaje. Es importante enseñar a los estudiantes a planificar sus actividades, organizarlas ya sea individualmente o en grupo, regulándose por sí mismos y realizando la autoevaluación respectiva con guía de su profesor.

En cuanto al fomento de valores y actitudes en el área académica, es importante durante el desarrollo, en cada una de las actividades que se realizan no solo se tiene en cuenta la parte cognitiva o procedimental de sus trabajos, también la evaluación actitudinal. En cada una de las rúbricas que se utilizan para la evaluación también encontramos en desarrollo de esta base importante en la evaluación formativa estudiantil, estas deben ser analizadas y canalizadas con los estudiantes junto a sus docentes antes de empezar las actividades; por ello la evaluación en todo momento es formativa esto implica el saber ser, saber conocer y saber hacer.

La docente A menciona que hace fichas de coevaluación para los grupos, fichas en la cual ellos se puedan evaluar, donde los criterios e indicadores sean claros. Por su parte, la docente B explica sobre el desarrollo de las habilidades blandas, que son las habilidades de empatía, habilidades sociales, de asertividad y la comunicación efectiva que se va a reflejar en el trabajo colaborativo, aquí se puede ver el trabajo del estudiante, cómo interactúa, cómo se relaciona, cómo escuchan al otro y si son atentos a la diversidad de ideas, toman o no iniciativas para hacer algo o están esperando que digan que tiene que hacer; en este momento, en el cual va regulando su actitud. Sin embargo, la docente $\mathrm{C}$ menciona que se debe trabajar los valores y actitudes en todas las áreas académicas y talleres fomentando la buena convivencia dando ejemplos adecuados como modelo durante la práctica pedagógica para transmitirlo a sus 
estudiantes. Por ende, la formación no solo debe ser académica si no también apuntar hacia el desarrollo actitudinal positivo para generar un ambiente y clima que sea propicio para el aprendizaje. En el área de Comunicación se tiene en cuenta las competencias ciudadanas y de convivencia en las evaluaciones de trabajos o actividades que se realiza en el aula; por ello, los temas en comunicación deben ser relacionados a nuestra sociedad, a lo que ocurre actualmente y sus intereses, entonces se fomentarán intervenciones.

En lo que respecta a las herramientas de empleo para evaluar a los estudiantes y a la utilización de estas, durante la reflexión de los aciertos o desaciertos de la actividad propuesta (procesos de metacognición), uno de los docentes entrevistados fomenta la transformación de la rúbrica a criterios de éxito. Cuando los estudiantes están redactando, se analiza su trabajo, se proyecta y se analiza a función de los criterios, a este momento lleva a la coevaluación y es una oportunidad para que mejoren; por ejemplo, una redacción, buscando el análisis por párrafos y observando si se cumplen o no los criterios empleados. Durante este proceso se hacen uso también de estrategias didácticas que permiten la formación de competencias estudiantiles en el área siendo las primordiales comprensiones, producción de textos y expresión oral.

En lo referido a la metodología respecto a la autoevaluación y coevaluación entre pares cuando se construyen nuevos conocimientos en el proceso de enseñanza-aprendizaje, estos se realizan oralmente o en papel impreso. Los estudiantes se evalúan y coevalúan sobre todo cuando trabajan el estándar de producción de textos y expresión oral.

En el caso de producción, los alumnos pueden rayar, marcar hacer correcciones en los borradores que han escrito sus compañeros, se hace el intercambio entre pares y luego tienen un momento de socialización, donde se dicen que han alcanzado y que les falta para mejorar; pero 
antes de que ellos lo trabajen solos. Como docentes realizamos un modelado antes de que los estudiantes redacten o se expresen que les sirve de ejemplo.

Es importante no solo dar retroalimentación de lo que le falta trabajar o mejorar, sino trabajar el aspecto actitudinal, la forma como el estudiante coevalúa, como se manifiestan entre compañeros, con respeto. Como profesores en el aula se debe generar una reflexión oportuna y asertiva, dar las felicitaciones necesarias, decirles que han logrado y que les falta para alcanzar los objetivos.

Los estudiantes autoevalúan su proceso, ya sea de forma oral o escrita y se ponen metas para seguir con las actividades, también en el aprendizaje colaborativo los estudiantes se coevalúan entre miembros del grupo o aula; por ejemplo, cuando salen a realizar una declamación del poema creado, los compañeros de clase también les realizan la retroalimentación respectiva de cada uno de los indicadores presentados, siendo críticos y analíticos en lo que van a decirle a su compañero. Esto les permite mejorar para una siguiente ves que se evaluará o saldrán a exponer un producto en el aula. Sobre los niveles de logro observa en sus estudiantes cuando emplean estrategias para el desarrollo de su propio aprendizaje, el docente debe ser el encargado de fortalecerlo.

El docente A, a través de los productos de las clases, debe felicitarlos para que se sigan motivando y mejorando. Para constatar vaya avanzando con sus niveles de logro se pueden emplear diferentes estrategias debiendo repotenciar el trabajo con el estudiante si es necesario dando soporte. El docente uno indica que realiza un diagnóstico para poder avanzar en base a ello, también se observa que se evalúa cuantitativamente, pero no se observa el análisis de competencias para mejorar estos niveles. 
Los niveles de logro deben variar poco a poco mientras el estudiante aprenda y comprenda que se espera de él mediante la rúbrica; los estudiantes deben comprender que todo es un proceso y que su rendimiento puedo ser inicial, procesual o logrado; por ello estos niveles se fortalecen durante las clases en el día a día con modelados del docente, modelados de sus compañeros realizando ejemplificación del cómo podría trabajar de la mejor manera y siempre realizando la retroalimentación del trabajo presentado. Para que se desarrollar la evaluación formativa los estudiantes deben de fortalecer su autonomía para que puedan resolver diferentes actividades y problemas en las sesiones de clase.

Se observa que los docentes realizan observación del trabajo y van direccionando a sus estudiantes al objetivo y apoya cuando van tomando decisiones de cómo hacer su trabajo o bajo qué punto van a adaptar. Por ello, se debe de desarrollar poco a poco para que ellos puedan tomar la dirección de cómo hacer su trabajo o bajo qué puntos ellos van a mejorar. La clase de comunicación debe ser bastante interactiva, los alumnos deben de participar constantemente, en la estrategia se nota la falta de conocimientos respecto del uso de estrategias que lo motiven, además siempre felicitarlos si lo logran y de esta manera vamos reforzando estas conductas. La autonomía es un proceso largo, que se tiene que trabajar poco a poco.

Durante la entrevista, los docentes refieren utilizan la retroalimentación con sus estudiantes en el proceso de enseñanza-aprendizaje cuando trabajan de forma autónoma o en grupos cooperativos, destacando la importancia de que la retroalimentación siempre se debe dar en la sesión de clase, en el caso de producciones se colocan puntuaciones y se les dice que hacer para mejorarla y en equipo también se realizan. 
En la entrevista se deduce que se carece de estrategias evaluativas ya que no se realiza la evaluación por competencias solo en escalas numéricas, no hay explicación en mayor profundización respecto a los tipos de evaluación y concientización del aprendizaje en este aspecto. De otra forma, la comprensión la evalúan en el área a través de preguntas que vayan a las respuestas que pueden ser literales, preguntas de nivel inferencial o preguntas de reflexión, de opinión para que interioricen el texto.

En el caso de la expresión oral, refiere la docente uno que se evalúa más rápido, con una ficha, a través de criterios de éxito. En el caso de la docente dos que tiene mayor tiempo de experiencia como docente, hace que el estudiante se autoevalúe luego de las participaciones. La docente tres indica que la retroalimentación siempre se da casi al final o un poco antes incluso, para verificar haciendo preguntas y repreguntas que formulamos, la docente no indica cual es la respuesta correcta, en cambio hace preguntas, indagando con el estudiante para ver qué cosa entiende y que no.

Respecto a la utilización de la rúbrica, como parte de evaluación formativa de sus procesos, las docentes tienen conocimiento respecto al trabajo con la rúbrica, pero no realizan el trabajo de la forma adecuada. La docente A la proyecta de forma general, en toda el aula, la lee y los estudiantes comienzan a trabajarla en base a esta, sin haber realizado la reflexión e interiorización de qué es y lo que se quiere de ella. Por su parte, la docente dos la presenta, la explica, pero no realiza la concientización previa con participaciones de los estudiantes, no la muestra en la sesión de clase y no la utiliza como parte de la retroalimentación, solo es utilizada para colocar la nota final del trabajo. 
La docente $\mathrm{C}$ indica que las utiliza pero en algunas ocasiones, y sabe que debe implementarlas en todas sus sesiones de enseñanza-aprendizaje para que sea una constante y obtenga mayores logros como docente, sabe que sus estudiantes deben conocer qué objetivos deben alcanzar, haciendo un análisis de cada uno de los indicadores fomentando sus participaciones y que interioricen para que lo puedan aplicar en la actividad.

Con respecto a las potencialidades curriculares de las rúbricas pedagógicas, estas facilitan un conocimiento de primera mano, por parte de los alumnos, de la importancia de los contenidos y los objetivos de los trabajos académicos que se les plantean, así como sus fortalezas y debilidades en las áreas (qué saben y qué deben mejorar). Facilitan la evaluación de desempeños del alumnado en las áreas del currículo y en el desarrollo de las competencias clave, deben tener siempre como punto de partida los estándares de aprendizaje evaluable del currículo, establecen una gradación (niveles de desempeño) de la calidad del cumplimiento de los estándares que contribuyen al desarrollo de competencias del alumnado a través de tareas, deben ser coherente con los objetivos educativos planteados en el currículo, deben adaptarse al nivel de desarrollo del alumnado. Durante la entrevista se pudo verificar que las docentes no saben con exactitud que potencialidades curriculares tiene la rúbrica para el desarrollo de la evaluación formativa durante el proceso de enseñanza aprendizaje, pero tienen objetivos de capacitarse para seguir formando integralmente a sus estudiantes.

\section{Análisis de los datos codificados del cuestionario a estudiantes}

Para la aplicación del cuestionario a los estudiantes se tomó la muestra de un total de 20 estudiantes de dos secciones de segundo grado de educación secundaria escogidos de forma aleatoria. Respecto a los resultados, estos nos indican que el $45 \%$ de los encuestados cree que a veces el profesor guía en el proceso pedagógico indicándoles sus aciertos y debilidades para que 
puedan construir su conocimiento, mientras que el 30\% considera que casi siempre el profesor lo hace, sin embargo, el 15\% opina que casi nunca lo hace, de otra forma el 5\% de los estudiantes indica que nunca lo hace y de igual manera el otro 5\% indica que siempre lo hace. Lo que indica que los docentes analizados deben ser más partícipes activos durante el desarrollo de las clases, buscando apoyar a todos sus estudiantes mientras realizan las actividades encomendadas.

Sobre si el docente analiza los resultados de sus estudiantes, proponiéndoles e indicándoles aspectos para que puedan mejorar su actividad, trabajo, realizando retroalimentación se observa que el 35\% de los encuestados cree que casi siempre, mientras que el $30 \%$ considera que a veces el profesor lo hace, sin embargo, el 15\% opina que siempre lo hace, de otro modo el 5\% de los encuestados dicen que el profesor no lo hace. Lo que indica que los docentes deben buscar estrategias que permitan la mejora académica de sus estudiantes analizando sus procesos y resultados.

Referente a si el profesor utiliza instrumentos de evaluación formativa, indicándoles cómo utilizarlos para que puedan evaluar sus aprendizajes, los resultados fueron que el $45 \%$ de los encuestados cree que a veces mientras que el $30 \%$ considera que casi nunca el profesor lo hace, del mismo modo, el 15\% opina que nunca lo hace; sin embargo, el 10\% de los encuestados indica que casi siempre utiliza dichos instrumentos. Lo que indica que el docente debe de tomar en cuenta formas que motiven al estudiante a evaluarse mediante instrumentos. De otra manera se obtuvieron resultados, donde indican que el $70 \%$ de los encuestados cree que a veces se pone en práctica las habilidades desarrolladas en el proceso de enseñanza - aprendizaje con orientaciones del docente, mientras que el $20 \%$ considera que casi nunca lo hace, sin embargo, el $5 \%$ opina que casi siempre lo hace y del mismo modo el $5 \%$ indica que nunca lo hace. Por lo 
tanto, el docente debe cerciorarse que sus estudiantes pongan en práctica lo aprendido en las clases, demostrando sus habilidades desarrolladas en el proceso de enseñanza - aprendizaje.

Sobre si el profesor fomenta en sus estudiantes la formación en valores, buenas actitudes en su área académica y los evalúa también en este aspecto; los resultados indican que el $35 \%$ de los encuestados cree que a veces, mientras que el $25 \%$ considera que casi nunca el profesor lo hace, del mismo modo, el $25 \%$ opina que siempre lo hace, sin embargo, el $15 \%$ indica que casi siempre lo hace. En consideración a este resultado podemos analizar que el docente no solo en el aula debe transmitir conocimientos a sus estudiantes, sino que debe tomar un papel formador en el proceso donde los valores y buenas actitudes se vean reflejadas durante la clase.

Respecto a que si el profesor toma en cuenta las competencias ciudadanas y de convivencia en las evaluaciones de los trabajos de sus estudiantes, para fortalecer sus conocimientos en la asignatura, se observa que el $45 \%$ de los encuestados cree que a veces, mientras que el $25 \%$ considera que casi nunca el profesor lo hace, del mismo modo, el $15 \%$ opina que nunca lo hace, sin embargo el $10 \%$ de los encuestados indica que el profesor casi siempre lo hace, de otra manera el $5 \%$ indico que siempre toma en cuenta las competencias ciudadanas. Los docentes deben insertar estrategias evaluativas no solo académicas, sino hacer competentes a los estudiantes en ciudadanía, respetándose los unos a los otros, respetando la diversidad, asignando roles y trabajo de la tolerancia, formándolos para la vida, fortaleciendo las normas de convivencia durante las clases.

Referente a si los estudiantes conocen y analizan los criterios o pautas para alcanzar el éxito de sus trabajos en clase, los resultados indican que el 35\% de los encuestados cree que casi 
nunca ellos como mientras que el $20 \%$ considera que a veces lo hacen, del mismo modo, el $20 \%$ opina que casi siempre lo hacen, sin embargo, el 15\% de los encuestados indica que nunca lo hace, de otro modo el $10 \%$ indica que siempre lo hace. Por ello el profesor debe de enseñar las herramientas necesarias a sus estudiantes para que puedan regular su aprendizaje, fomentando el análisis de los criterios requeridos para el avance de las actividades formativas en el aula. Sobre si el profesor verifica que sus estudiantes conozcan y enseñe el instrumento de la rúbrica pedagógica antes de iniciar su clase o actividad para que puedan trabajar con ella se observa que el 25\% de los encuestados cree que nunca, de igual manera que el 25\% considera que casi nunca el profesor lo hace, del mismo modo, el 15\% opina que a veces lo hace, mientras el 10\% de los encuestados dice que el profesor siempre verifica que conozcan la rúbrica.

El docente debe hacer que en clase, sus estudiantes antes de realizar un trabajo, conozcan los criterios con los que será evaluado, por ello la necesidad de analizar estos puntos a través de la herramienta de la rúbrica que se utiliza para constatar de que el estudiante o equipo formado, sepa cómo se le evaluará; cuando lo sepan será más fácil para ellos saber que espera el docente de sus trabajos.

De la misma forma, se obtuvieron resultados sobre si el profesor otorga espacios de autoevaluación y coevaluación estudiantil para la toma de conciencia de los procesos metacognitivos, construyendo sus aprendizajes colaborativamente o autónomamente se observa que el $45 \%$ de los encuestados cree que a veces durante la sesión de clases, mientras que el 25\% considera que casi siempre el profesor lo hace, del mismo modo, el $20 \%$ opina que casi nunca lo hace, del mismo modo tenemos un 5\% de estudiantes que indican que nunca lo hace y el otro 5\% que dice que siempre lo hace. Los docentes en el desarrollo de sus clases impartidas debe trabajar la evaluación formativa, donde los estudiantes tengan espacios de autoevaluación, 
coevaluación y heteroevaluación; que les permitan la concientización en cada una de las actividades realizadas ya sea individual o en equipos. Sobre si el estudiante mide sus niveles de logro al trabajar con rúbricas y propone las mejoras necesarias para que este sea exitoso, el resultado indica que el $35 \%$ de los encuestados cree que a veces en la sesión de clase, mientras que el $30 \%$ considera que casi nunca se logra.

En la lectura de análisis de las respuestas, del mismo modo, el $25 \%$ opina que casi siempre se logra, de otro modo el $10 \%$ de los encuestados indica que nunca el estudiante mide sus niveles de logro con la rúbrica. Por ello, el profesor observa a cada uno de sus estudiantes y su desenvolvimiento de lo que está logrando y lo que le falta para que afiance su aprendizaje. Durante los resultados del cuestionario aplicado también obtuvimos que el $40 \%$ de los encuestados cree que a veces los estudiantes desarrollan sus actividades propuestas bajo los lineamientos establecidos en indicadores permitiéndote valorar su trabajo, mientras que el $25 \%$ considera que casi siempre sucede esto, del mismo modo, el $20 \%$ opina que nunca se hace; sin embargo, el $10 \%$ indica que siempre lo hace, de otro modo el $5 \%$ de los encuestados indica que casi nunca los estudiantes lo hacen. El estudiante debe de conocer muy bien la actividad que realiza y que se le evaluará, por ello el docente debe permitir momentos donde se analicen los criterios a evaluar en el antes, durante y al final del proceso.

Sobre si se observa que el docente fomenta que sus estudiantes se desempeñen con autonomía gestionando su propio aprendizaje durante la clase, que el $45 \%$ de los encuestados cree que a veces mientras que el $25 \%$ considera que casi nunca el docente lo hace, sin embargo, el $20 \%$ opina que casi siempre lo hace, del mismo modo el $5 \%$ de los estudiantes indican que nunca lo hace. Los docentes deben buscar que sus estudiantes trabajen con autonomía gestionando sus aprendizajes, es por ello que se debe promover en el aula el desarrollo de 
habilidades, haciéndolos autosuficientes para que trabajen con éxito, donde los acompañará, pero esto permitirá que este se focalice a los estudiantes con mayor necesidad para trabajar más personalizada con ellos.

Con lo que respecta si el docente plantea problemas de tal modo que sus estudiantes tengan la capacidad de analizarlo resolviéndolo con creatividad e innovación utilizando la rúbrica, se obtuvo como resultado que el $35 \%$ de los encuestados cree que a veces el mientras que el $25 \%$ considera que casi nunca el docente lo hace; del mismo modo, el $15 \%$ opina que siempre lo hace, sin embargo el $10 \%$ de los encuestados indican que casi siempre lo hace. Lo que indica que los profesores deben buscar que sus estudiantes a través de situaciones problémicas o retos, puedan buscar diferentes formas de como analizarlo y resolverlos, ayudándolos a crear e innovar para la gestión de su conocimiento.

Los resultados nos indican que también un $40 \%$ de los encuestados cree que casi nunca el profesor conoce las habilidades de cada uno de sus estudiantes y los guía en el mejoramiento de sus procesos, mientras que el $25 \%$ considera que a veces el profesor lo hace, del mismo modo, el $20 \%$ opina que casi siempre lo hace; sin embargo, el $10 \%$ indica que nunca lo hace, por otro lado, un 5\% de los encuestados dicen que siempre el profesor conoce las habilidades de cada uno de sus estudiantes. En tal sentido la observación en los estudiantes es muy importante para el docente y el logro de aprendizajes, enfocándose en el logro de competencias a mejorar, de igual modo el reconocer sus aciertos para la mejora continua de cada uno de ellos.

Por otro lado, sobre si el profesor se preocupa por constatar el logro de los objetivos del aprendizaje durante todo el proceso con criterios establecidos desde el inicio de la clase, se observa que el $35 \%$ de los encuestados cree que a veces, mientras que el $25 \%$ considera que casi 
nunca el profesor lo hace, del mismo modo, el $20 \%$ opina que casi siempre lo hace, sin embargo, el $15 \%$ indica que nunca lo hace, de otra forma el porcentaje del $5 \%$ de los encuestados dicen que siempre el profesor se preocupa. Durante las clases las metas deben ser compartidas desde que se empieza la sesión de aprendizaje, estas deben ser reforzadas en el durante y realizar el proceso metacognitivo para constatar los logros obtenidos, los indicadores deben ser claros y visibles.

En otro aspecto, referente a que, si el profesor contribuye al desarrollo del mejoramiento evaluativo de los procesos mediante las rúbricas en los contenidos o estándares trabajados en clase, se observa que el 35\% de los encuestados cree que casi nunca la clase de tu mientras que el $30 \%$ considera que a veces la clase contribuye, del mismo modo, el $20 \%$ opina que casi siempre lo hace, sin embargo, el $15 \%$ de los estudiantes dicen que siempre lo hace. La rúbrica debe ser una herramienta esencial en el proceso evaluativo, desarrollo de habilidades y competencias, de tal forma que se haga una práctica en el aula en su uso para fortalecer las actividades en clase.

\section{Análisis e interpretación de las categorías apriorísticas y emergentes}

A continuación, se presentan las categorías emergentes que surgieron al realizar el proceso de codificación, categorización, triangulación metodológica. En lo que respecta después del proceso de la triangulación metodológica y de datos, se realizó la redacción de las conclusiones aproximativas para cada categoría emergente, la cual se realizó con la base de códigos agrupados. Luego se realizó la interpretación y discusión de los resultados, en esta discusión se aplicó la triangulación teórica, al respecto Okuda y Gómez (2005) manifestaron que, “durante la conceptualización del trabajo de investigación cualitativa suele definirse de antemano la teoría con la cual se analizarán e interpretarán los hallazgos” (p. 122-123). 
Dimensión cognitiva Las entrevistadas manifiestan que la cognición es parte indispensable para el aprendizaje, a través del conocimiento se pueden generar nuevos conocimientos haciéndolos más sólidos. Sin embargo en la observación de clases no se generó actividades para el desarrollo de las capacidades, conocimientos y competencias en los estudiantes, se observó el poco uso de instrumentos de evaluación formativa en el proceso de aprender a aprender (metacognición), como rúbricas, anecdotarios, etc; y en cada uno de los procesos cognitivos de sus estudiantes, siendo importante crear espacios de

Dimensión procedimental En lo que refiere a la dimensión procedimental, las entrevistadas refieren que se deben tomar en cuenta dentro de las clases los procesos de los estudiantes, permitiéndoles autoevaluarse en sus aciertos y desaciertos de las actividades que hagan mediante participaciones o una lista de cotejo que les permita reflexionar sobre su desenvolvimiento. En la parte procedimental observamos que aún se deben tener en cuenta la aplicación de los saberes previos, también la utilización estrategias para que puedan llegar a los estudiantes, insertando en sus clases el aprendizaje colaborativo, elaborando productos; a una docente aún le falta trabajar el análisis de los niveles y criterios de la calidad del trabajo que asigna, utilizando la retroalimentación para que les permita a sus alumnos tomar conciencia de lo que se quiere lograr y así construir sus conocimientos.

Dimensión actitudinal De acuerdo a las docentes entrevistadas podemos mencionar que debemos de desarrollar en el proceso de enseñanza aprendizaje el desarrollo actitudinal positivo en los estudiantes, fortaleciendo las competencias valorativas y de buena convivencia para realizar un óptimo trabajo. En la evaluación formativa se busca que los estudiantes aprendan en equipo para construir sus aprendizajes esto hace que tengan una diversidad de opiniones de los temas que el docente propone en su clase, este tipo de trabajo desarrolla habilidades sociales; de lo observado podemos mencionar que el docente debe llegar a sus estudiantes por medio de la asertividad, comunicación efectiva, empatía; siendo este formador, haciendo consciente al estudiante que de su autodisciplina y constancia depende mucho su aprendizaje. El docente debe de fortalecer la autonomía del estudiante, esto le permitirá a aumentar la confianza en si mismo.

Figura 1: Categorias apriorísticas y emergentes

Fuente: Elaboración propia (2019)
Rol del docente: Nuestras docentes entrevistadas mencionan que el profesor debe acercar al estudiante al trabajo colaborativo esencial para el aprendizaje, sin dejar de lado el trabajo individual ya que se complementan; siendo necesaria la dirección eficaz del profesor, siendo un modelo para sus estudiantes. En el marco de la evaluación formativa insertar estrategias que permitan mejorar su práctica pedagógica, con el uso de herramientas como la rúbrica, la motivación constante para el avance de cada uno de sus alumnos, incentivar las preguntas y repreguntas para la comprobación del entendimiento de las actividades. Sin embargo, un buen porcentaje de los encuestados cree que solo a veces el docente utiliza la rúbrica mediante su rol de formador, como también se comprobó en las observaciones de clase, mientras la docente uno las utiliza con deficiencia las rúbricas, la docente dos no la usa en el proceso de aprender aprender.

\section{RÚBRICA PEDAGÓGICA PARA DESARROLLAR LA EVALUACIÓN FORMATIVA}

Desempeño del estudiante En lo que refiere al desempeño del estudiante eh su proceso de aprender a aprender, las entrevistadas indican que la actividad mental del conocimiento se construye; por ello el docente debe generar diversas estrategias que propicien ello como el análisis de los criterios de éxito en las actividades, por ejemplo fomentando el entendimiento de las rúbricas y sus indicadores para que los estudiantes vayan siendo conscientes de sus logros y dificultades en el proceso para implementar las mejoras necesarias de sus trabajos; el estudiante debe aprender asumir posturas, expresando sus ideas a través del lenguaje, ser autónomo, freativo en la resolución de dificultades durante el proceso, organizando y planificando, ya sea en equipo o trabajo individual. En la observación de clase se evidencia solo que a veces el estudiante emplea instrumentos de evaluación formativa, la falta de atención concentración de un grupo de estudiantes, el poco uso de la innovación y creatividad en el desarrollo de sus propuestas de trabajo.

Niveles de dominio De acuerdo a las entrevistas realizadas, respecto al conocimiento de niveles de dominio de la rúbrica, la docente informa que se realiza la adaptación de las rúbricas de acuerdo a la necesidad de la clase y nos indica de la importancia del ańlisis de los indicadores para una correcta reflexion, análisis de procesos cognitivos y autoevaluación. Podemos ver que la docente con mayor experiencia en la escuela maneja mejor este tipo de conocimiento y los aplica con sus estudiantes, mientras la docente dos no lo fomenta, ni presenta la rúbrica a sus estudiantes, no realizándose un análisis eficaz de lo que se espera del trabajo de los estudiantes. De igual modo ya que no se observa que los estudiantes conozcan los lineamientos establecidos de la rúbrica, los niveles de dominio no son fortalecidos de forma progresiva.
Falta de motivación en el proceso de enseñanza aprendizaje En las entrevistas a los docentes, en las observaciones de clases y en los resultados de las encuestas a los estudiantes se evidencia que la clase de comunicación es poco interactiva y motivadora para ellos. Se observó que en aula hay estudiantes con diferentes características y estilos de aprendizajes; donde el docente debe estimular más las habilidades metacognitivas, usando estrategias innovadoras y didácticas. Durante el proceso, en el momento de la retroalimentación, haciendo primero una felicitación del avance, reforzando conductas positivas y luego la indicación de las acciones de mejora de las actividades, esto hará fortalecer los niveles de logro de cada uno de sus alumnos, generando un clima de aula propicio, de confianza, fomentando la autonomía para el desarrollo del propio aprendizaje, propiciando un proceso continuo de reflexión.

Poco uso de estrategias evaluativas

De acuerdo a las entrevistadas se deben de desarrollar estrategias evaluativas diferente a las que comúnmente se usan, ya que estas permiten tener más objetividad a momento de colocar una calificación, por medio de las rúbricas los estudiantes conocerán que se espera que logren en las actividades. La autoevaluación de cada estudiante, la autoevaluación del proceso de la actividad realizada, la coevaluación de los grupos o entre compañeros del mismo equipo, la hetero evaluación junto con el docente, y la retroalimentación en el proceso, ya sea de forma escrita u oral, contribuyen al mejoramiento del proceso evaluativo. Se evidencia, sin embargo el poco uso de estrategias evaluativas para la mejora y evaluar formativamente, igualmente los estudiantes manifiestan esta carencia, ya que están acostumbrados hacer calificado cualitativamente, no contribuyendo a su desarrollo.

Competencias a desarrollar en el área de comunicación Las docentes del área de comunicación manifiestan que es importante el desarrollo de las competencia del área de comunicación: producción de textos, expresión oral y comprensión de textos. Ellas analizan y sugieren una rúbrica de evaluación precisa para fortalecer estas competencias en los estudiantes; actualmente una docente de las observadas solo lo realiza mediante la lluvia de ideas o listas de cotejo poco específicas; mientras la docente dos trata de establecer criterios más específicos. Estas fortalecerán las capacidades lingüísticas, de escritura, de análisis y entendimiento en los estudiantes; también son importantes porque si se plasman en una rúbrica se clarificarían los desempeños esperados de cada estudiante. 


\section{Categoría referida a la evaluación Formativa}

\section{Dimensión cognitiva.}

Las entrevistadas manifiestan que la cognición es parte indispensable para el aprendizaje, ya que a través del conocimiento se pueden generar nuevos conocimientos haciéndolos más sólidos. Sin embargo, en la observación de clases no se generó actividades para el desarrollo de las capacidades, conocimientos y competencias en los estudiantes, se observó el poco uso de instrumentos de evaluación formativa en el proceso de aprender a aprender (metacognición), como rúbricas, anecdotarios, y en cada uno de los procesos cognitivos de sus estudiantes, siendo importante crear espacios de asimilación de información de hechos, conceptos, procedimientos y valores. Resnick y Klopfer (1997). El maestro debe dedicarse no a transmitir conocimientos, sino a crear ambientes cognitivos de aprendizaje a sus alumnos. Para ello debería asegurar al menos tres condiciones: Proponer a los alumnos tareas y retos real, que parte de la solución de la tarea exija práctica en el contexto natural real, que el alumno tenga la oportunidad de observar a otros haciendo lo que se espera que él aprenda, no sólo para obtener pautas en vivo, sino para verbalizar críticamente lo observado a través de la evaluación conjunta.

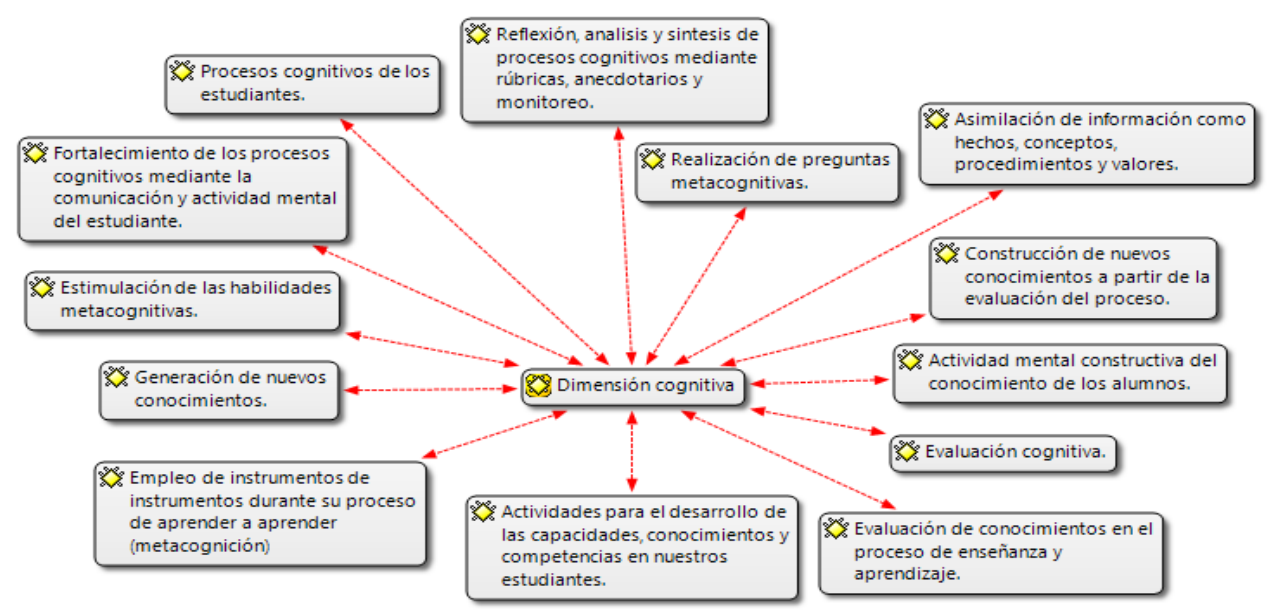

Figura 2. Dimensión cognitiva. 


\section{Dimensión procedimental.}

En lo que refiere a la dimensión procedimental, las entrevistadas refieren que se deben tomar en cuenta dentro de las clases los procesos de los estudiantes, permitiéndoles autoevaluarse en sus aciertos y desaciertos de las actividades que hagan mediante participaciones o una lista de cotejo que les permita reflexionar sobre su desenvolvimiento. En la parte procedimental se observó s que aún se deben tener en cuenta la aplicación de los saberes previos, también la utilización estrategias para que puedan llegar a los estudiantes, insertando en sus clases el aprendizaje colaborativo, elaborando productos; a una docente aún le falta trabajar el análisis de los niveles y criterios de la calidad del trabajo que asigna, utilizando la retroalimentación para que les permita a sus alumnos tomar conciencia de lo que se quiere lograr y así construir sus conocimientos.

Para que una clase contemple de procesos de evaluación formativa primero se debe generar un ambiente y clima propicio para el aprendizaje, y utilizar estrategias evaluativas centradas en el proceso, fortalecer los momentos de retroalimentación y apoyo con rubricas de evaluación, orientando contantemente a los estudiantes de forma oportuna y asertiva, generando la reflexión, análisis y síntesis de sus procesos metacognitivos.

Como refiere Melquisedec (2015) la evaluación formativa aplicada en la escuela es un recurso vital utilizado para lograr el aprendizaje significativo, que en forma oportuna e inmediata dan a conocer el proceso que han seguido los estudiantes, ya sea en la adquisición del conocimiento como en el fortalecimiento y desarrollo de las competencias. Es decir, la acción procesual será eficaz si el docente facilita al educando estrategias, métodos o medios necesarios que lo lleve a inferir, deducir, formular hipótesis, razonar, reflexionar y observar sobre hechos o fenómenos tratados o estudiados en el área curricular, esta acción hará poner en juego la 
creatividad, deducción o inducción haciéndolos pensar para descubrir la verdad e interiorizarla en esquemas y estructuras mentales del estudiante.

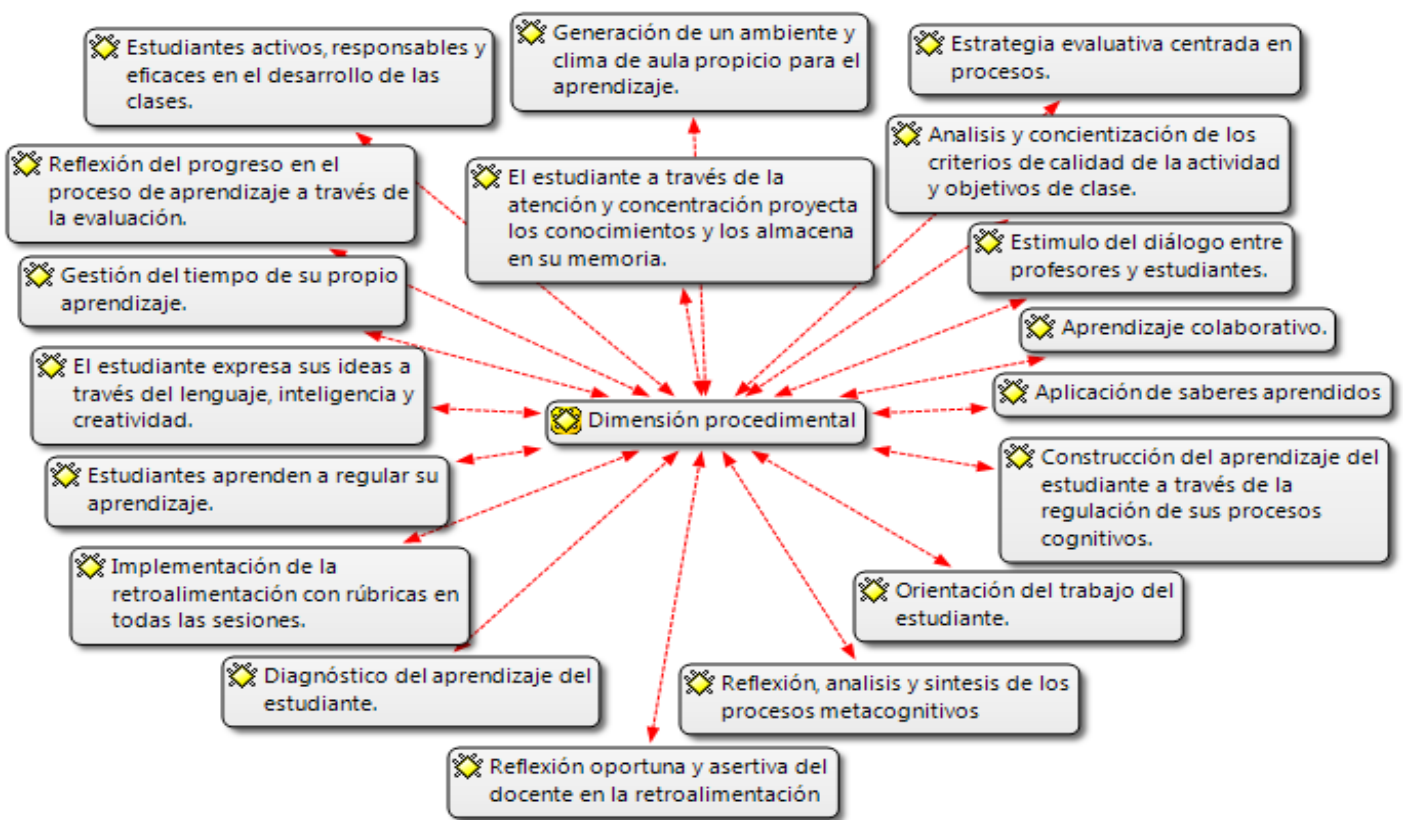

Figura 3. Dimensión procedimental.

\section{Dimensión actitudinal.}

De acuerdo a las docentes entrevistadas podemos mencionar que debemos de desarrollar en el proceso de enseñanza aprendizaje el desarrollo actitudinal positivo en los estudiantes, fortaleciendo las competencias valorativas y de buena convivencia para realizar un óptimo trabajo.

En la evaluación formativa se busca que los estudiantes aprendan en equipo para construir sus aprendizajes esto hace que tengan una diversidad de opiniones de los temas que el docente propone en su clase, este tipo de trabajo desarrolla habilidades sociales; de lo observado podemos 
mencionar que el docente debe llegar a sus estudiantes por medio de la asertividad, comunicación efectiva, empatía; siendo este formador, haciendo consciente al estudiante que de su autodisciplina y constancia depende mucho su aprendizaje. El docente debe de fortalecer la autonomía del estudiante, esto le permitirá a aumentar la confianza en sí mismo.

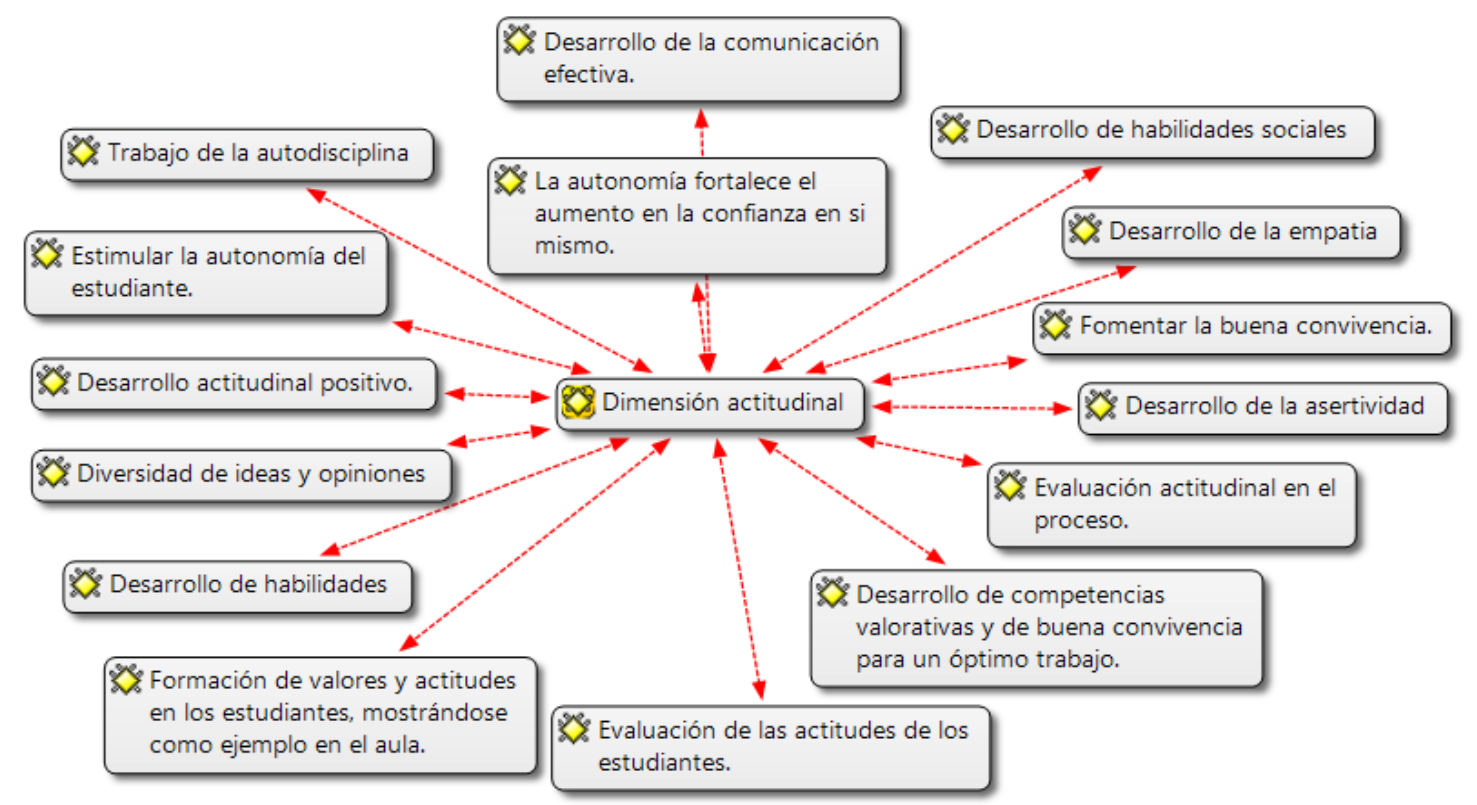

Figura 4. Dimensión actitudinal.

\section{Categoría referida a la rúbrica pedagógica}

\section{Desempeño del estudiante.}

En lo que refiere al desempeño del estudiante, en su proceso de aprender a aprender, las entrevistadas indican que la actividad mental del conocimiento se construye; por ello el docente debe generar diversas estrategias que propicien ello como el análisis de los criterios de éxito en las actividades, por ejemplo fomentando el entendimiento de las rúbricas y sus indicadores para que los estudiantes vayan siendo conscientes de sus logros y dificultades en el proceso para implementar las mejoras necesarias de sus trabajos; el estudiante debe aprender asumir posturas, expresando sus ideas a través del lenguaje, ser autónomo, creativo en la resolución de 
dificultades durante el proceso, organizando y planificando, ya sea en equipo o trabajo individual. En la observación de clase se evidencia solo que a veces el estudiante emplea instrumentos de evaluación formativa, la falta de atención y concentración de un grupo de estudiantes, el poco uso de la innovación y creatividad en el desarrollo de sus propuestas de trabajo.

Como lo menciona Melquisedec (2015) se desarrolla el conocimiento y se desarrollan las competencias del estudiante, donde el evaluador obtiene y analiza las evidencias del desempeño durante el proceso basado a los criterios u objetivos, para emitir un juicio, igualmente, permite al estudiante distinguir las áreas que necesitan ser fortalecidas para lograr un nivel de desempeño eficaz de la competencia trabajada, consolidado el aprendizaje y que sea evidenciado en el manejo y utilización adecuada de los procedimientos, técnicas, métodos y estrategias para la solución de situaciones problemáticas o nuevas.

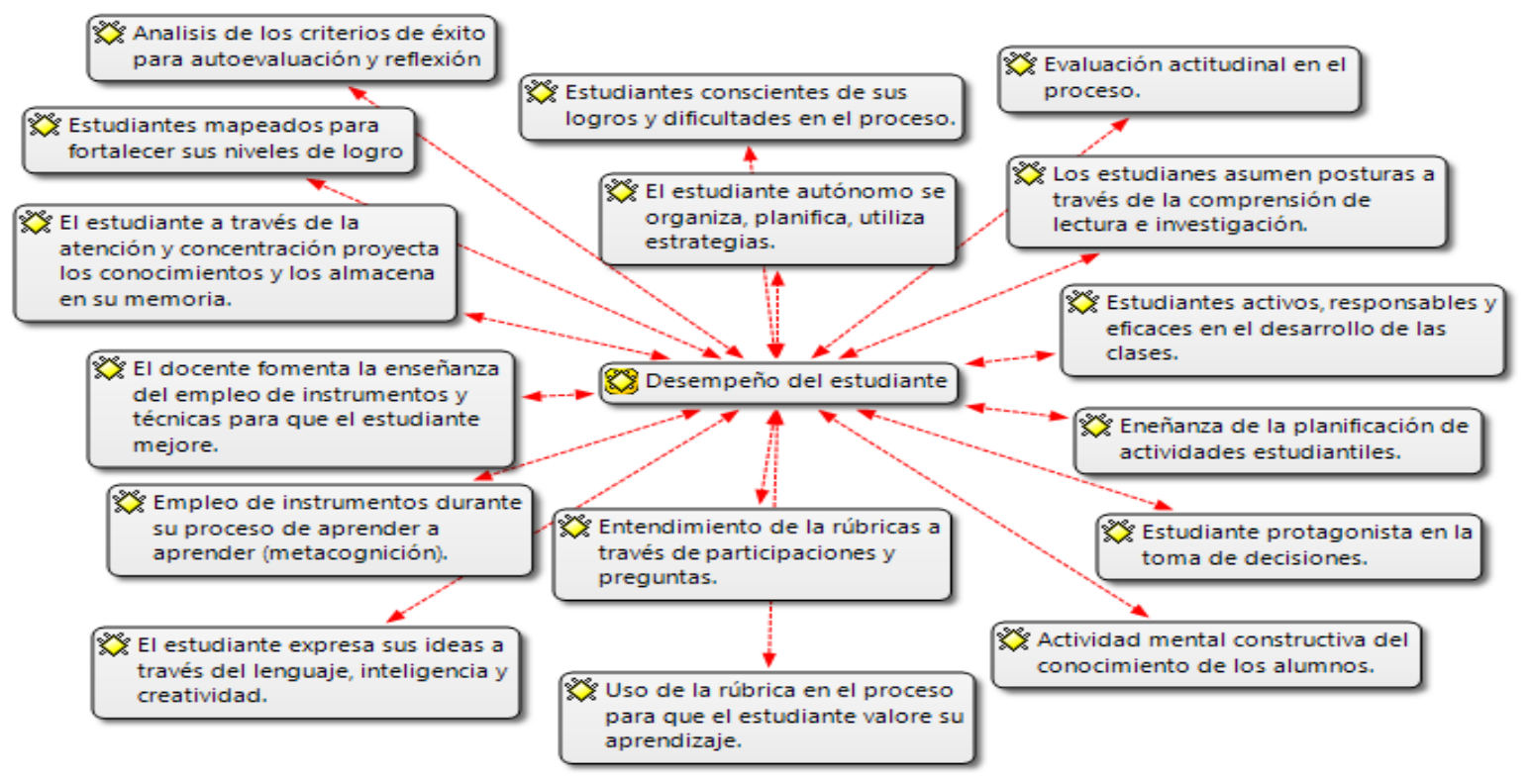

Figura 5. Desempeño del estudiante. 


\section{Niveles de dominio.}

De acuerdo a las entrevistas realizadas, respecto al conocimiento de niveles de dominio de la rúbrica, la docente informa que se realiza la adaptación de las rúbricas de acuerdo a la necesidad de la clase y nos indica de la importancia del análisis de los indicadores para una correcta reflexión, análisis de procesos cognitivos y autoevaluación. Podemos ver que la docente con mayor experiencia en la escuela maneja mejor este tipo de conocimiento y los aplica con sus estudiantes, mientras la docente dos no lo fomenta, ni presenta la rúbrica a sus estudiantes, no realizándose un análisis eficaz de lo que se espera del trabajo de los estudiantes. De igual modo ya que no se observa que los estudiantes conozcan los lineamientos establecidos de la rúbrica, los niveles de dominio no son fortalecidos de forma progresiva. Por ello es importante que se cuente con un instrumento de evaluación eficaz, fomentando la explicación de los niveles de dominio que adquieren los estudiantes progresivamente, en el plenario de clase y fortaleciéndolo con la retroalimentación identificando las fortalezas y debilidades de los trabajos. Este instrumento cuantitativo y cualitativo permite la formación y desarrollo de competencias dentro del marco de la evaluación formativa

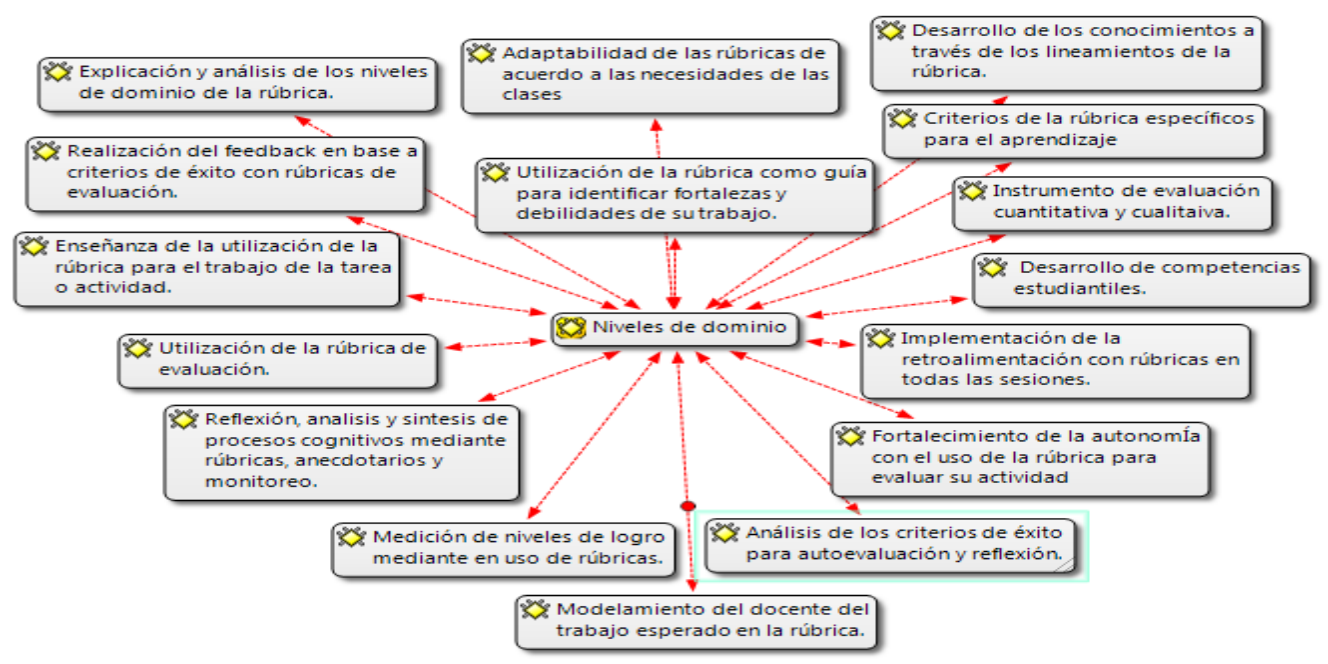

Figura 6. Niveles de dominio. 


\section{Rol del docente.}

Nuestras docentes entrevistadas mencionan que el docente debe acercar al estudiante al trabajo colaborativo esencial para el aprendizaje, sin dejar de lado el trabajo individual ya que se complementan; siendo necesaria la dirección eficaz del profesor, siendo un modelo para sus estudiantes. En el marco de la evaluación formativa insertar estrategias que permitan mejorar su práctica pedagógica, con el uso de herramientas como la rúbrica, la motivación constante para el avance de cada uno de sus alumnos, incentivar las preguntas y repreguntas para la comprobación del entendimiento de las actividades. Sin embargo, un buen porcentaje de los encuestados cree que solo a veces el docente utiliza la rúbrica mediante su rol de formador, como también se comprobó en las observaciones de clase, mientras la docente uno las utiliza con deficiencia las rúbricas, la docente dos no la usa en el proceso de aprender a aprender.

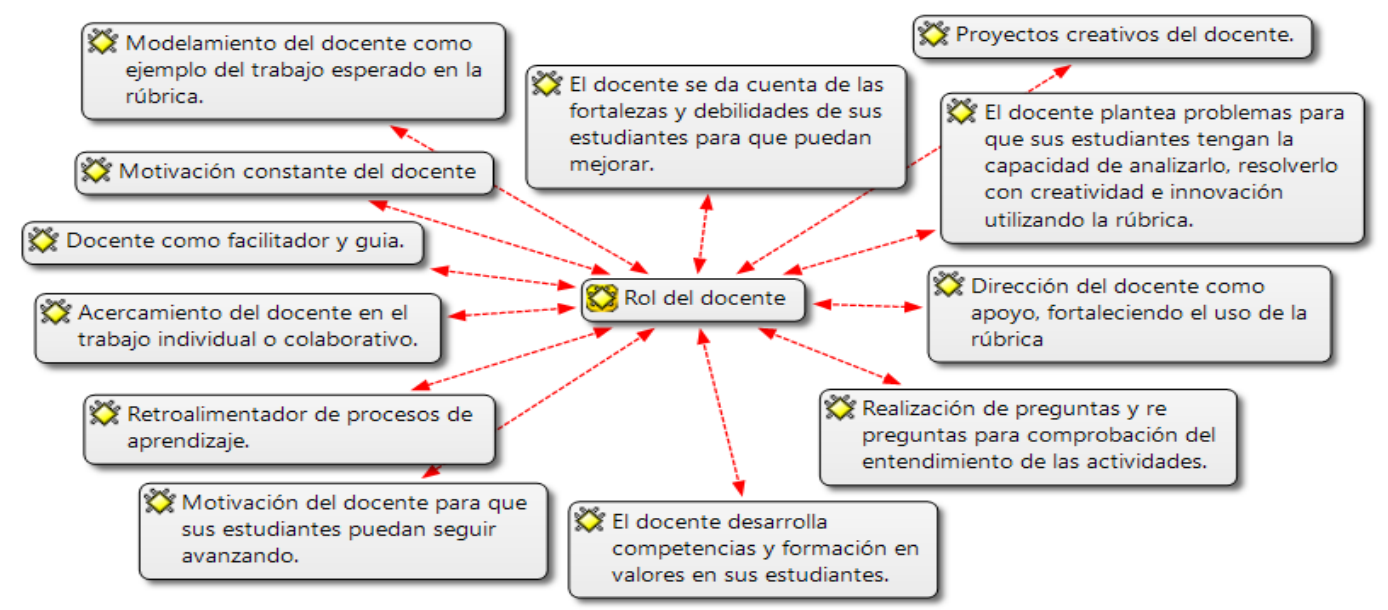

Figura 7. Rol del docente.

\section{Análisis e interpretación de las categorías emergentes}

De este proceso se identificaron las siguientes categorías emergentes: Falta de motivación durante el proceso de enseñanza aprendizaje, poco uso de estrategias evaluativas y deficiencia del desarrollo de competencias en el área de comunicación. Sobre la falta de motivación durante 
el proceso de enseñanza aprendizaje y en vista de nuestro estudio de campo y experiencia es importante incluir la motivación en el proceso de enseñanza- aprendizaje para el modelo de la evaluación formativa actual.

Según Dörnyei (2008) la motivación es una característica humana abstracta, que explica el comportamiento y la forma de pensar de la gente; siendo la motivación crucial en la enseñanza, el docente debe de valerse de varias estrategias para promoverla con los estudiantes. Sobre el poco uso de estrategias evaluativas, estas deben incluirse para fortalecer los aprendizajes durante el proceso de evaluación formativa, utilizando diferentes instrumentos de evaluación que fomenten el análisis de sus actividades en clases que los ayuden a retroalimentar sus procesos con la guía del docente a cargo.

Por otro lado, el docente debe aplicar en sus clases diferentes estrategias metodológicas de evaluación que concuerden con las necesidades de los estudiantes, en coherencia con las metas de aprendizaje y procesos evaluativos, que contribuyan a mejorar los procesos de enseñanza-aprendizaje como nos menciona Alsina y otros (2013). Sobre la deficiencia del desarrollo de competencias en el área de comunicación, la escuela debe lograr insertar a cabalidad el enfoque comunicativo en sus aulas tomando en cuenta el uso de instrumentos como rúbricas. El enfoque comunicacional se desarrolla a partir de las metodologías audioorales y audiovisuales para la enseñanza de lenguas; siendo su fin establecer comunicación, dándole importancia a las aptitudes que el estudiante debe desarrollar como la comprensión y expresión oral o comprensión y expresión escrita como lo refiere Bérard (1995). Así mismo, el Ministerio de Educación (2016) refiere que el área de Comunicación tiene por objetivo el desarrollo de competencias comunicativas para la interacción con otras personas, comprendiendo, construyendo la realidad y representando el mundo de forma real o imaginaria. 


\section{Conclusiones aproximativas del estudio de campo}

El estudio realizado permitió arribar a las conclusiones aproximativas siguientes:

Sobre la falta de motivación durante el proceso de enseñanza aprendizaje, en las entrevistas a los docentes, en las observaciones de clases y en los resultados de las encuestas a los estudiantes se evidencia que la clase de comunicación es poco interactiva y motivadora para ellos. Se observó que en aula hay estudiantes con diferentes características y estilos de aprendizajes; donde el docente debe estimular más las habilidades metacognitivas, usando estrategias innovadoras y didácticas. Durante el proceso, en el momento de la retroalimentación, haciendo primero una felicitación del avance, reforzando conductas positivas y luego la indicación de las acciones de mejora de las actividades, esto hará fortalecer los niveles de logro de cada uno de sus alumnos, generando un clima de aula propicio, de confianza, fomentando la autonomía para el desarrollo del propio aprendizaje, propiciando un proceso continuo de reflexión.

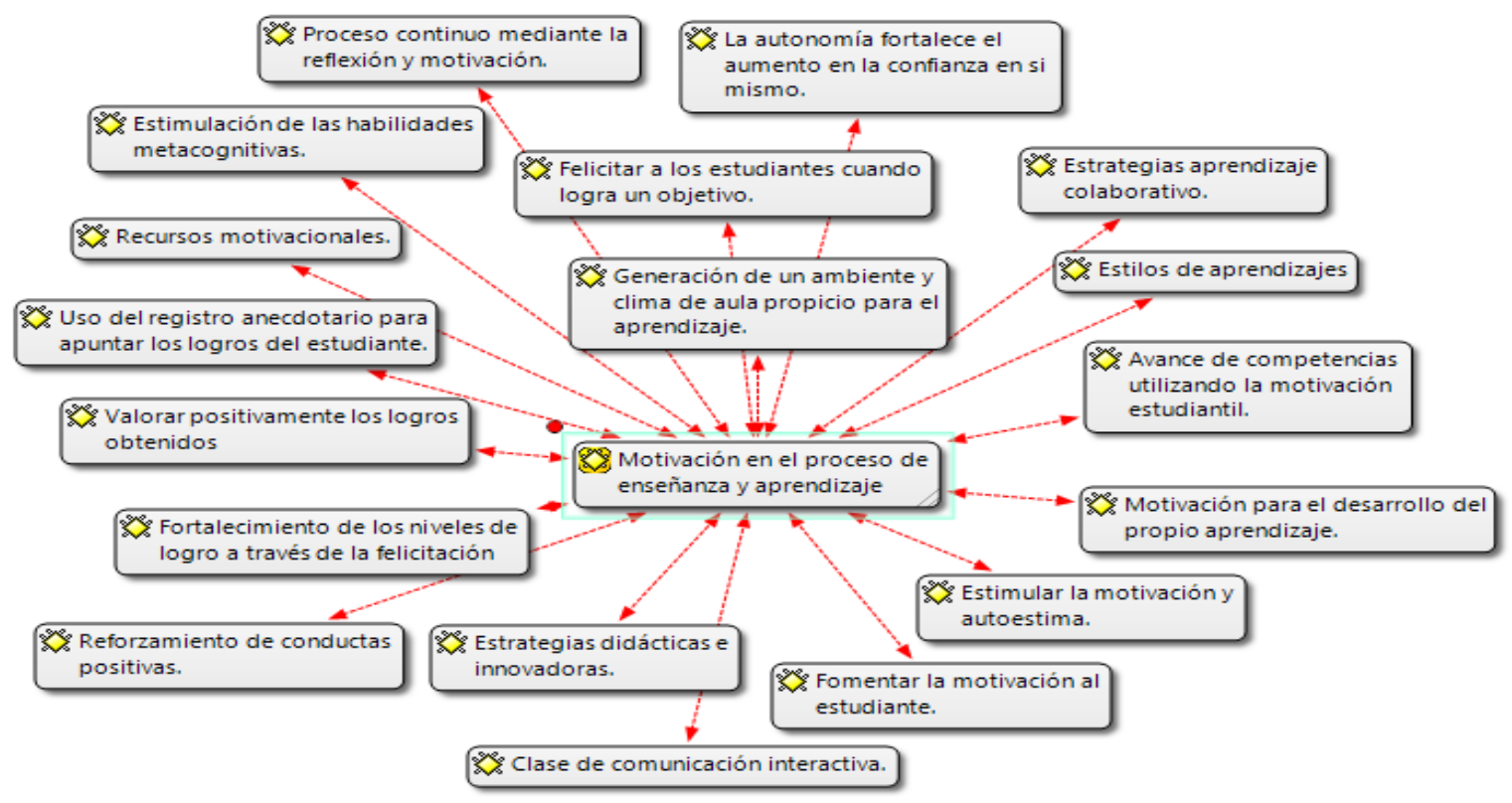

Figura 8. Motivación en el proceso de enseñanza y aprendizaje. 
Sobre el poco uso de estrategias evaluativas, de acuerdo a las entrevistadas se deben de desarrollar estrategias evaluativas diferentes a las que comúnmente se usan, ya que estas permiten tener más objetividad al momento de colocar una calificación, por medio de las rúbricas los estudiantes conocerán que se espera que logren en las actividades y en el área de comunicación es muy importante trabajarlas para desarrollar las competencias que queremos que logren, como la expresión oral, producción de textos y comprensión. Cabe mencionar que la autoevaluación de cada estudiante, la autoevaluación del proceso de la actividad realizada, la coevaluación de los grupos o entre compañeros del mismo equipo, la heteroevaluación junto con el docente y la retroalimentación en el proceso, ya sea de forma escrita u oral, contribuyen al mejoramiento del proceso evaluativo. Se evidencia, sin embargo, el poco uso de estrategias evaluativas para la mejora y evaluar formativamente, igualmente los estudiantes manifiestan esta carencia, ya que están acostumbrados hacer calificados cualitativamente, no contribuyendo a su desarrollo.

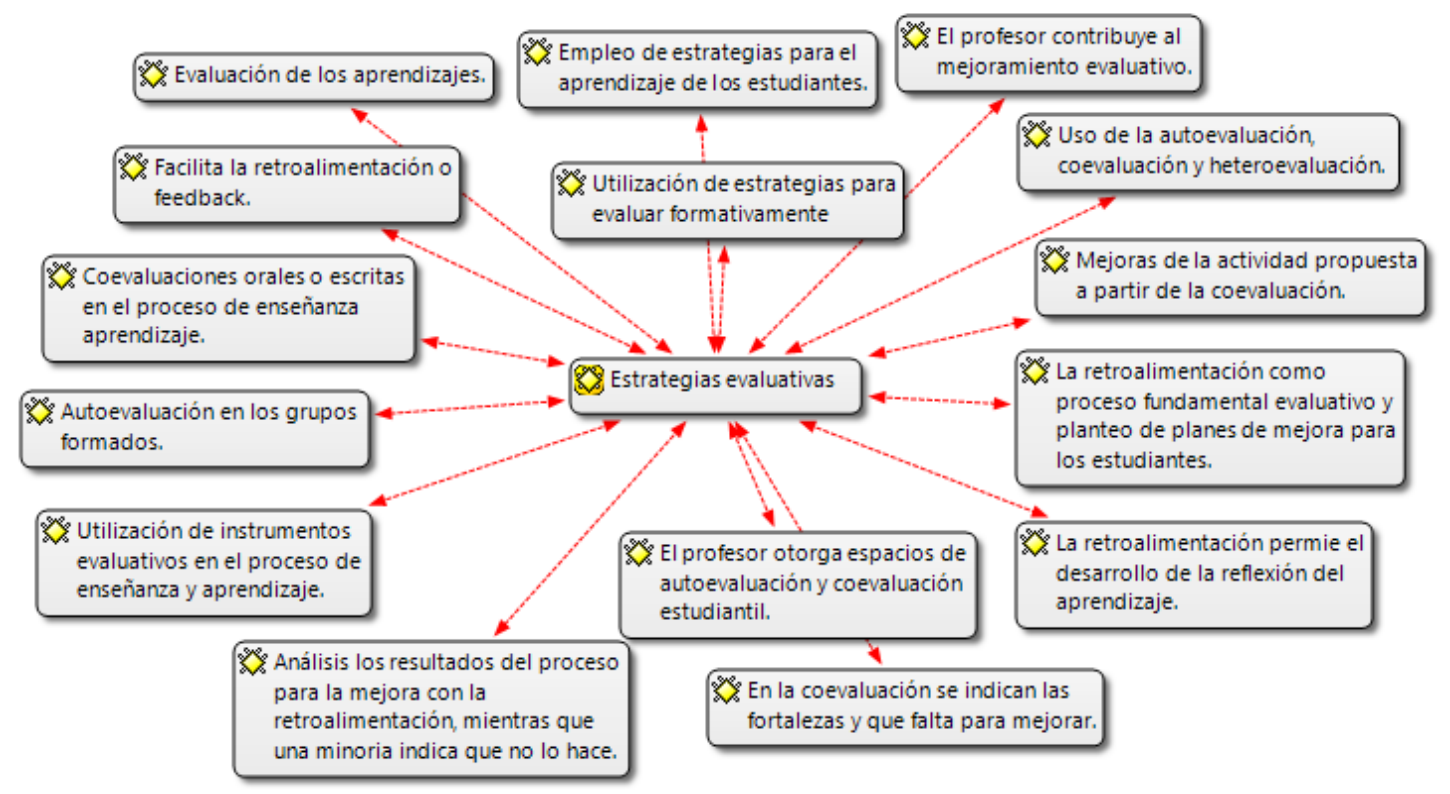

Figura 9. Estrategias evaluativas. 
Sobre la eficiencia del desarrollo de competencias en el área de comunicación, las docentes del área de comunicación manifiestan que es importante el desarrollo de las competencias del área de comunicación: producción de textos, expresión oral y comprensión de textos. Ellas analizan y sugieren una rúbrica de evaluación precisa para fortalecer estas competencias en los estudiantes; actualmente una docente de las observadas solo lo realiza mediante la lluvia de ideas o listas de cotejo poco específicas; mientras la docente dos trata de establecer criterios más específicos. Estas fortalecerán las capacidades lingüísticas, de escritura, de análisis y entendimiento en los estudiantes; también son importantes porque si se plasman en una rúbrica se clarificarían los desempeños esperados de cada estudiante.

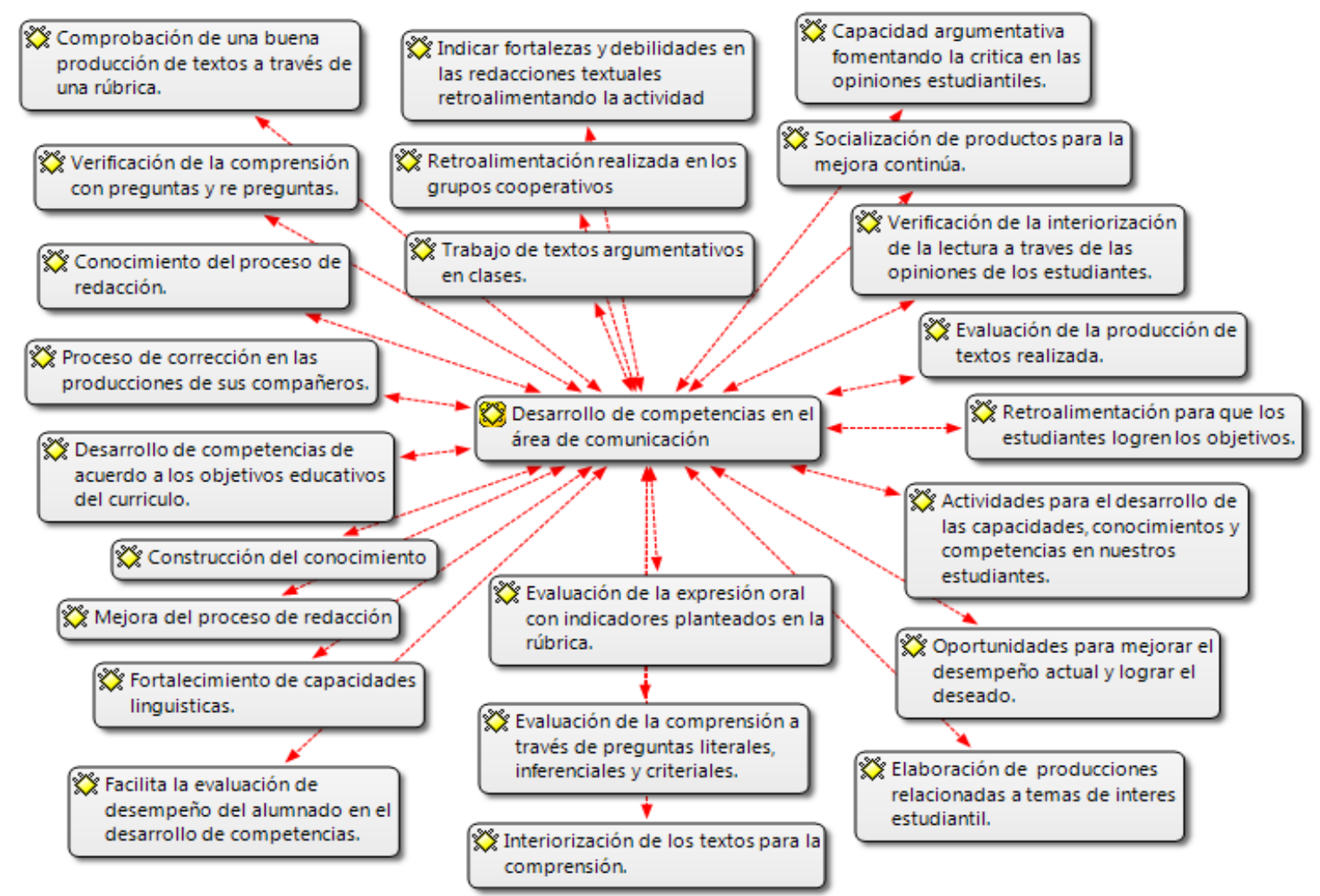

Figura 10. Desarrollo de competencias en el área de comunicación. 


\section{RESULTADO DEL PROCESO DE DIÁGNOSTICO DE CAMPO}

\section{CATEGORIAS APRIORISTICAS}

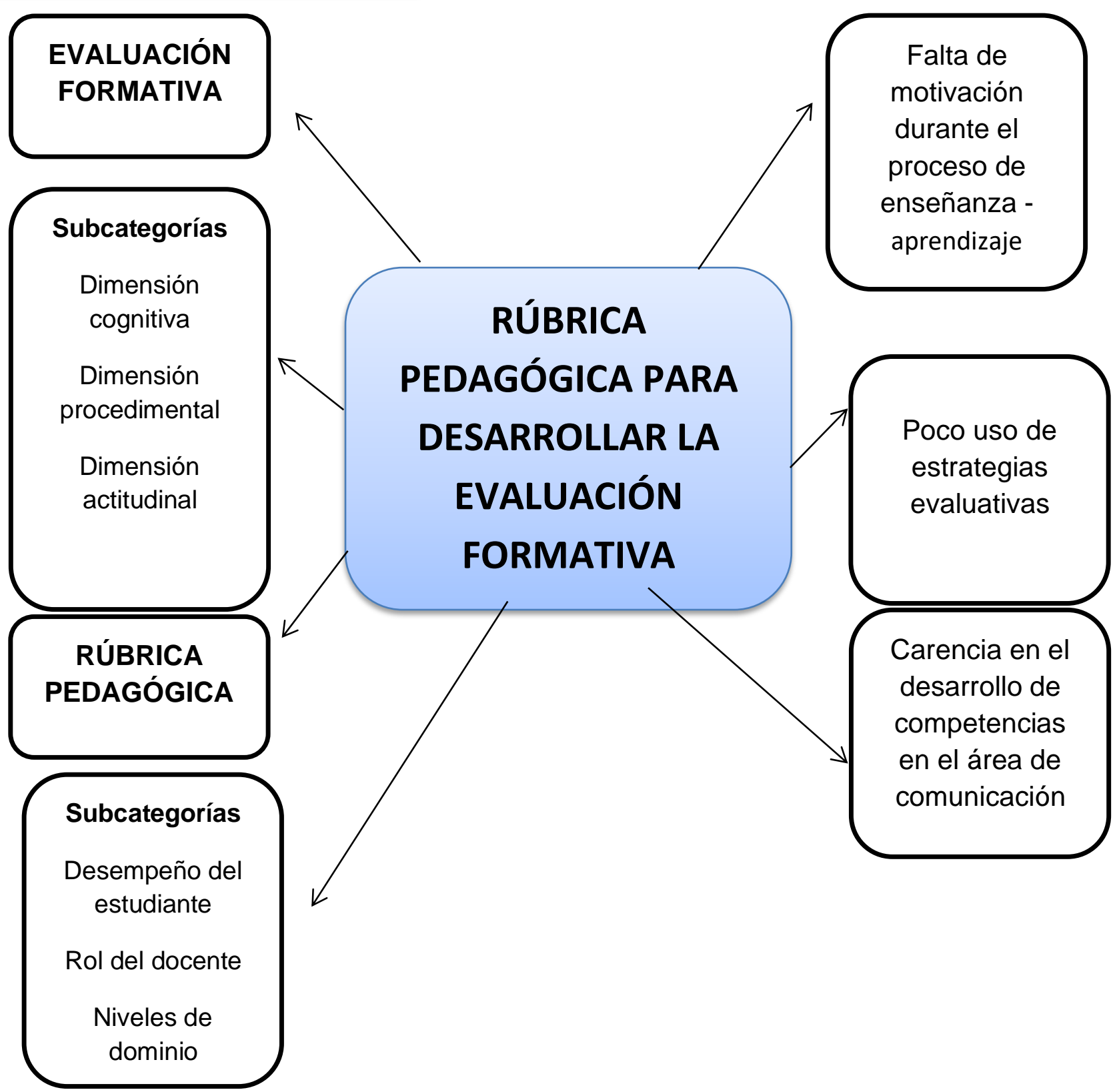

CATEGORIAS EMERGENTES 


\section{Capitulo III}

\section{Modelación de la propuesta}

\section{Introducción}

Como resultado del proceso de investigación, en el proceso de trabajo de campo y el diagnóstico, se diseña la propuesta de rúbrica pedagógica para desarrollar la evaluación formativa en los estudiantes del nivel Secundaria de una institución educativa particular del distrito de San Miguel en el área de Comunicación.

Dicha rúbrica pedagógica se propone en base a los fundamentos teóricos, los resultados que se obtuvieron en la aplicación de instrumentos y la identificación de las categorías emergentes: Falta de motivación durante el proceso de enseñanza aprendizaje, poco uso de estrategias evaluativas y deficiencia del desarrollo de competencias en el área de comunicación. Luego del análisis respectivo se procedió a modelar la propuesta metodológica como producto del proceso investigativo orientado a cambiar la problemática objeto de estudio, aportando significativamente en el desarrollo de la evaluación formativa.

\section{Propósito de la propuesta metodológica}

La propuesta metodológica tiene como propósito contribuir con el desarrollo de la evaluación formativa en los estudiantes del nivel secundaria de una institución educativa particular a través de la rúbrica pedagógica en el área de comunicación.

\section{Fundamentación de la propuesta}

\section{Fundamente filosófico.}

La propuesta descansa en los postulados de la Filosofía de la Educación y de la Evaluación dentro del proceso de enseñanza-aprendizaje a través de la utilización de un enfoque formativo 
por medio del uso de rúbricas para la mejora de las competencias estudiantiles en el área de comunicación integral.

Como lo señala Rodríguez (2017) una de las cuestiones filosóficas fundamentales que se abordan en la Educación, clarifica el ideal de la humanidad, este se asume que es el motor que pone en marcha todo el proceso educativo. Por ello, para la evaluación se tiene que en tener claro que perfil se quiere desarrollar, esto permitirá la formulación de estrategias coherentes en las actividades educativas y los procesos evaluativos.

La evaluación debe ser revolución, donde el docente y estudiante construyan un cambio permanente, donde exista un respeto entre ellos. Al respecto, la evaluación es valiosa, porque permite también preguntarse y analizar sobre los procesos que ocurren en la parte educativa, la concepción de evaluación interacciona en todo proceso en el contexto educativo como lo menciona Rodríguez (2017). La evaluación formativa es un procedimiento que es utilizado por estudiantes y profesores, durante el proceso de enseñanza-aprendizaje, este aporta la necesaria información para ajustar lo que se requiera, para que los alumnos logren las metas planteadas, los contenidos curriculares o competencias propuestas en las clases, como lo menciona Melmer et al. (2008).

Dunn y Mulvenon (2009), consideran a la evaluación formativa como una serie de procedimientos de evaluación, que dentro del proceso de enseñanza-aprendizaje están integrados y son orientados a mejorar, modificar y realizar la comprensión del aprendizaje por parte de los estudiantes. Como sostienen Condemarín y Medina (2000), la evaluación formativa durante el proceso de enseñanza realimenta el aprendizaje, posibilitando la regulación por parte del estudiante y con la mediación del docente se ajusta su progreso, adaptando las actividades con sus necesidades y posibilidades; por ende es importante que el docente sepa y analice dónde se 
encuentra el estudiante respecto a un aprendizaje determinado, para que se ponga objetivos hasta dónde puede llegar.

\section{Fundamento socioeducativo.}

La propuesta metodológica está dirigida a los estudiantes de segundo grado de Educación Secundaria de la EBR en el área curricular de Comunicación Integral en una institución educativa particular ubicado en el del distrito de San Miguel. Este es uno de los 43 distritos de la parte Oeste de la ciudad capital de Lima. La institución educativa es privada con un buen prestigio, cuenta con 285 estudiantes distribuidos en nueve aulas.

Este colegio cobra pensiones mensuales por igual a todos los estudiantes y también se dan becas a estudiantes con buen rendimiento académico, por falta de economía de los PPFF o por destacar como deportista calificado a nivel nacional o internacional. La institución cuenta con veinte aulas, laboratorio de ciencias, laboratorio con computadoras, canchas deportivas, bibliotecas y más servicios que han hecho que esté licenciada por Sunedu y acreditada internacionalmente.

La población estudiantil del segundo grado de Secundaria que se les imparte aprendizajes es de 52 estudiantes, distribuidos en dos secciones de clase; las edades de los educandos son entre doce y trece años. Se cuenta con tres docentes especializados en el área de comunicación, que por cuestión de horas pedagógicas impartidas dos de ellas enseñan en segundo grado de secundaria en diferentes secciones, una de ellas en la sección A y otra en la sección B. En general la institución de nivel Secundaria está conformada por quince docentes, en el caso del área investigada se cuenta con tres profesoras con especialidad en el área de Comunicación. Ante la necesidad para mejorar su eficacia en el desarrollo de la enseñanza - 
aprendizaje, por las demandas y nuevas formas de enseñanza del siglo XXI, la institución las capacita para lograr la formación integral de las futuras generaciones.

Entre los principios pedagógicos del modelo educativo tomado en la propuesta metodológica se basa en un aprendizaje por competencias, aprendizaje centrado en el estudiante y el modelo sociocultural de Vigosky. El conocimiento es algo que se construye por medio de operaciones y habilidades cognoscitivas que se adquieren en la interacción social. El desarrollo intelectual del sujeto no puede entenderse aislado del medio social; el desarrollo de las funciones psicológicas se da en el plano social y después en el plano individual; siendo el aprendizaje la resultante de la influencia de factores sociales, como la interacción comunicativa, esta construcción resultado de una experiencia de aprendizaje se transmite mediante operaciones mentales que se suceden durante la interacción de la persona con el mundo material y social como lo señala Vigotsky (1979).

De acuerdo a Moffett y a Wagner (1992) para que una clase sea centrada en el alumno, los estudiantes deben tener tres cosas para el aprendizaje: individualización, interacción e integración. Por lo tanto, un currículum centrado en el alumno: "le enseña a cada alumno a seleccionar y a secuenciar sus propias actividades y materiales (individualización); a organizar a los alumnos para que se centren y se enseñen unos a otros (interacción); entrelaza todos los temas simbolizados y simbólicos para que el alumno pueda sintetizar efectivamente las estructuras del conocimiento en su propia mente (integración)" como nos menciona Tobón (2016). La formación basada en competencias constituye una propuesta que parte del aprendizaje significativo y se orienta a la formación humana integral; integra la teoría con la práctica en las diferentes actividades y fomenta la construcción del aprendizaje. 
Ahora, desde un enfoque formativo, se evalúan las competencias, eso quiere decir, los niveles cada vez más complejos de uso pertinente y combinado de las capacidades, tomando como referente los estándares de aprendizaje porque describen el desarrollo de una competencia y definen qué se espera logren todos los estudiantes al finalizar un ciclo en la Educación Básica. Por ello, los estándares constituyen criterios precisos y comunes para comunicar no solo si se ha alcanzado el estándar, sino para señalar cuán lejos o cerca está cada estudiante de alcanzarlo como lo señala el Currículo Nacional del Minedu (2017).

En tal sentido, Tobón (2007) sostiene que el enfoque de la formación basada en competencias en la educación orienta el aprendizaje acorde a los problemas y retos del contexto social, comunitario, profesional, organizacional y disciplinar - investigativo, mediante estudios sistemáticos tales como el análisis funcional, el estudio de problemas, el registro de comportamientos, el análisis de procesos, etc., teniendo en cuenta el desarrollo humano sostenible, y las necesidades vitales de las personas. Ello permite que el aprendizaje, la enseñanza y la evaluación tengan sentido, no sólo para los estudiantes, sino también para los docentes, las instituciones educativas y la sociedad.

\section{Fundamento pedagógico.}

La propuesta se ubica dentro del paradigma de la evaluación formativa, y tiene como bases teóricas los fundamentos del constructivismo. Estos serán los encargados de guiar las diferentes estrategias de evaluación, donde el estudiante cumpla un rol activo como creador de significado, autoorganizador y de evolución progresiva de las estructuras del conocimiento. Los principales referentes del enfoque constructivista son Piaget, Vygotski, Bruner y Ausubel, en este los estudiantes consiguen un conjunto de construcciones personales, formando su propio conocimiento, dándoles la oportunidad de seguir aprendiendo; en este método, se busca que se 
adquiera la capacidad de aplicar los conocimientos aprendidos y pueda aportar un nuevo significado al conocimiento, esta requiere compromiso mutuo en la relación maestro-estudiante, con la finalidad de reflexionar sobre los posibles métodos para optimizarla, transformándola en una herramienta para el conocimiento de nuevos contenidos como lo menciona Marchese (2013). La propuesta se basa también en el enfoque metacognitivo; la metacognición, está referida hacia los propios procesos para la formación del conocimiento, la supervisión activa, la regulación y organización de estos procesos, están relacionadas en metas u objetivos concretos como lo refiere Flavell (1976).

Como lo señala el Marco del Buen Desempeño Docente (2016) el docente debe prever la utilización de diversas estrategias metacognitivas y de retroalimentación, en concordancia con el enfoque formativo de la evaluación. Para Ausubel (1983) sostiene que para que el estudiante alcance un saber metacognitivo requiere de una participación activa; entonces, mientras más relacionado esté un saber nuevo a los saberes que el individuo ya tiene incorporado, más accesible, fácil y retadora le resultará la tarea, logrando un aprendizaje significativo.

\section{Fundamento curricular.}

El diseño de la propuesta metodológica del desarrollo de la evaluación formativa se basa en las exigencias del currículo nacional del Ministerio de Educación (2017) conforme lo señala el Reglamento de dicha norma, en donde especifica como uno de los roles más importantes la mejora de la calidad de los aprendizajes, este nos brinda orientaciones para la evaluación formativa y para la diversificación curricular, aprendizajes que deben lograr los estudiantes (perfil de egreso), competencias nacionales y estándares.

En la política pedagógica peruana, dada en el Reglamento de la Ley General de Educación, el proceso de la evaluación se considera formativo, integral y continuo; este 
identifica el avance, problemas y logros del alumno, con la finalidad de apoyarlos en lo que necesiten para la mejora. Por lo tanto, se evalúan con criterios, niveles de logro, así como técnicas e instrumentos que nos permiten tener información para la toma de decisiones que retroalimentan al estudiante. Minedu en el currículo nacional también nos menciona que la evaluación impulsa el avance de los resultados educativos y de la práctica del docente en el proceso de enseñanza aprendizaje.

El Currículo Nacional del Minedu propone la evaluación con rúbricas para valorar la posición de los estudiantes, ya que estas ofrecen información acerca del nivel de progreso de la competencia en el que se encuentran los alumnos. Por otro lado, nos brinda orientaciones para la evaluación formativa de las competencias en el aula. Al respecto, Shepard (2001) argumenta que las teorías cognitivas y constructivistas del aprendizaje, las nuevas tendencias curriculares y las nuevas visiones sobre evaluación del aprendizaje exigen que se hagan cambios radicales en la forma como se usan las evaluaciones en el aula de clase. Sugiere que la evaluación sea parte integral del proceso de aprendizaje. Esto requiere que la evaluación se utilice para retroalimentar a los estudiantes sobre cómo van en ese proceso. Por lo tanto, es importante que los profesores promuevan un ambiente propicio dentro del aula de clase para que las evaluaciones faciliten el aprendizaje.

\section{Fundamento lingüístico.}

En el Perú se han elaborado los mapas de progreso de los estudiantes de Educación Básica Regular con estándares nacionales de aprendizaje describiendo del progreso de ciclo a ciclo las diferentes competencias, en este caso, referida a la investigación nos centramos al área de comunicación. El área curricular de Comunicación plantea el aprendizaje de la lengua en uso, siendo el objetivo del área desarrollar competencias comunicativas en los estudiantes, 
implicando el uso del sistema gramatical de la lengua, adecuación a diversos contextos socioculturales -formales e informales, el uso de diferentes tipos de textos orales y escritos, la utilización de recursos y estrategias para lograr los propósitos comunicativos como lo refiere el Minedu (2013).

En este sentido, para desarrollar estas competencias lingüísticas se deben garantizar prácticas y experiencias para satisfacer sus necesidades e intereses comunicativos, estas situaciones también serán logradas en parte de su vida dentro del medio social donde se desenvuelve el ser humano.

En los mapas de progreso encontramos descritas las cuatro competencias lingüísticas básicas: leer, escribir, hablar y escuchar (Cassany, 2005). En tal sentido, estas competencias son diferentes y se complementan cuando se hace uso de la lengua en diferentes situaciones comunicativas y se organizan en tres mapas de progreso: Lectura (leer), Escritura (escribir), Comunicación oral (hablar y escuchar) como lo plantea el Minedu (2013).

\section{Diseño de la propuesta metodológica}

La propuesta de rúbrica pedagógica para desarrollar la evaluación formativa en los estudiantes ha sido diseñada sobre la base de los fundamentos socioeducativos, pedagógicos y curriculares mencionados en la investigación; permitiendo orientar la labor pedagógica del profesorado durante el proceso de enseñanza aprendizaje, con la finalidad de lograr un cambio metodológico en su accionar docente en la búsqueda de la formación de competencias y por ende del aprendizaje. La propuesta se representa en dos partes, se inicia primero con un esquema gráfico teórico funcional de la propuesta modelada y luego en la segunda se especifica el desarrollo de la propuesta. 


\section{Esquema teórico- funcional de la propuesta de la rúbrica pedagógica}

A continuación, se presenta de manera gráfica el esquema de la propuesta, la cual representa el

funcionamiento interno de la rúbrica pedagógica para desarrollar la evaluación formativa en los estudiantes de segundo año de educación secundaria. 


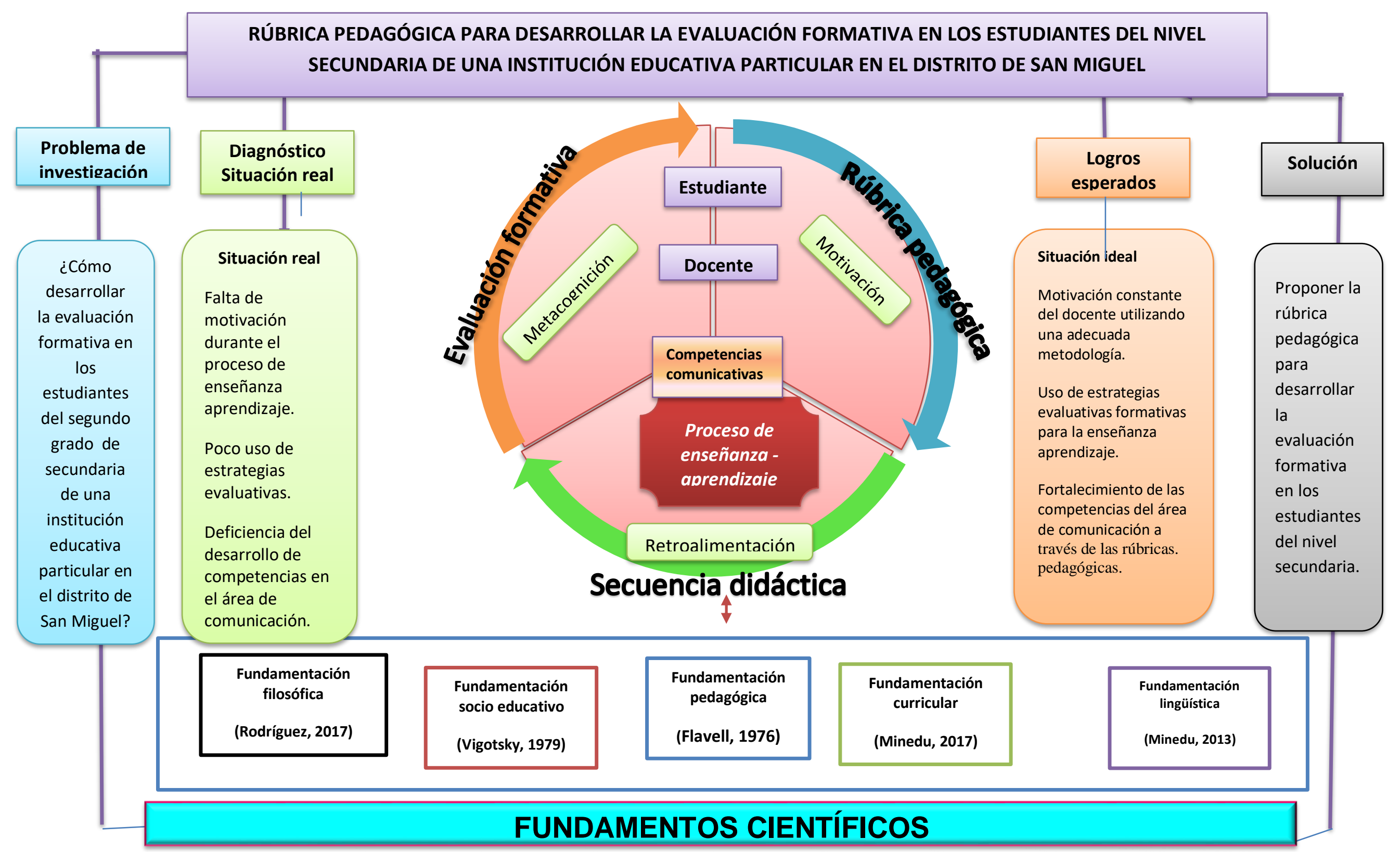

Figura 12. Esquema feónico funcional que representa la propuesta.

Fuente. Elaboración propia (2019). 


\section{DESARROLLO DE LA PROPUESTA}

El diseño de esta propuesta se realiza tomando en cuenta los fundamentos de diferentes autores ha diseño con el propósito de desarrollar la evaluación formativa en los estudiantes del nivel secundaria para una población y muestra específica, esta propuesta debe ser utilizada en el proceso de enseñanza aprendizaje para mejorar el rendimiento escolar. Con respecto a la rúbrica pedagógica está será insertada en las sesiones de aprendizaje del área de Comunicación para el desarrollo de la evaluación formativa mediante una serie de procesos de enseñanza aprendizaje donde se involucra al docente y a los estudiantes para la formación de competencias del curso en el cual nos enfocamos (comunicación oral, producción de textos y comprensión de textos); tomándose en cuenta el enfoque de Tobón (2010). De tal manera, se diseñó la propuesta tomando en cuenta los enfoques de evaluación formativa, ya explicados en los fundamentos curriculares, socioeducativos, psicológicos y pedagógicos.

\section{PROPUESTA DE RÚBRICA PEDAGÓGICA}

Basándonos en el Currículo Nacional de la Educación Básica 2017, que orienta los aprendizajes que se deben garantizar como Estado y sociedad; debe ser usado como fundamento de la práctica pedagógica en las diversas instituciones y programas educativos. En este se encuentran descritos el perfil de egreso, las competencias, capacidades, estándares de aprendizajes, desempeños, áreas curriculares, planes de estudio de EBR, además orientaciones para el proceso de enseñanza aprendizaje, orientaciones para la evaluación formativa de las competencias y orientaciones para la diversificación curricular. 


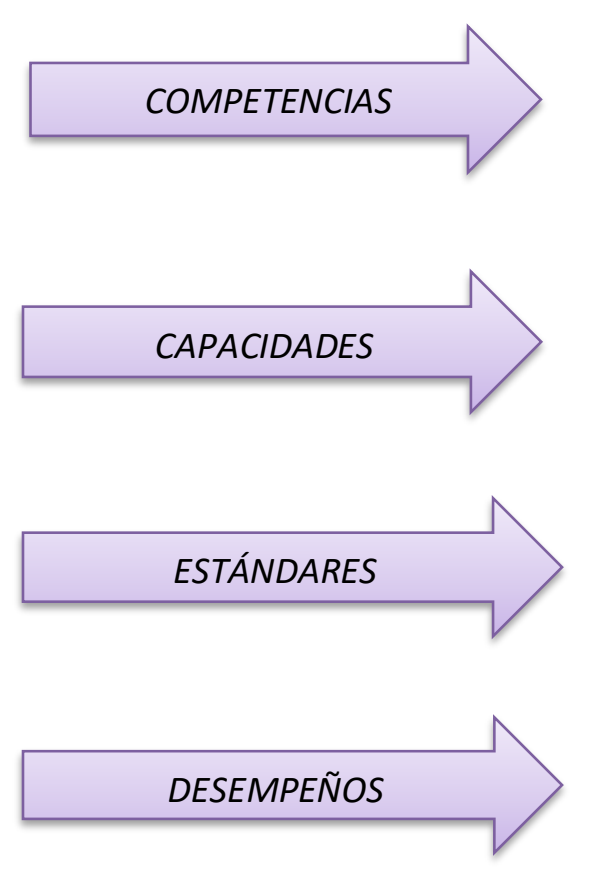

Es la facultad que tiene una persona de combinar un conjunto de capacidades a fin de lograr un propósito específico.

Son recursos para actuar de manera competente. Estos recursos son los conocimientos, habilidades y actitudes que los estudiantes utilizan para afrontar una situación determinada

Son descripciones del desarrollo de la competencia en niveles de creciente complejidad, desde el inicio hasta el fin de la Educación Básica.

Son descripciones específicas de lo que hacen los estudiantes respecto a los niveles de desarrollo de las competencias (estándares de aprendizaje). Son observables en una diversidad de situaciones o contextos

Figura 13. Conceptualización de competencias, capacidades, estándares y desempeños. Fuente: Elaboración propia a partir del Currículo Nacional de Educación Básica (2017).

En este marco se diseña la propuesta con la orientación y guía del currículo, tomando las competencias del área de Comunicación Integral que son comunicación oral, producción de textos y comprensión de textos; en la que se sustentó la propuesta de rúbrica pedagógica de la investigación. A continuación, se presenta el cuadro de áreas curriculares, competencias y niveles educativos de la EBR del nivel de Educación Secundaria. 


\section{Tabla 2.}

\section{Áreas curriculares, competencias y niveles educativos de la Educación Básica Regular}

\section{EDUCACIÓN SECUNDARIA}

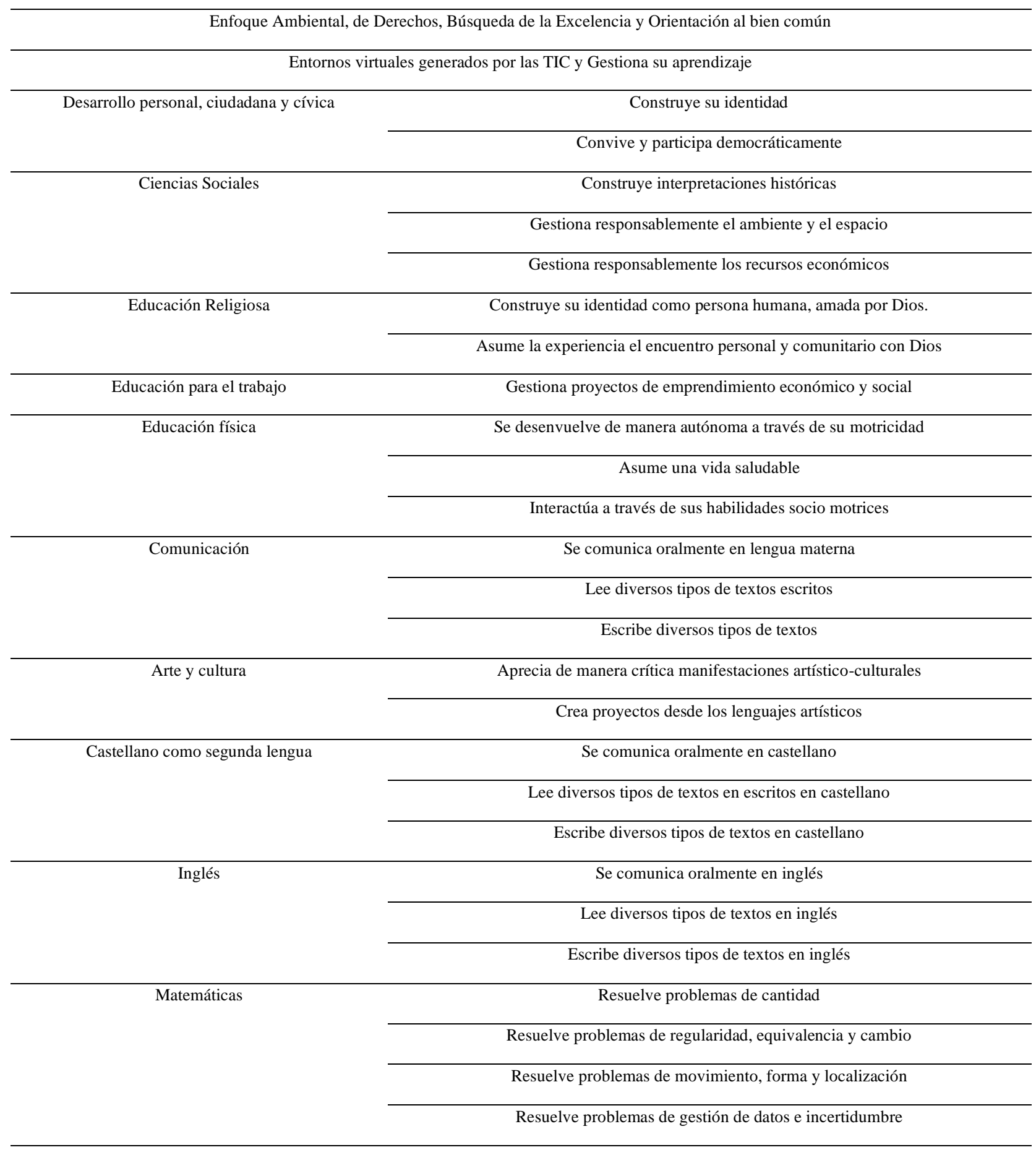

Fuente: Currículo Nacional de Educación Básica (2017). 


\section{DISEÑO}

A partir de la propuesta rúbrica pedagógica prepararemos una unidad; dentro de estas estarán las secuencias didácticas que serán las sesiones de clase que contemplarán el desarrollo de la evaluación formativa en los estudiantes con actividades como la indagación de los saberes previos, motivación, trabajo colaborativo, retroalimentación constante, investigación, procesos metacognitivos, etc; en la cual insertaremos la rúbrica pedagógica para la formación de competencias con la mediación y guía que es el docente, se realizarán coevaluaciones, autoevaluaciones y heteroevaluaciones. Estas secuencias didácticas de aprendizaje incluirían pasos para su desarrollo en los momentos pedagógicos de una clase inicio, desarrollo y cierre.

\section{SECUENCIA DIDÁCTICA}

La evaluación de las competencias se trabaja de forma continua en las actividades de aprendizaje y se realiza en la secuencia didáctica de la clase; la evaluación dentro de estás se aborda mediante rúbricas como lo refiere Tobón (2010). Las secuencias didácticas son un conjunto de actividades articuladas para el aprendizaje y evaluación, siendo el docente un mediador y buscando el logro de metas, incluyendo recursos. Así mismo, en el modelo de competencias, las secuencias didácticas son una metodología para la mediación de los procesos de aprendizaje o refuerzo de competencias. Los principales componentes de las secuencias son situaciones didácticas (a las que se debe dirigir la secuencia), actividades pertinentes y evaluación formativa (orientada a enjuiciar sistemáticamente el proceso), etc. 


\section{SECUENCIA DIDÁCTICA POR COMPETENCIAS}

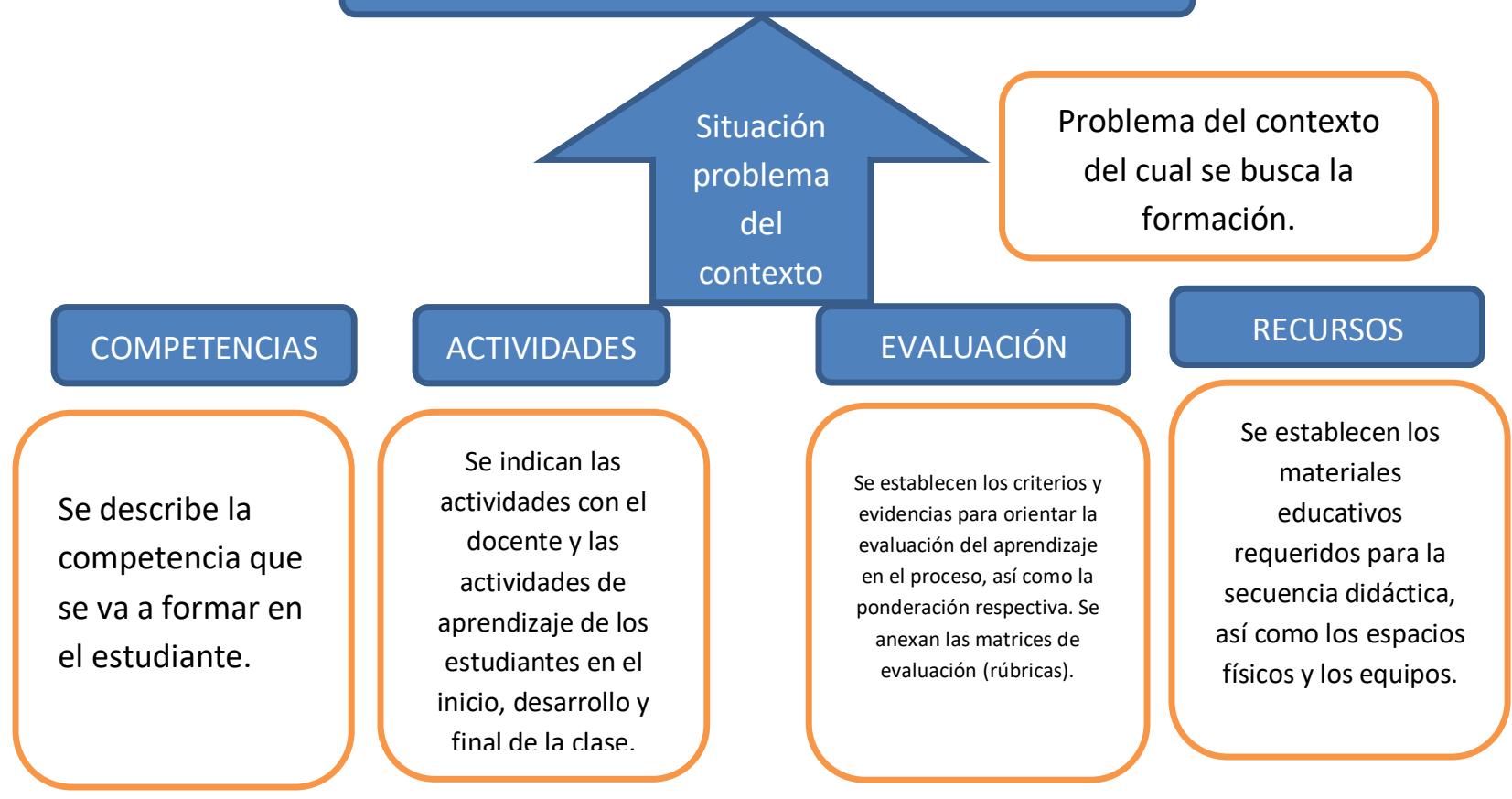

\section{PROCESO METACOGNITIVO}

Se describen las principales sugerencias para que el estudiante reflexione y se autorregule en el proceso de aprendizaje.

Figura 14. Secuencia didáctica por competencias.

Fuente: Elaboración propia a partir de Tobón (2009a, 2010) y Pimienta y Enríquez (2009).

\section{RÚBRICA}

Se puede definir a la rúbrica como un poderoso instrumento para la evaluación de cualquier tipo de tarea, destacando especialmente su valor para evaluar tareas de la vida real, tareas auténticas; en este sentido, se manifiesta como una herramienta idónea para la evaluación de competencias, pues permite diseccionar las tareas complejas que conforman una competencia en tareas más simples distribuidas de forma operativa y gradual como sostienen Alcina y otros (2013). 
A continuación, se presenta el cuadro de indicadores de niveles de dominio que se colocarán en la rúbrica planteada para las competencias del área de comunicación que se está tomando para esta investigación.

Tabla 3. Indicadores de niveles de dominio.

\section{Indicadores de niveles de dominio}

\begin{tabular}{ll}
\hline \multicolumn{1}{c}{ Nivel de dominio } & Caracteristicas \\
\hline Nivel Inicial-receptivo & Tiene nociones sobre el tema y algunos acercamientos al cirterio considerado. Requiere \\
& apoyo continuo \\
\hline Nivel básico & Tiene algunos conceptos escenciales de la competencia y puede resolver problemas \\
& sencillos \\
\hline Nivel autónomo & Se personaliza de su proceso formativo, tiene criterio y argumenta procesos \\
\hline Nivel estrategico & Analiza sistematicamentelas situaciones, considera el pasado y el futuro. Presenta \\
& creatividad e innovación. \\
\hline
\end{tabular}

Fuente: Niveles de dominio, Tobón (2010). 
Tabla 4.

Rúbrica pedagógica para la Comunicación Oral.

Nombre:

Fecha:

Área: Comunicación

Grado: $2^{\circ}$ secundaria

\begin{tabular}{|c|c|c|c|c|}
\hline CRITERIOS & NIVEL INICIAL & NIVEL BÁSICO & NIVEL AUTÓNOMO & NIVEL ESTRATÉGICO \\
\hline $\begin{array}{l}\text { Adecuación al tema y } \\
\text { al tipo de texto }\end{array}$ & $\begin{array}{l}\text { Desarrolla ideas (vinculadas con } \\
\text { emociones, intereses u opiniones) } \\
\text { basadas en la situación e intención } \\
\text { comunicativas, pero no responden } \\
\text { a la consigna ni al insumo dado. } \\
\text { Encuentra dificultades para } \\
\text { diferenciar el registro formal del } \\
\text { informal. }\end{array}$ & $\begin{array}{l}\text { Desarrolla ideas (vinculadas con } \\
\text { emociones, intereses u opiniones) basadas } \\
\text { en la situación e intención comunicativas, } \\
\text { distinguiendo solo el registro informal, de } \\
\text { modo que responden parcialmente a la } \\
\text { consigna o al insumo dado. }\end{array}$ & $\begin{array}{l}\text { Desarrolla ideas (vinculadas con } \\
\text { emociones, intereses u opiniones) } \\
\text { basadas en la situación e intención } \\
\text { comunicativas, distinguiendo el registro } \\
\text { formal e informal. Además elige los } \\
\text { recursos lingüísticos apropiados a fin de } \\
\text { responder a la consigna y al insumo } \\
\text { dado. }\end{array}$ & $\begin{array}{l}\text { Desarrolla ideas (vinculadas con emociones, } \\
\text { intereses u opiniones) basadas en la situación e } \\
\text { intención comunicativas, distinguiendo el registro } \\
\text { formal e informal. Evalúa apropiadamente los } \\
\text { momentos para intervenir y elige los recursos } \\
\text { lingüísticos apropiados a fin de responder a la } \\
\text { consigna y al insumo dado. }\end{array}$ \\
\hline $\begin{array}{l}\text { Organización de la } \\
\text { información }\end{array}$ & $\begin{array}{l}\text { Organiza y distribuye } \\
\text { adecuadamente la información en } \\
\text { ideas claras. En pocos casos, las } \\
\text { desarrolla de forma lógica y se } \\
\text { mantiene en el tema. Aún presenta } \\
\text { dificultades para reconocer la } \\
\text { secuencia de diferentes textos } \\
\text { discursivos. }\end{array}$ & $\begin{array}{l}\text { Organiza y distribuye adecuadamente la } \\
\text { información en ideas claras. En la } \\
\text { mayoría de los casos, las desarrolla de } \\
\text { forma lógica y se mantiene en el tema. } \\
\text { Aún presenta dificultades para reconocer } \\
\text { y aplicar la secuencia de diferentes textos } \\
\text { discursivos. }\end{array}$ & $\begin{array}{l}\text { Organiza y distribuye adecuadamente la } \\
\text { información en ideas claras. Las } \\
\text { desarrolla de forma lógica y se mantiene } \\
\text { en el tema. Reconoce, aplica y evalúa la } \\
\text { secuencia de diferentes textos } \\
\text { discursivos. }\end{array}$ & $\begin{array}{l}\text { Organiza y distribuye adecuadamente la } \\
\text { información en ideas claras. Las desarrolla de } \\
\text { forma lógica y se mantiene en el tema. Elige la } \\
\text { secuencia discursiva a partir del análisis del } \\
\text { contexto y propósito comunicativo. }\end{array}$ \\
\hline \multirow[b]{2}{*}{ Coherencia textual } & $\begin{array}{l}\text { Pocas veces, incluye información } \\
\text { relevante. }\end{array}$ & $\begin{array}{l}\text { En la mayor parte de su presentación, } \\
\text { incluye información relevante y sin } \\
\text { contradicciones. }\end{array}$ & $\begin{array}{l}\text { En toda su presentación, incluye } \\
\text { información relevante y sin } \\
\text { contradicciones. Pocas veces, se } \\
\text { encuentran vacíos de información. }\end{array}$ & $\begin{array}{l}\text { En toda su presentación, incluye información } \\
\text { relevante y sin contradicciones. No se encuentran } \\
\text { vacíos de información. }\end{array}$ \\
\hline & $\begin{array}{l}\text { La información no se presenta de } \\
\text { forma progresiva y se encuentran } \\
\text { muchas reiteraciones innecesarias. }\end{array}$ & $\begin{array}{l}\text { La información se presenta de forma } \\
\text { progresiva, aunque aún se encuentran } \\
\text { algunas reiteraciones innecesarias. }\end{array}$ & $\begin{array}{l}\text { Desarrolla el tema con cierto grado } \\
\text { de profundidad. La información se } \\
\text { presenta de forma progresiva y no se } \\
\text { encuentran reiteraciones innecesarias. }\end{array}$ & $\begin{array}{l}\text { Desarrolla el tema con suficiencia; es } \\
\text { decir, con profundidad. Enriquece el tema tratado } \\
\text { a través de preguntas y contribuciones relevantes } \\
\text { que } \\
\text { recogen las ideas de otros. }\end{array}$ \\
\hline \multirow{2}{*}{$\begin{array}{l}\text { Cohesión textual } \\
\text { (fluidez de la } \\
\text { información) }\end{array}$} & $\begin{array}{l}\text { Emplea pocas veces pronombres } \\
\text { (personales, demostrativos y } \\
\text { relativos), adverbios de lugar y } \\
\text { mecanismos de sustitución } \\
\text { (sinónimos e hiperónimos) como } \\
\text { referentes discursivos, y comete } \\
\text { errores en su uso. }\end{array}$ & $\begin{array}{l}\text { Emplea adecuadamente pronombres } \\
\text { (personales, demostrativos y relativos) y } \\
\text { adverbios de lugar como referentes } \\
\text { discursivos. Aún presenta errores en el } \\
\text { uso de los mecanismos de sustitución } \\
\text { (sinónimos e hiperónimos). }\end{array}$ & $\begin{array}{l}\text { Emplea pronombres (personales, } \\
\text { demostrativos y relativos), adverbios de } \\
\text { lugar y mecanismos de sustitución } \\
\text { (sinónimos e hiperónimos) como } \\
\text { referentes discursivos. }\end{array}$ & $\begin{array}{l}\text { Emplea pronombres (personales, demostrativos y } \\
\text { relativos), adverbios de lugar, mecanismos de } \\
\text { sustitución (sinónimos e hiperónimos) y elipsis } \\
\text { como referentes discursivos anafóricos. Además, } \\
\text { utiliza expresiones. }\end{array}$ \\
\hline & $\begin{array}{l}\text { Emplea inadecuadamente los } \\
\text { conectores (adición, disyunción, } \\
\text { consecuencia, causa y contraste) } \\
\text { en su presentación. }\end{array}$ & $\begin{array}{l}\text { Emplea conectores (adición, disyunción, } \\
\text { consecuencia, causa y contraste) en su } \\
\text { presentación, pero se encuentran algunos } \\
\text { errores en su uso. }\end{array}$ & $\begin{array}{l}\text { Emplea los conectores (adición, } \\
\text { disyunción, consecuencia, causa y } \\
\text { contraste) de manera pertinente. Cabe } \\
\text { precisar que su uso debe aportar en la } \\
\text { cohesión del discurso. Sin embargo, su } \\
\text { empleo no es obligatorio, de modo que }\end{array}$ & $\begin{array}{l}\text { Emplea los conectores (adición, disyunción, } \\
\text { consecuencia, causa, contraste, secuencia, } \\
\text { explicación) y otros marcadores textuales de } \\
\text { manera pertinente. Cabe precisar que su uso debe } \\
\text { aportar en la cohesión del discurso. }\end{array}$ \\
\hline
\end{tabular}




\begin{tabular}{|c|c|c|c|c|}
\hline Léxico & $\begin{array}{l}\text { Pocas veces emplea vocabulario } \\
\text { pertinente de acuerdo con la } \\
\text { situación e intención } \\
\text { comunicativa. Tampoco incluye } \\
\text { términos especializados. En la } \\
\text { mayoría de los casos, confunde la } \\
\text { ubicación y significados de las } \\
\text { categorías gramaticales que } \\
\text { corresponden con su nivel } \\
\text { (artículos, sustantivos, adjetivos, } \\
\text { pronombres, adverbios, } \\
\text { preposiciones) }\end{array}$ & $\begin{array}{l}\text { En la mayoría de los casos, emplea } \\
\text { vocabulario pertinente de acuerdo con la } \\
\text { situación e intención comunicativa, pero } \\
\text { no incluye términos especializados. } \\
\text { Utiliza las categorías gramaticales que } \\
\text { corresponden con su nivel (artículos, } \\
\text { sustantivos, adjetivos, pronombres, } \\
\text { adverbios, preposiciones y conjunciones). } \\
\text { En pocas ocasiones, confunde la } \\
\text { ubicación y significado de estas } \\
\text { categorías. }\end{array}$ & $\begin{array}{l}\text { Emplea vocabulario pertinente, que } \\
\text { incluye algunos términos especializados } \\
\text { de acuerdo con la situación e intención } \\
\text { comunicativa. Además, utiliza las } \\
\text { categorías gramaticales que } \\
\text { corresponden con su nivel (artículos, } \\
\text { sustantivos, adjetivos, pronombres, } \\
\text { adverbios, preposiciones y } \\
\text { conjunciones) de manera adecuada. }\end{array}$ & $\begin{array}{l}\text { Emplea vocabulario pertinente, que incluye } \\
\text { algunos términos especializados de acuerdo con } \\
\text { la situación e intención comunicativa. Además, } \\
\text { utiliza las categorías gramaticales que } \\
\text { corresponden con su nivel (artículos, sustantivos, } \\
\text { adjetivos, pronombres, adverbios, preposiciones y } \\
\text { conjunciones) de manera adecuada. }\end{array}$ \\
\hline $\begin{array}{l}\text { Obtención de } \\
\text { información oral }\end{array}$ & $\begin{array}{l}\text { Pocas veces infiere el propósito, } \\
\text { tema, conclusiones y hechos a } \\
\text { partir de información explícita en } \\
\text { diferentes discursos a partir de sus } \\
\text { conocimientos y el contexto } \\
\text { sociocultural. Tampoco logra } \\
\text { inferir información implícita ni } \\
\text { puede interpretar la intención del } \\
\text { interlocutor en discursos que } \\
\text { contienen ironías y sesgos. }\end{array}$ & $\begin{array}{l}\text { Infiere el propósito, tema conclusiones y } \\
\text { hechos a partir de información explícita } \\
\text { en diferentes discursos a partir de sus } \\
\text { conocimientos y el contexto sociocultural. } \\
\text { Sin embargo, aún no logra inferir } \\
\text { información implícita ni puede interpretar } \\
\text { la intención del interlocutor en discursos } \\
\text { que contienen ironías y sesgos. }\end{array}$ & $\begin{array}{l}\text { Infiere el propósito, tema conclusiones y } \\
\text { hechos a partir de información explícita } \\
\text { e implícita, e interpreta la intención del } \\
\text { interlocutor en discursos que contienen } \\
\text { ironías y sesgos, a partir de sus } \\
\text { conocimientos y el contexto } \\
\text { sociocultural. }\end{array}$ & $\begin{array}{l}\text { Infiere información importante y las } \\
\text { conclusiones, interpretando la intención del } \\
\text { interlocutor y las relaciones en los discursos que } \\
\text { contienen falacias, sesgos y ambigüedades, a } \\
\text { partir de fuentes de información, conocimientos, } \\
\text { y contexto sociocultural. }\end{array}$ \\
\hline \multirow[t]{2}{*}{$\begin{array}{c}\text { Ritmo, entonación y } \\
\text { volumen }\end{array}$} & $\begin{array}{l}\text { La mayoría de veces, vocaliza y } \\
\text { pronuncia correctamente todas las } \\
\text { palabras de su presentación. Sin } \\
\text { embargo, no varía su entonación } \\
\text { para transmitir emociones, } \\
\text { enfatizar algunas ideas, mantener } \\
\text { el interés del público, o producir } \\
\text { efectos como el suspenso o } \\
\text { entretenimiento. }\end{array}$ & $\begin{array}{l}\text { Vocaliza y pronuncia correctamente todas } \\
\text { las palabras de su presentación y varía su } \\
\text { entonación solo para enfatizar la } \\
\text { información o mantener el interés del } \\
\text { público. }\end{array}$ & $\begin{array}{l}\text { Vocaliza y pronuncia correctamente } \\
\text { todas las palabras de su presentación. } \\
\text { Varía su entonación para transmitir } \\
\text { emociones, enfatizar algunas ideas, } \\
\text { mantener el interés del público, o } \\
\text { producir efectos como el suspenso o } \\
\text { entretenimiento. }\end{array}$ & $\begin{array}{l}\text { Vocaliza y pronuncia correctamente todas las } \\
\text { palabras de su presentación. Varía y evalúa su } \\
\text { entonación a fin de transmitir emociones, } \\
\text { enfatizar algunas ideas, mantener el interés del } \\
\text { público, o producir efectos como el suspenso o } \\
\text { entretenimiento. }\end{array}$ \\
\hline & $\begin{array}{l}\text { Se expresa con volumen muy bajo. } \\
\text { Realiza pocas pausas en su } \\
\text { presentación oral. }\end{array}$ & $\begin{array}{l}\text { Se expresa con volumen medianamente } \\
\text { audible. Realiza pausas para enfatizar } \\
\text { algunas ideas o mantener el interés del } \\
\text { público. }\end{array}$ & $\begin{array}{l}\text { Ajusta su volumen según el espacio } \\
\text { donde se realiza la presentación. Realiza } \\
\text { pausas pertinentes para enfatizar } \\
\text { algunas ideas, mantener el interés del } \\
\text { público, o producir efectos como el } \\
\text { suspenso o entretenimiento. }\end{array}$ & $\begin{array}{l}\text { Ajusta su volumen según el espacio donde se } \\
\text { realiza la presentación. Utiliza pausas estratégicas } \\
\text { para enfatizar algunas ideas, mantener el interés } \\
\text { del público, o producir efectos como el suspenso } \\
\text { o entretenimiento. }\end{array}$ \\
\hline \multirow{2}{*}{$\begin{array}{c}\text { Gestos y lenguaje } \\
\text { corporal }\end{array}$} & $\begin{array}{l}\text { Pocas veces, mantiene una postura } \\
\text { adecuada y establece contacto } \\
\text { visual natural y espontáneo con su } \\
\text { auditorio durante su presentación. }\end{array}$ & $\begin{array}{l}\text { En la mayoría de los casos, mantiene una } \\
\text { postura adecuada y establece contacto } \\
\text { visual natural y espontáneo con su } \\
\text { auditorio durante su presentación. }\end{array}$ & $\begin{array}{l}\text { Mantiene una postura y cercanía } \\
\text { adecuada. Establece contacto visual } \\
\text { natural y espontáneo con su auditorio } \\
\text { durante toda su presentación. }\end{array}$ & $\begin{array}{l}\text { Mantiene una postura y cercanía adecuada. } \\
\text { Establece contacto visual natural, espontáneo y } \\
\text { personalizado con su auditorio durante toda su } \\
\text { presentación. }\end{array}$ \\
\hline & $\begin{array}{l}\text { Realiza pocos movimientos } \\
\text { corporales y gestuales. Estos, a } \\
\text { veces, pueden no ser coherentes } \\
\text { con su lenguaje verbal. }\end{array}$ & $\begin{array}{l}\text { Realiza movimientos corporales y } \\
\text { gestuales para enfatizar o atenuar lo que } \\
\text { dice. Estos, a veces, pueden no ser } \\
\text { coherentes con su lenguaje verbal. }\end{array}$ & $\begin{array}{l}\text { Acompaña su lenguaje verbal con } \\
\text { movimientos corporales y gestuales } \\
\text { pertinentes que enfatizan o atenúan lo } \\
\text { que dice. }\end{array}$ & $\begin{array}{l}\text { Acompaña estratégicamente su lenguaje verbal } \\
\text { con movimientos corporales y gestuales que } \\
\text { enfatizan o atenúan lo que dice. }\end{array}$ \\
\hline
\end{tabular}




\begin{tabular}{|c|c|c|c|c|}
\hline & $\begin{array}{l}\text { Al finalizar el primer ensayo, solo } \\
\text { reflexiona sobre la adecuación de } \\
\text { las presentaciones a un elemento } \\
\text { de la situación comunicativa: } \\
\text { destinatario, propósito, tema, } \\
\text { registro o tipo discursivo. }\end{array}$ & $\begin{array}{l}\text { Al finalizar el primer ensayo, solo es } \\
\text { capaz de reflexionar y opinar sobre la } \\
\text { adecuación del contenido a la situación } \\
\text { comunicativa o si existen contradicciones. }\end{array}$ & $\begin{array}{l}\text { Reflexiona y opina, al terminar el primer } \\
\text { ensayo, de las presentaciones que } \\
\text { evalúa, revisando si el contenido se } \\
\text { ajusta a la situación comunicativa, o si } \\
\text { existen contradicciones o vacíos que } \\
\text { afectan la coherencia entre las ideas. }\end{array}$ & $\begin{array}{l}\text { Reflexiona y opina, durante todos los ensayos, de } \\
\text { las presentaciones que evalúa, revisando si el } \\
\text { contenido se ajusta a la situación comunicativa, si } \\
\text { existen contradicciones o vacíos que afectan la } \\
\text { coherencia entre las ideas, o si se desarrolla con } \\
\text { suficiente profundidad. }\end{array}$ \\
\hline $\begin{array}{l}\text { Reflexión, opinión y } \\
\text { evaluación }\end{array}$ & $\begin{array}{l}\text { Solo evalúa la cohesión entre las } \\
\text { ideas. Le cuesta reconocer los } \\
\text { errores de léxico. Tampoco, } \\
\text { reconoce el sentido de los recursos } \\
\text { gramaticales utilizados. }\end{array}$ & $\begin{array}{l}\text { Solo evalúa la cohesión entre las ideas y } \\
\text { el uso del vocabulario pertinente como } \\
\text { elementos para garantizar el sentido de las } \\
\text { presentaciones. Aún no reconoce el } \\
\text { sentido de los recursos gramaticales } \\
\text { utilizados. }\end{array}$ & $\begin{array}{l}\text { Evalúa si el uso de conectores y } \\
\text { referentes asegura la cohesión entre las } \\
\text { ideas. Determina la pertinencia del } \\
\text { vocabulario como elementos que } \\
\text { garantizan el sentido de las } \\
\text { presentaciones. Además, opina sobre el } \\
\text { sentido de los recursos gramaticales } \\
\text { considerando su propósito al momento } \\
\text { de ser expresados. }\end{array}$ & $\begin{array}{l}\text { Evalúa si el uso de conectores y referentes } \\
\text { asegura la cohesión entre las ideas. Determina la } \\
\text { pertinencia del vocabulario como elemento para } \\
\text { garantizar el sentido de su texto. Además, opina } \\
\text { sobre el sentido de los recursos gramaticales y } \\
\text { estilísticos considerando el propósito al momento } \\
\text { de ser expresados. }\end{array}$ \\
\hline
\end{tabular}

Fuente: Elaboración propia a partir de Innova Schools (2018). 
Tabla 5.

Rúbrica pedagógica para la Producción de textos.

\begin{tabular}{|c|c|c|c|c|}
\hline \multicolumn{3}{|l|}{ Nombre: } & \multicolumn{2}{|l|}{ Fecha: } \\
\hline \multicolumn{2}{|c|}{ Área: Comunicación } & \multicolumn{3}{|c|}{ Grado: $2^{\circ}$ secundaria } \\
\hline CRITERIOS & NIVEL INICIAL & NIVEL BÁSICO & NIVEL AUTÓNOMO & NIVEL ESTRATÉGICO \\
\hline $\begin{array}{l}\text { Adecuación al tema } \\
\text { y al tipo de texto }\end{array}$ & $\begin{array}{l}\text { Desarrolla ideas (vinculadas con } \\
\text { emociones, intereses u opiniones) } \\
\text { basadas en la situación e intención } \\
\text { comunicativas, pero no responden a la } \\
\text { consigna ni al insumo dado. Encuentra } \\
\text { dificultades para diferenciar el registro } \\
\text { formal del informal. }\end{array}$ & $\begin{array}{l}\text { Desarrolla ideas (vinculadas con } \\
\text { emociones, intereses u opiniones) } \\
\text { basadas en la situación e intención } \\
\text { comunicativas, distinguiendo solo el } \\
\text { registro informal, de modo que } \\
\text { responden parcialmente a la consigna o } \\
\text { al insumo dado. }\end{array}$ & $\begin{array}{l}\text { Desarrolla ideas (vinculadas con emociones, } \\
\text { intereses u opiniones) basadas en la situación } \\
\text { e intención comunicativas, distinguiendo el } \\
\text { registro formal e informal. Además elige los } \\
\text { recursos lingüísticos apropiados a fin de } \\
\text { responder a la consigna y al insumo dado. }\end{array}$ & $\begin{array}{l}\text { Desarrolla ideas (vinculadas con emociones, } \\
\text { intereses u opiniones) basadas en la situación } \\
\text { e intención comunicativas, distinguiendo el } \\
\text { registro formal e informal. Evalúa y elige los } \\
\text { recursos lingüísticos apropiados a fin de } \\
\text { responder a la consigna y al insumo dado. }\end{array}$ \\
\hline $\begin{array}{l}\text { Organización de la } \\
\text { información }\end{array}$ & $\begin{array}{l}\text { Organiza y distribuye adecuadamente } \\
\text { la información en párrafos. En pocos } \\
\text { casos, la organización de las ideas } \\
\text { responde a un orden lógico y se } \\
\text { mantienen en el tema. Aún presenta } \\
\text { dificultades para reconocer la secuencia } \\
\text { de diferentes tipos de textos. }\end{array}$ & $\begin{array}{l}\text { Organiza y distribuye adecuadamente la } \\
\text { información en párrafos, cada uno de los } \\
\text { cuales desarrolla una idea principal. En } \\
\text { la mayoría de los casos, la organización } \\
\text { de las ideas responde a un orden lógico } \\
\text { que las relaciona directamente con el } \\
\text { tema. Aún presenta dificultades para } \\
\text { reconocer y aplicar la secuencia de } \\
\text { diferentes tipos de textos. }\end{array}$ & $\begin{array}{l}\text { Organiza y distribuye adecuadamente la } \\
\text { información en párrafos, cada uno de los } \\
\text { cuales desarrolla una idea principal. La } \\
\text { organización de las ideas responde a un } \\
\text { orden lógico que las relaciona directamente } \\
\text { con el tema. Reconoce, aplica y evalúa la } \\
\text { secuencia de diferentes tipos de texto. }\end{array}$ & $\begin{array}{l}\text { Organiza y distribuye adecuadamente la } \\
\text { información en párrafos, cada uno de los } \\
\text { cuales desarrolla una idea principal. La } \\
\text { organización de las ideas responde a un } \\
\text { orden lógico que las relaciona directamente } \\
\text { con el tema. Elige la secuencia textual a a } \\
\text { partir del análisis del contexto y propósito } \\
\text { comunicativo. }\end{array}$ \\
\hline \multirow[b]{2}{*}{ Coherencia textual } & $\begin{array}{l}\text { Pocas veces, incluye información } \\
\text { relevante. }\end{array}$ & $\begin{array}{l}\text { En la mayor parte de su presentación, } \\
\text { incluye información relevante y sin } \\
\text { contradicciones. }\end{array}$ & $\begin{array}{l}\text { En toda su redacción, incluye información } \\
\text { relevante y sin contradicciones. Pocas veces, } \\
\text { se encuentran vacíos de información. }\end{array}$ & $\begin{array}{l}\text { En toda su redacción, incluye información } \\
\text { relevante y sin contradicciones. No se } \\
\text { encuentran vacíos de información. }\end{array}$ \\
\hline & $\begin{array}{l}\text { La información no se presenta de forma } \\
\text { progresiva y se encuentran muchas } \\
\text { reiteraciones innecesarias. }\end{array}$ & $\begin{array}{l}\text { La información se presenta de forma } \\
\text { progresiva, aunque aún se encuentran } \\
\text { algunas reiteraciones innecesarias. }\end{array}$ & $\begin{array}{l}\text { Desarrolla el tema con cierto grado de } \\
\text { profundidad. La información se presenta de } \\
\text { forma progresiva y no se encuentran } \\
\text { reiteraciones innecesarias. }\end{array}$ & $\begin{array}{l}\text { Desarrolla el tema con suficiencia; es } \\
\text { decir, con profundidad. Enriquece el tema } \\
\text { tratado a través de preguntas y contribuciones } \\
\text { relevantes que recogen las ideas de otros. }\end{array}$ \\
\hline \multirow{2}{*}{$\begin{array}{l}\text { Cohesión textual } \\
\text { (fluidez de la } \\
\text { información) }\end{array}$} & $\begin{array}{l}\text { Emplea pocas veces pronombres } \\
\text { (personales, demostrativos y relativos), } \\
\text { adverbios de lugar y mecanismos de } \\
\text { sustitución (sinónimos e hiperónimos) } \\
\text { como referentes textuales, y comete } \\
\text { errores en su uso. }\end{array}$ & $\begin{array}{l}\text { Emplea adecuadamente pronombres } \\
\text { (personales, demostrativos y relativos) y } \\
\text { adverbios de lugar como referentes } \\
\text { textuales. Aún presenta errores en el uso } \\
\text { de los mecanismos de sustitución } \\
\text { (sinónimos e hiperónimos). }\end{array}$ & $\begin{array}{l}\text { Emplea pronombres (personales, } \\
\text { demostrativos y relativos), adverbios de lugar } \\
\text { y mecanismos de sustitución (sinónimos e } \\
\text { hiperónimos) como referentes textuales. }\end{array}$ & $\begin{array}{l}\text { Emplea pronombres (personales, } \\
\text { demostrativos y relativos), adverbios de } \\
\text { lugar, mecanismos de sustitución (sinónimos } \\
\text { e hiperónimos) y elipsis como referentes } \\
\text { textuales anafóricos. Además, utiliza } \\
\text { expresiones }\end{array}$ \\
\hline & $\begin{array}{l}\text { Emplea inadecuadamente los } \\
\text { conectores (adición, disyunción, } \\
\text { consecuencia, causa y contraste) en su } \\
\text { texto. }\end{array}$ & $\begin{array}{l}\text { Emplea conectores (adición, disyunción, } \\
\text { consecuencia, causa y contraste) en su } \\
\text { texto, pero se encuentran algunos errores } \\
\text { en su uso. }\end{array}$ & $\begin{array}{l}\text { Emplea los conectores (adición, disyunción, } \\
\text { consecuencia, causa y contraste) de manera } \\
\text { pertinente. Cabe precisar que su uso debe } \\
\text { aportar en la cohesión del texto. Sin } \\
\text { embargo, su empleo no es obligatorio, de } \\
\text { modo que su ausencia no constituye }\end{array}$ & $\begin{array}{l}\text { Emplea los conectores (adición, disyunción, } \\
\text { consecuencia, causa, contraste, secuencia, } \\
\text { explicación) y otros marcadores textuales de } \\
\text { manera pertinente. Cabe precisar que su uso } \\
\text { debe aportar en la cohesión del texto. }\end{array}$ \\
\hline
\end{tabular}




\begin{tabular}{|c|c|c|c|c|}
\hline Gramática & $\begin{array}{l}\text { Construye algunos enunciados que son } \\
\text { oraciones. Sin embargo, en algunas } \\
\text { ocasiones, no guardan concordancia } \\
\text { nominal (género y de número) ni verbal } \\
\text { (número, tiempo y persona). }\end{array}$ & $\begin{array}{l}\text { Construye oraciones (con verbos } \\
\text { simples en tiempo presente, pasado y } \\
\text { futuro) que guardan adecuada } \\
\text { concordancia nominal. Aún se } \\
\text { encuentran errores de concordancia } \\
\text { verbal (número, tiempo y persona). }\end{array}$ & $\begin{array}{l}\text { Construye oraciones (con verbos simples en } \\
\text { tiempo presente, pasado y futuro) que } \\
\text { guardan adecuada concordancia nominal y } \\
\text { verbal (número, tiempo y persona). }\end{array}$ & $\begin{array}{l}\text { Construye oraciones (con verbos simples en } \\
\text { tiempo presente, pasado y futuro) que } \\
\text { guardan concordancia nominal y verbal } \\
\text { (número, tiempo, persona y modo). Incluyen } \\
\text { oraciones compuestas coordinadas que, en la } \\
\text { mayoría de los casos, no interrumpen la } \\
\text { comprensión del mensaje. }\end{array}$ \\
\hline Puntuación & $\begin{array}{l}\text { Pocas veces utiliza el punto y seguido, } \\
\text { el punto y aparte, la coma } \\
\text { (enumerativa, explicativa, elíptica e } \\
\text { hiperbática) y los dos puntos de manera } \\
\text { adecuada. }\end{array}$ & $\begin{array}{l}\text { Solo utiliza el punto y seguido, el punto } \\
\text { y aparte, la coma (enumerativa y } \\
\text { explicativa), los signos de interrogación } \\
\text { y exclamación, y los dos puntos de } \\
\text { manera adecuada. Aún comete errores } \\
\text { en el uso de las comas. }\end{array}$ & $\begin{array}{l}\text { Utiliza el punto y seguido, el punto y aparte, } \\
\text { la coma (enumerativa, explicativa, elíptica e } \\
\text { hiperbática) y los dos puntos de manera } \\
\text { adecuada. }\end{array}$ & $\begin{array}{l}\text { Utiliza el punto y seguido, el punto y aparte, } \\
\text { la coma (enumerativa, explicativa, } \\
\text { hiperbática, elíptica y de conectores lógicos) } \\
\text { y los dos puntos de manera adecuada. }\end{array}$ \\
\hline Léxico & $\begin{array}{l}\text { Pocas veces emplea vocabulario } \\
\text { pertinente de acuerdo con la situación e } \\
\text { intención comunicativa. Tampoco } \\
\text { incluye términos especializados. En la } \\
\text { mayoría de los casos, confunde la } \\
\text { ubicación y significados de las } \\
\text { categorías gramaticales que } \\
\begin{array}{l}\text { corresponden con su nivel (artículos, } \\
\text { sustantivos, adjetivos, pronombres, } \\
\text { adverbios, preposiciones } \\
\text { conjunciones). }\end{array}\end{array}$ & $\begin{array}{l}\text { En la mayoría de los casos, emplea } \\
\text { vocabulario pertinente de acuerdo con la } \\
\text { situación e intención comunicativa, pero } \\
\text { no incluye términos especializados. } \\
\text { Utiliza las categorías gramaticales que } \\
\text { corresponden con su nivel (artículos, } \\
\text { sustantivos, adjetivos, pronombres, } \\
\text { adverbios, preposiciones y } \\
\text { conjunciones). En pocas ocasiones, } \\
\text { confunde la ubicación y significado de } \\
\text { estas categorías. }\end{array}$ & $\begin{array}{l}\text { Emplea vocabulario pertinente, que incluye } \\
\text { algunos términos especializados de acuerdo } \\
\text { con la situación e intención comunicativa. } \\
\text { Además, utiliza las categorías gramaticales } \\
\text { que corresponden con su nivel (artículos, } \\
\text { sustantivos, adjetivos, pronombres, } \\
\text { adverbios, preposiciones y conjunciones) de } \\
\text { manera adecuada. }\end{array}$ & $\begin{array}{l}\text { Emplea vocabulario pertinente y preciso, que } \\
\text { incluye algunos términos especializados de } \\
\text { acuerdo con la situación e intención } \\
\text { comunicativa. Además, utiliza las categorías } \\
\text { gramaticales que corresponden con su nivel } \\
\text { (artículos, sustantivos, adjetivos, } \\
\text { pronombres, adverbios, preposiciones y } \\
\text { conjunciones) de manera adecuada. }\end{array}$ \\
\hline \multirow[t]{2}{*}{ Ortografía } & $\begin{array}{l}\text { Solo emplea las mayúsculas a inicio de } \\
\text { oración y nombres propios de personas. }\end{array}$ & $\begin{array}{l}\text { Emplea las mayúsculas correctamente } \\
\text { en la mayoría de los siguientes casos: al } \\
\text { inicio de oración y nombres propios } \\
\text { (personas, animales, lugares, } \\
\text { instituciones, divinidades cristianas). }\end{array}$ & $\begin{array}{l}\text { Emplea las mayúsculas correctamente en } \\
\text { todos los siguientes casos: al inicio de } \\
\text { oración y nombres propios (personas, } \\
\text { animales, lugares, instituciones, divinidades } \\
\text { cristianas). }\end{array}$ & $\begin{array}{l}\text { Emplea las mayúsculas correctamente en } \\
\text { todos los siguientes casos: al inicio de } \\
\text { oración, nombres propios (personas, } \\
\text { animales, lugares, instituciones, divinidades } \\
\text { cristianas), sobrenombres, obras artísticas y } \\
\text { puntos cardinales. }\end{array}$ \\
\hline & $\begin{array}{l}\text { Solo aplica las reglas de uso de las } \\
\text { grafías (b-v/c-s-z /g-j /ll-y). Aún } \\
\text { comete errores de atildamiento general. }\end{array}$ & $\begin{array}{l}\text { Aplica las reglas de uso de las grafías } \\
\text { (b-v/c-s-z /g-j /ll-y) y atildamiento } \\
\text { general en la mayoría de los casos. }\end{array}$ & $\begin{array}{l}\text { Aplica las reglas de uso de las grafías y } \\
\text { atildamiento general en todos los casos. }\end{array}$ & $\begin{array}{l}\text { Aplica las reglas de uso de las grafías y de } \\
\text { atildamiento (general y diacrítica) en todos } \\
\text { los casos. }\end{array}$ \\
\hline $\begin{array}{l}\text { Reflexión, opinión y } \\
\text { evaluación }\end{array}$ & $\begin{array}{l}\text { Al finalizar las primeras versiones, solo } \\
\text { reflexiona sobre la adecuación de los } \\
\text { textos a un elemento de la situación } \\
\text { comunicativa: destinatario, propósito, } \\
\text { tema, registro o tipo textual. }\end{array}$ & $\begin{array}{l}\text { Al finalizar las primeras versiones, solo } \\
\text { es capaz de reflexionar y opinar sobre la } \\
\text { adecuación del contenido a la situación } \\
\text { comunicativa o si r existen } \\
\text { contradicciones. }\end{array}$ & $\begin{array}{l}\text { Reflexiona y opina, al terminar las primeras } \\
\text { versiones, sobre el texto que evalúa, } \\
\text { revisando si el contenido se ajusta a la } \\
\text { situación comunicativa, o si existen } \\
\text { contradicciones, digresiones o vacíos que } \\
\text { afectan la coherencia entre las ideas. }\end{array}$ & $\begin{array}{l}\text { Reflexiona y opina, durante el proceso de } \\
\text { escritura, sobre el texto que evalúa, revisando } \\
\text { si el contenido se ajusta a la situación } \\
\text { comunicativa, si existen contradicciones, } \\
\text { digresiones o vacíos que afectan la } \\
\text { coherencia entre las ideas, o si se desarrolla } \\
\text { con suficiente profundidad. }\end{array}$ \\
\hline
\end{tabular}


Evalúa si el uso de conectores y referentes Evalúa si el uso de conectores y referentes Solo evalúa la cohesión entre las ideas, asegura la cohesión entre las ideas. asegura la cohesión entre las ideas. Solo evalúa la cohesión entre las ideas. el uso de los referentes, vocabulario Determina la eficacia de los recursos Determina la eficacia de los recursos Le cuesta reconocer los errores de pertinente y los recursos ortográficos ortográficos utilizados y la pertinencia del ortográficos utilizados y la pertinencia del léxico y ortografía. Tampoco, reconoce empleados como elementos que vocabulario como elementos que garantizan vocabulario como elementos que garantizan el sentido de los recursos gramaticales garantizan el sentido de los textos. Aún el sentido de los textos. Además, opina sobre el sentido de los textos. Además, opina sobre 
Tabla 6.

Rúbrica pedagógica para la Comprensión de textos.

\begin{tabular}{|c|c|c|c|c|}
\hline \multicolumn{4}{|l|}{ Nombre: } & \multirow{2}{*}{$\begin{array}{l}\text { Fecha: } \\
\text { Grado: SEGUNDO AÑO }\end{array}$} \\
\hline Área: Comunicac & ción & & & \\
\hline CRITERIOS & NIVEL INICIAL & NIVEL BÁSICO & NIVEL AUTÓNOMO & NIVEL ESTRATÉGICO \\
\hline $\begin{array}{l}\text { Identificación de } \\
\text { la clase y finalidad } \\
\text { del texto }\end{array}$ & $\begin{array}{l}\text { No reconoce la clase de texto } \\
\text { (noticia, página web, receta, cartel, } \\
\text { reglas de un juego, etc.) y la } \\
\text { finalidad con que se usa (informar, } \\
\text { dar instrucciones, aconsejar, etc.). }\end{array}$ & $\begin{array}{l}\text { Todavía tiene dificultades para } \\
\text { identificar la clase de texto (noticia, } \\
\text { página web, receta, cartel, reglas de } \\
\text { un juego, etc.) y la finalidad con que } \\
\text { se usa (informar, dar instrucciones, } \\
\text { aconsejar, etc.). }\end{array}$ & $\begin{array}{l}\text { Es capaz casi siempre de identificar la } \\
\text { clase de texto (noticia, página web, } \\
\text { receta, cartel, reglas de un juego, etc.) y } \\
\text { la finalidad para la que se usa (informar, } \\
\text { dar instrucciones, aconsejar, etc.). }\end{array}$ & $\begin{array}{l}\text { Es capaz siempre de identificar la clase } \\
\text { de texto (noticia, página web, receta, } \\
\text { cartel, reglas de un juego, etc.) y la } \\
\text { finalidad para la que se usa (informar, } \\
\text { dar instrucciones, aconsejar, etc.). }\end{array}$ \\
\hline $\begin{array}{l}\text { Determinación del } \\
\text { tema del texto }\end{array}$ & $\begin{array}{l}\text { No reconoce de qué trata el } \\
\text { texto ni identifica sus ideas } \\
\text { principales. }\end{array}$ & $\begin{array}{l}\text { Reconoce todavía con } \\
\text { dificultades de qué trata el texto } \\
\text { y algunas de sus ideas } \\
\text { principales. }\end{array}$ & $\begin{array}{l}\text { Sabe reconocer casi siempre de qué } \\
\text { trata el texto y casi siempre identifica } \\
\text { alguna de sus ideas principales. }\end{array}$ & $\begin{array}{l}\text { Sabe reconocer siempre de qué trata el } \\
\text { texto y siempre identifica alguna de } \\
\text { sus ideas principales. }\end{array}$ \\
\hline $\begin{array}{l}\text { Identificación de } \\
\text { la estructura del } \\
\text { texto }\end{array}$ & $\begin{array}{l}\text { No percibe la relación entre } \\
\text { las partes de los textos. }\end{array}$ & $\begin{array}{l}\text { No siempre percibe la relación } \\
\text { entre las partes de los textos y su } \\
\text { relación. }\end{array}$ & $\begin{array}{l}\text { Puede reconocer casi siempre las partes } \\
\text { de los textos y cómo se relacionan. }\end{array}$ & $\begin{array}{l}\text { Reconoce siempre las partes de los textos y } \\
\text { cómose relacionan. }\end{array}$ \\
\hline $\begin{array}{l}\text { Inferencia entre } \\
\text { datos e ideas del } \\
\text { texto }\end{array}$ & $\begin{array}{l}\text { Presenta todavía dificultades } \\
\text { para percibir cómo se } \\
\text { relacionan ideas o datos en el } \\
\text { texto: identificar el orden de } \\
\text { las acciones, emparejar ideas } \\
\text { con ilustraciones, sustituir } \\
\text { conectores, etc. }\end{array}$ & $\begin{array}{l}\text { Todavía le cuesta percibir } \\
\text { cómo se relacionan las ideas } \\
\text { o datos en el texto: identificar } \\
\text { el orden delas acciones, } \\
\text { emparejar ideas con } \\
\text { ilustraciones, sustituir } \\
\text { conectores, etc. }\end{array}$ & $\begin{array}{l}\text { Es capaz la mayor parte de las veces de } \\
\text { percibir cómo se relacionan ideas o datos } \\
\text { en el texto: identificar el orden de las } \\
\text { acciones, emparejar ideas con } \\
\text { ilustraciones, sustituir conectores, etc. }\end{array}$ & $\begin{array}{l}\text { Es capaz siempre de percibir cómo se } \\
\text { relacionan ideas o datos en el texto: } \\
\text { identificar el orden de las acciones, } \\
\text { emparejar ideas con ilustraciones, } \\
\text { sustituir conectores, etc. }\end{array}$ \\
\hline $\begin{array}{l}\text { Inferencia } \quad \text { del } \\
\text { significado } \\
\text { palabras por el } \\
\text { contexto }\end{array}$ & $\begin{array}{l}\text { Todavía no deduce qué significa } \\
\text { una palabra o una expresión a } \\
\text { partir de la información que da el } \\
\text { texto. }\end{array}$ & $\begin{array}{l}\text { Tiene dificultades todavía para } \\
\text { deducir qué significa una palabra o } \\
\text { una expresión a partir de la } \\
\text { información que da el texto. }\end{array}$ & $\begin{array}{l}\text { Casi siempre es capaz de deducir qué } \\
\text { significa una palabra o una expresión a } \\
\text { partir de la información que da el } \\
\text { texto. }\end{array}$ & $\begin{array}{l}\text { Siempre es capaz de deducir qué } \\
\text { significa una palabra o una expresión a } \\
\text { partir de la información que da el texto. }\end{array}$ \\
\hline $\begin{array}{l}\text { Localización de } \\
\text { información } \\
\text { explicita }\end{array}$ & $\begin{array}{l}\text { No localiza informaciones } \\
\text { explícitas en el texto (qué, } \\
\text { quién, cuándo, dónde, qué } \\
\text { cantidad, cómo, etc.). }\end{array}$ & $\begin{array}{l}\text { A veces tiene dificultades para } \\
\text { localizar informaciones } \\
\text { explícitas en el texto (qué, quién, } \\
\text { cuándo, dónde, qué cantidad, } \\
\text { cómo, etc.). }\end{array}$ & $\begin{array}{l}\text { Localiza casi siempre informaciones } \\
\text { explícitas en el texto (qué, quién, } \\
\text { cuándo, dónde, qué cantidad, cómo, } \\
\text { etc.). }\end{array}$ & $\begin{array}{l}\text { Localiza fácilmente informaciones } \\
\text { explícitas en el texto (qué, quién, } \\
\text { cuándo, dónde, qué cantidad, cómo, } \\
\text { etc.). }\end{array}$ \\
\hline
\end{tabular}




\begin{tabular}{|c|c|c|c|c|}
\hline $\begin{array}{l}\text { Reflexión sobre } \\
\text { contenido y forma } \\
\text { del texto }\end{array}$ & $\begin{array}{l}\text { No es capaz de ir más allá de } \\
\text { la comprensión literal del } \\
\text { texto y percibir características } \\
\text { de su forma: reconocer el uso } \\
\text { de tipos de letras diferentes, } \\
\text { utilizar el texto como modelo } \\
\text { para escribir otro semejante, } \\
\text { etc. }\end{array}$ & $\begin{array}{l}\text { Tiene dificultades para ir más } \\
\text { allá de la comprensión literal } \\
\text { del texto y percibir } \\
\text { características de su forma: } \\
\text { reconocer el uso de tipos de } \\
\text { letras diferentes, utilizar el texto } \\
\text { como modelo para escribir otro } \\
\text { semejante, etc. }\end{array}$ & $\begin{array}{l}\text { Casi siempre es capaz de ir más allá de la } \\
\text { comprensión literal del texto y percibe } \\
\text { características de su forma: reconocer el } \\
\text { uso de tipos de letras diferentes, utilizar } \\
\text { el texto como modelo para escribir otro } \\
\text { semejante, etc. }\end{array}$ & $\begin{array}{l}\text { Es capaz de ir más allá de la comprensión literal } \\
\text { del texto y percibe características de su forma: } \\
\text { reconocer el uso de tipos de letras diferentes, } \\
\text { utilizar el texto como modelo para escribir otro } \\
\text { semejante, etc. }\end{array}$ \\
\hline
\end{tabular}

Fuente: Elaboración propia a partir de Andújar (2019). 


\section{Secuencias didácticas por competencias}

Ejemplificación de una unidad de clases con un enfoque de evaluación formativa para estudiantes de segundo grado de educación secundaria, donde las actividades a desarrollar trabajan el proceso metacognitivo en todas las sesiones donde se utilizan las rúbricas mostradas en el presente capítulo referidas a las competencias del área de comunicación.

\section{Secuencia didáctica: Unidad de aprendizaje por competencias.}

\section{UNIDAD: ENTRE LAS REDES SOCIALES}

PROPÓSITO DE LA UNIDAD: Los estudiantes analizan las redes sociales y reflexionan sobre su impacto en la vida de las personas.

\section{DESCRIPCIÓN DE LA UNIDAD:}

Los estudiantes trabajarán una crónica periodística y se realizará discusiones grupales.

Los estudiantes reflexionan en torno al impacto de las redes sociales en la humanidad a partir del análisis de sus propias experiencias y las de los demás. Investigarán en distintas fuentes de información sobre las posturas relacionadas con las redes sociales y asumirán un punto de vista definido y fundamentado acerca de la influencia de ellas en la vida de las personas.

EVALUACIÓN: Registro anecdotario, Rúbrica de producción de textos, Rúbrica de comunicación oral y Rúbrica de comprensión de textos.

\section{Grado: $2^{\circ}$ año de secundaria $\quad$ Docente:}

\section{COMPETENCIAS:}

\section{Comunicación oral:}

Construcción del significado: Se comunica oralmente mediante diversos tipos de textos, infiere el tema, propósitos, hechos, y conclusiones a partir de la información explicita e implícita, e interpreta la intención del interlocutor en discursos que contienen ironías y sesgos. Organiza y 
desarrolla sus ideas en torno a un tema y las relaciona mediante el uso de diversos conectores y referentes, así como de un vocabulario variado y pertinente. Enfatiza significados mediante el uso de recursos no verbales y para verbales.

Reflexión y evaluación: Reflexiona sobre el texto y evalúa su fiabilidad de acuerdo a sus conocimientos y al contexto sociocultural. Se expresa adecuándose a situaciones comunicativas formales e informales. En un intercambio, hace preguntas y utiliza las respuestas escuchadas para desarrollar sus ideas y contribuciones, tomando en cuenta los puntos de vista de otros.

\section{Comprensión de textos:}

Construcción del significado: Lee diversos tipos de texto con estructuras complejas y vocabulario variado. Integra información contrapuesta que está en distintas partes del texto. Interpreta el texto considerando información relevante y complementaria para construir su sentido global, valiéndose de otros textos.

Reflexión y evaluación:_Reflexiona sobre formas y contenidos del texto a partir del conocimiento y experiencia. Evalúa el uso del lenguaje, la intención de los recursos textuales y el efecto del texto y en el lector a partir de su conocimiento y del contexto sociocultural.

\section{Producción de textos:}

Construcción del significado: Escribe diversos tipos de textos de forma reflexiva. Adecua su texto al destinatario, propósito y registro a partir de su experiencia previa y fuentes de información complementarias. Organiza y desarrolla lógicamente las ideas en torno a un tema, y las estructuras en párrafos y subtítulos de acuerdo a algunos géneros discursivos. Establece relaciones entre ideas a través del uso adecuado de varios tipos de conectores, referentes y emplea vocabulario variado. Utiliza recursos ortográficos y textuales para separar y aclarar expresiones e ideas, así como diferenciar el significado de las palabras con la intención de darle 
claridad y sentido a su texto.

Reflexión y evaluación: Reflexiona y evalúa de manera permanente la coherencia y cohesión de las ideas en el texto que describe, así como el uso del lenguaje para argumentar, reforzar o sugerir sentidos y producir diversos efectos en el lector según la situación comunicativa.

\section{SESIÓN 1: Situación comunicativa, presentación de las actividades y rutas de la unidad.}

Meta de actividad: Analizar la red social preferida por los adolescentes y elaborar conclusiones del texto leído.

\section{ACTIVIDADES A DESARROLLAR:}

I. Antes de la lectura: Realizar el juego charada pero vinculada a las redes sociales, por ello se forman equipos y entrega a cada uno el nombre de una de ellas: Twitter, facebook, whatsApp, spotify, instagram y sapchat. Brindar un tiempo determinado para que los equipos se pongan de acuerdo acerca de la forma en que van a representar la red social otorgada a través de mímicas, la duración para la representación es un minuto o hasta que otro equipo adivine. Anotar los nombres de las redes sociales en la pizarra cuando hayan sido descubiertas. Al finalizar, realiza la siguiente pregunta: ¿Cuál es la red social que más utilizan? ¿Por qué? Solicitar a cada equipo que escriba su respuesta en una tira de papel y al término el líder lo pegue en la pizarra, siendo esto la anticipación a la lectura.

Explicar a los estudiantes que en esta unidad, hablarán acerca de las diferentes redes sociales tanto a partir de sus propias experiencias como la de los demás y de diversas fuentes. Para ello, analizar las posturas en torno a las redes sociales y su impacto en las personas en variados ámbitos de la cotidianidad. La unidad girará en torno a la pregunta: ¿Qué influencia tienen las redes sociales en la vida de las personas?. 
Entregar a cada estudiante los textos "6 redes sociales que prefieren más los adolescentes" y "Qué dicen los chicos". Explicar y modelar cómo tienen que subrayar y sumillar (sobre todo cómo inferir). Leer de forma silenciosa con el propósito de enfocar su atención en contrastar lo leído acerca de las preferencias de los adolescentes en relación con las redes sociales con los resultados propuestos de la anticipación. Analizar la rúbrica de comprensión de textos y realizar un plenario elaborando los criterios de éxito a partir del análisis.

II. Durante la lectura: Motivar a que lo lean a consciencia, solicita que utilicen el subrayado y sumillado, no de todo el texto, sino de lo solicitado en los criterios de éxito. Monitorear por equipos preguntando y verificando si están comprendido lo que tienen que subrayar. Detecta que criterio de éxito de mayor dificultad para ellos y brinde retroalimentación.

III. Después de la lectura: Invitar a compartir ideas y llegar a consensos en razón a lo solicitado en los criterios de éxitos y las preguntas de profundización. Luego realizar preguntas y repreguntas sobre lo solicitado en los criterios y profundiza en el texto, para ello ten en cuenta lo siguiente: Contrasta lo leído, lo anotado en la pizarra con los estudiantes y formula las siguientes preguntas, para profundizar en el texto:

a. De acuerdo a los textos, ¿cuál es la red social que prefieren los adolescentes?

b. Teniendo en cuenta ambos textos, ¿cuál presenta una información más completa acerca de las preferencias de las redes sociales? Fundamenta tu respuesta con información de los textos.

3. Finalmente recoge las respuestas en plenario y registra en la pizarra lo consolidado del texto. Cuestiona, problematiza, pregunta.

Los estudiantes deben intercambiar sus textos y retroalimentarse entre ellos a partir de la rúbrica 
analizando sus niveles de logro. Al finalizar, por equipo escribir tres conclusiones sobre lo leído, en forma de tuits de 280 caracteres cada uno. Orienta la socialización de algunas conclusiones al azar.

Tarea: Explorar una de las redes sociales que más utilizan o que les llamen la atención y tomar nota de los aspectos relevantes relacionados con la experiencia. .

\section{SESIÓN 2: Análisis de posturas entorno a las redes sociales}

Meta de actividad: Inferir información de un texto para elaborar un cuadro comparativo sobre los aspectos positivos y negativos relacionados con las redes sociales.

\section{ACTIVIDADES A DESARROLLAR:}

Antes de la lectura: Mostrar a los estudiantes las imágenes de dos adolescentes e indícales que uno representa la adicción a las redes sociales y el otro, lo opuesto. Pedir a cada estudiante que imagine y escriba los aspectos positivos y negativos relacionados con las redes sociales a partir de lo que representa cada uno, esto sería la anticipación al texto. Cuando todos terminen, forma equipos y bríndales un tiempo determinado para compartir sus ideas hasta llegar a consensos. Brindar una tira de papel a cada equipo para que registren sus ideas y el líder lo pegue en la pizarra. El docente muestra con los estudiantes la rúbrica de producción de textos y brinda los criterios de éxito, para ello redacta teniendo en cuenta lo que se solicitó en la anticipación y lo que debe inferir en las preguntas de profundización. Explicar y modelar cómo tienen que subrayar y sumillar (sobre todo cómo inferir), ello debe quedar registrado en la pizarra.

Comunicar a los estudiantes que van a leer acerca de los aspectos positivos y negativos vinculados con las redes sociales. Para ello, indícales que, durante la lectura, deben enfocar su atención en el propósito: Los aspectos positivos y negativos relacionados con las redes sociales. 


\begin{abstract}
Según el texto de qué manera se puede consensuar el buen uso de las redes sociales. A continuación, entregar a cada estudiante el texto "Redes sociales y adolescencia: ¿oportunidad o peligro?”. Brindar el tiempo necesario para que lo lea en forma silenciosa con el propósito de enfocar su atención en los dos rubros indicados.
\end{abstract}

II. Durante la lectura: Acompañar a los estudiantes durante la lectura silenciosa, motivar a que lo lean a consciencia. Solicitar que utilicen el subrayado y sumillado, no de todo el texto, sino de lo solicitado en los criterios de éxito. Monitorear equipo por equipo preguntando y verificando si han comprendido lo que tienen que subrayar. Detectar que criterio de éxito han logrado la mayoría de los estudiantes y en qué criterio tienen dificultad para que pueda brindar retroalimentación.

III. Después de la lectura: Analizar junto con los estudiantes la rúbrica a emplear, interactuando con ellos e indicarles que esta les servirá de andamiaje para que logren la comprensión del texto. Esta observará el desenvolvimiento de cada uno de sus alumnos.

Brindar un tiempo para que los estudiantes puedan responder las siguientes preguntas de manera individual, ya que calificarás Comprensión de Textos:

a) ¿A qué público se dirige Álvaro Bilbao?, ¿qué elementos del texto permiten definirlo?

b) Elabora un cuadro comparativo sobre los aspectos positivos y negativos relacionado con las redes sociales.

c) Según el texto de qué manera se puede consensuar el buen uso de las redes sociales.

d) ¿Con cuál de los dos expertos estás de acuerdo? Explica tu respuesta utilizando tus propias palabras para lo que se dice en una o en ambos textos. 
Invita a los estudiantes a compartir ideas y llegar a consensos en razón a lo solicitado en los criterios de éxitos y las preguntas de profundización, para ello ten en cuenta lo siguiente:

1. Contrastar lo leído y lo anotado en la pizarra con los estudiantes.

2.Consolidar con los estudiantes las preguntas que se calificaban y registra en la pizarra,

Tarea: Traer apuntes personales relacionados con los aspectos relevantes de la experiencia de exploración de la red social que han elegido.

\section{SESIÓN 3: Redacción de la planificación crónica periodística}

Meta de actividad: Analizar un modelo de crónica periodística a fin de identificar la estructura y las características para elaborar la planificación de la misma

\section{ACTIVIDADES A DESARROLLAR:}

Descripción: Agrupar a los estudiantes de acuerdo con las redes sociales que han elegido y motívalos a compartir libremente las experiencias vividas durante la exploración de aquellas. Refuerza el objetivo de este intercambio: recibir y brindar comentarios al respecto. Recoge algunos de ellos al azar._Los estudiantes pueden valerse de las siguientes preguntas para el intercambio (elige algunas o propón otras que sean pertinentes para tal fin):

1. ¿Cómo inició mi exploración de la red social? ¿Qué dispositivo utilicé para ingresar? ¿En qué lugar lo realicé?

2. ¿Qué encontré en mi red social? ¿Qué es lo que me llamó más la atención? ¿Qué no me agradó de la exploración?

5. ¿Cómo me sentí al explorar la red social? Describe las sensaciones o emociones que te 
causó la actividad.

6. ¿Cuánto tiempo permanecí? ¿Qué hice antes de dar por finalizada la exploración?

I. Andamiaje: A continuación, comunicar a los estudiantes que van a escribir una crónica periodística relacionada con la exploración personal de la red social elegida. Para ello preséntales el modelo de crónica periodística y realiza las siguientes preguntas:

1. ¿Cuál el propósito comunicativo?

2. ¿Cuáles son las características de una crónica periodística?

3. ¿Cuál es la estructura?

4. ¿Qué conectores puedo incluir en mi crónica periodística?

Construir estas respuestas con los estudiantes y regístralas en la pizarra.

II. Además, revisar con los estudiantes la rúbrica para Producción de Textos (entregada en la primera unidad) y comparte con ellos los criterios sobre los que harás énfasis en el texto.

III. Antes de que los estudiantes escriban las crónicas invítalos a realizar la planificación de la crónica. Para tal fin puedes valerte de lo siguiente

- ¿Cómo inició mi exploración de la red social? ¿Qué dispositivo utilicé para ingresar? ¿Cuánto tiempo duró la exploración

-¿Qué encontré en mi red social? ¿Qué es lo que me llamó más la atención y por qué? ¿Qué no me agradó de la exploración y por qué

-¿Cómo me sentí al explorar la red social? ¿Describe las sensaciones o emociones que te causó 
la actividad?

¿¿Qué opino sobre la exploración de la red social que hice, teniendo en cuenta los textos leídos?

-¿De qué manera voy a narrar mi experiencia en la red social? (narración cronológica, estilo, recursos literarios)

Luego de que los estudiantes hayan realizado la planificación de sus textos, brindar el tiempo para que intercambien sus escritos con otros compañeros para que los revisen tomando en cuenta el propósito comunicativo (contar en forma detallada lo que significó la exploración de la red social elegida y dar su punto de vista sobre la exploración realizada) teniendo en cuenta los criterios de éxito y análisis de la rúbrica de producción. Al concluir con este intercambio, los estudiantes devuelven a sus dueños los trabajos con las correcciones y observaciones respectivas tomando en cuenta la rúbrica previamente analizada. Propiciar que se reúnan en pares para aclarar dudas en torno a estas o realizar consultas. Recordar acompañar todo el proceso para ofrecer retroalimentación tomando en cuenta los criterios destacados de la rúbrica. Durante el monitoreo, acompañar a los estudiantes e identificar las necesidades que se presentan para que las abordes en un plenario. Así, se podrá asegurar contenidos como sintaxis, ortografía, gramática, etc.

\section{Sesión 4: Borrador y redacción final de la crónica periodística}

Meta de actividad: Redactar una crónica periodística sobre la exploración de la red social escogida y dar su punto de vista sobre ello.

Descripción: Proyectar un ejemplo de los errores más comunes que cometieron los estudiantes en su planificación, para que a partir de ello puedas construir con los estudiantes las pautas que 
deben tener en cuenta para corregir sus errores y mejorar la redacción de su borrador; estas pautas registrarlas en la pizarra. Los estudiantes tendrán la rúbrica de producción de textos para que retroalimenten a sus compañeros de las posibles fallas y avances en su redacción. Recordarles el propósito comunicativo (contar en forma detallada lo que significó la exploración de la red social elegida y dar su punto de vista sobre la exploración realizada), las características y la estructura de la crónica periodística. Brindar los criterios de éxito para la crónica periodística según el siguiente desempeño: Desarrollar lógicamente las ideas en una crónica periodística en torno a su experiencia en la red social elegida y de fuentes de información complementarias; estructurándolo en párrafos. Establecer relaciones entre ideas a través del uso adecuado de varios tipos de conectores, referentes; emplea recursos ortográficos que le dan claridad a su escrito.

Dar un tiempo a los estudiantes para que redacten su borrador teniendo en cuenta las ideas de la planificación y los criterios de éxito. Monitorear de equipo en equipo preguntando y verificando si los estudiantes están cumpliendo con los criterios de éxito, para retroalimentarlos oportunamente. Después indicar a los estudiantes que intercambien sus textos para que se retroalimenten en base a los criterios, esto debe ser guía, criterio por criterio. Finalmente, solicitar a los estudiantes que realicen la versión final de las crónicas periodísticas, al término recoger para que las califiques con los criterios de la rúbrica.

\section{Sesión 5: Narración de crónicas periodísticas}

Meta de actividad: Narrar la crónica periodística dando su punto de vista

\section{ACTIVIDADES A DESARROLLAR:}

Descripción: Recordar a los estudiantes el propósito de la unidad: analizar las redes sociales y 
reflexionar sobre su impacto en la vida de las personas. Invitar a los estudiantes a que narren su crónica periodística como si estuvieran en la radio o en la televisión._Realiza las siguientes preguntas y repreguntas a los estudiantes:

1. El propósito comunicativo de la narración crónica periodística: Exponer la crónica periodística con el propósito de contar en forma detallada lo que significó la exploración de la red social elegida y dar su punto de vista sobre la exploración realizada.

2. Las ideas parafraseadas de los textos que le pueden ayudar a asumir un punto de vista en su crónica periodística sobre la exploración realizada.

3. Los conectores y referentes que le pueden ayudar en su narración.

4. La estructura que pueden seguir para su narración.

Analizar la rúbrica de expresión oral y brindar los criterios de éxito de acuerdo con el siguiente desempeño: Desarrollar sus ideas en torno a la red social elegida para su crónica periodística y las relaciona mediante el uso de diversos conectores y referentes. Enfatizar significados mediante el uso de recursos no verbales y paraverbales. Modelar a los estudiantes la narración de la crónica periodística de otro tema y solicita a los estudiantes que te retroalimenten en base a los criterios de éxito y brindarles un tiempo para que los estudiantes ensayen. Al término de cada narración, brinda un tiempo para que los estudiantes se retroalimenten en base a los criterios y tú también. Al finalizar las narraciones, analicen sobre el mayor punto de vista que tuvo el salón en razón al uso de las redes sociales.

\section{Sesión 6: Análisis de argumentos}




\section{Meta de actividad: Analizar un texto y extraer diferentes tipos de argumentos que servirá}

como insumo para las discusiones grupales sobre las redes sociales.

\section{ACTIVIDADES A DESARROLLAR:}

1. Antes de la lectura: Proyecta una imagen alusiva a la técnica señalada y pide a los estudiantes que comenten en equipos cómo se imaginan que se va a desarrollar. Guía la puesta en común para asegurar la comprensión de los roles: El coordinador lleva el sombrero azul (lidera al equipo), el sumarizador lleva el sombrero blanco (anota las ideas en una hoja para luego exponerlas y además aporta con hechos e información objetiva), el emotivo lleva el sombrero rojo (expresa sensaciones y emociones), el negativo lleva el sombrero negro (manifiesta críticas y dificultades), el positivo lleva el sombrero amarillo (aporta ideas constructivas y beneficios) y el innovador lleva el sombrero verde (señala ideas creativas y novedosas). Después de presentar la técnica de los seis sombreros para pensar, motiva a los estudiantes a plantear un argumento grupal en relación con las redes sociales desde la perspectiva que les corresponde. Por ejemplo, si conforman el equipo amarillo, deben ofrecer una razón grupal que apunte a los beneficios de las redes sociales. Entrega una tira de papelote a cada equipo para que registre su argumento y lo coloque en la pizarra a manera de anticipación a la lectura.

Brinda los criterios de éxito, para ello redáctalos teniendo en cuenta lo que le solicitaste en la anticipación y lo que debe inferir en las preguntas de profundización. Explícales y modélales cómo tienen que subrayar y sumillar, ello debe quedar registrado en la pizarra. Acto seguido, entrega a cada estudiante el texto "Al fin y al cabo, ¿nos hacen bien o mal las redes sociales?" Brinda el tiempo necesario para que lo lea en forma silenciosa con el propósito de confirmar su atención si las ideas propuestas en la anticipación aparecen en el texto. 
II. Durante la lectura: Acompaña a los estudiantes durante la lectura silenciosa, motiva a que lo lean a consciencia. Solicita que utilicen el subrayado y sumillado, no de todo el texto, sino de lo solicitado en los criterios de éxito. Monitorear equipo por equipo preguntando y verificando si han comprendido lo que tienen que subrayar. Detectar que criterio de éxito han logrado la mayoría de tus estudiantes y en qué criterio tienen dificultad para que puedas brindar retroalimentación.

III. Después del texto: Después, del trabajo individual, motivar a los estudiantes a compartir sus ideas al interior de sus equipos y llegar a conclusiones sobre la anticipación. Guiar la puesta en común de estas para verificar lo anotado en la pizarra con lo encontrado en el texto. Cuestiona, problematiza y pregunta. Lo que se consolida con los estudiantes regístrarlo en la pizarra. Al finalizar, proponer a cada estudiante que responda por escrito las siguientes preguntas: Teniendo en cuenta la información del texto, ¿Qué significa la expresión: “desintoxicación digital”?, ¿Cuál es el propósito de haber incorporado en el texto la sección "¿De qué tribu eres?" Fundamenta tu respuesta con información del texto.

Luego de leer el texto dos estudiantes de 2 do grado mencionan lo siguiente:

Diego: "Me parece que el texto muestra ideas que indican que el uso de las redes sociales nos afectan".

Grecia: "No estoy de acuerdo con lo que mencionas. A mí me parece que el texto presenta ideas claras acerca de que el uso de las redes sociales no son perjudiciales"

¿Con qué afirmación estás de acuerdo? Fundamenta tu respuesta con información del texto. 
¿Por qué en el texto se hace uso de varias citas textuales?, ¿cuál es el impacto que genera en el lector?

Fundamenta, ¿Cuál es la intención del autor al plantear en pregunta el título del texto y los subtemas del texto? Recoger las respuestas elaboradas por los estudiantes para calificarlas. Además, indícales la actividad para trabajar fuera de clase y revisen los textos leídos a partir de la rúbrica hasta el momento para que en la próxima clase redacten argumentos. Recuerden que deben tomar en cuenta la perspectiva del sombrero asignado, pues van a desarrollar sus razones de forma personal.

Sesión 7: Redacción de argumento para las discusiones grupales

Meta de actividad: Redactar argumentos persuasivos para las discusiones grupales sobre las redes sociales

\section{ACTIVIDADES A DESARROLLAR:}

Descripción: Brindar un ejemplo de argumentos persuasivos, para a partir de ello construir con los estudiantes el propósito comunicativo, las características y cómo elaborar la redacción de sus argumentos y regístralo en la pizarra. Reunir a los estudiantes en equipos en los que debe haber un integrante de cada color de los seis sombreros para que cada uno asuma su rol en la redacción de su argumento. A cada equipo designar un subtema sobre las redes sociales a través de un sorteo, para que a partir del subtema y de su rol como integrante de un color de los seis sombreros redacte sus argumentos. Los subtemas serían:

- El uso de las redes sociales para la comunicación interpersonal

- Los adictos a las redes sociales 
- El uso de las redes sociales para la educación

- La información compartida en las redes sociales

- Las redes sociales para inmigrantes digitales

- Las redes sociales y los negocios

Incentivar a los estudiantes a situarse en el subtema asignado y planificar individualmente qué argumentos (de los que han traído y trabajado anteriormente) podrían ajustarse mejor de acuerdo con la postura que se la ha asignado por el sombrero. Presenta los criterios de éxito.

Realizar una planificación con los estudiantes teniendo en cuenta el uso de los textos leídos para incluir en los argumentos. A partir de la planificación, los estudiantes elaboran su borrador con el propósito de redactar argumentos que persuadan según el rol que asume sobre un tema de las redes sociales. Es muy importante que se retroalimente a cada equipo para que puedan llegar al producto del desempeño. Brindar también un espacio para que los estudiantes se retroalimenten de acuerdo a la rúbrica de producción de textos, a partir de ello reflexionen y redacten la versión final. Recoger los argumentos para calificarlos de acuerdo a las rúbricas presentadas.

\section{Sesión 8: Presentación de las discusiones grupales}

Meta de actividad: Presentar las discusiones grupales sobre las redes sociales para analizar quién persuade.

\section{ACTIVIDADES A DESARROLLAR:}

Descripción: Reunir a los estudiantes en equipos en los que debe haber un integrante de cada color de los seis sombreros para pensar y motívalos a ensayar sus discusiones grupales. Realiza 
preguntas y repreguntas a los estudiantes sobre los argumentos de los textos leídos que podrían reforzar los temas (sesión anterior), esas ideas regístrala en la pizarra. Además, revisar con ellos la rúbrica para Comunicación oral y comparte los criterios sobre los que vas a hacer énfasis en esta presentación. En ese momento, recuérdales que, como público observador, deben tomar apuntes de los argumentos de uno de los participantes (que no tenga el mismo color de sombrero). De igual forma, recuérdales que el sumarizador (de sombrero blanco) debe ofrecer las conclusiones de la discusión al finalizar la presentación.

Al concluir esta explicación, ofrecer el tiempo y el espacio suficiente para que los estudiantes practiquen las discusiones grupales. Brindar retroalimentación durante el proceso en razón a los criterios de la rúbrica. Posteriormente, se realizan las discusiones grupales. Para ello, entrega los sombreros $\mathrm{y}$, después de cada presentación, propicia el intercambio de ideas entre las conclusiones del sumarizador y los apuntes personales de los oyentes. Adicionalmente, fomenta el intercambio de ideas entre los estudiantes en relación con el desempeño de cada uno en la discusión grupal y compleméntalas a manera de retroalimentación para ellos. Cuando todas las discusiones grupales hayan terminado, recoger algunas conclusiones sobre las redes sociales. Toda la actividad de discusión se evalúa con la rúbrica de expresión oral.

Felicitar a los estudiantes por todo el trabajo realizado en esta unidad de aprendizaje y se da por finalizada.

Fuente: Elaboración propia a partir de sesiones IS (2018).

\section{Orientaciones para la aplicación de la propuesta}

Para lograr los objetivos de la propuesta presentada, es importante considerar la secuencias didácticas elementales de la evaluación formativa, coordinando con los gestores para que ellos a 
su vez informen a los docentes a cerca de los fundamentos teóricos y didácticos de la propuesta de rubrica pedagógica en la enseñanza- aprendizaje de la asignatura del área de comunicación del segundo grado de educación secundaria, realizando capacitación antes del abordaje en las aulas, manifestando las características de estos fundamentos y de su contribución en el desarrollo de los competencias, conocimientos y las habilidades en los estudiantes a partir del trabajo activo que realizaran y la importancia de su rol docente. Analizar con las profesoras participantes de la implementación de la propuesta del uso de rúbrica pedagógica para desarrollar la evaluación formativa, elaborar la estructura de las competencias a desarrollar en el área, incluyéndolas en el proceso de enseñanza aprendizaje mediante métodos, actividades, medios, recursos y materiales.

Uso de diversas estrategias para las clases, considerando la evaluación formativa como dentro del proceso incluyendo la retroalimentación efectiva como parte esencial. Realizar un diagnóstico de las competencias de los estudiantes y analizar los resultados en un primer momento, luego de haber aplicado en la práctica pedagógica el trabajo del desarrollo de competencias mediante las rúbricas, evaluar el avance de los estudiantes nuevamente, ello permite identificar que debemos de fortalecer. La secuencia didáctica por competencias diseñada donde se encuentra la unidad de aprendizaje y sesiones se modelan como parte de la propuesta poniendo énfasis en el uso de las rúbricas pedagógicas para el desarrollo de competencias a partir de la evaluación formativa del proceso.

En la parte didáctica, se consideran las rúbricas como puntos clave a tomar en cuenta antes del desarrollo de las actividades en las cuales el estudiante de segundo de secundaria junto con su docente y grupo de compañeros analizan lo que se quiere lograr en cada una de las sesiones y mediante estrategias, retroalimentación y procesos metacognitivos se van logrando el desarrollo de las competencias del área de comunicación: Comprensión, Producción y expresión 
oral. El proceso de implementación debe ser guiado por los directores y/o coordinadores encargados del desarrollo de esta y hacer seguimiento, monitoreo de las actividades y verificación en las aulas para que se logren los objetivos propuestos.

\section{Validación de la propuesta por juicio de expertos}

Para validar la propuesta presentada con el propósito de mejorar el estado actual del proceso de enseñanza aprendizaje en el desarrollo de la evaluación formativa en la escuela, se emplearon los métodos de validación por juicio de expertos y determinar aspectos internos y externos de la propuesta. El método empleado implica condiciones para su aplicación; igualmente, requiere de personas expertas seleccionados por sus capacidades, competencias y experiencia en el ámbito educativo.

\section{Características de los expertos}

Los expertos selectos para validar la propuesta dada son excelentes profesionales que cuentan con grado doctoral en educación y cuentan con una amplia trayectoria educativa, por ello son autoridad para valorar la propuesta de la tesis.

Tabla 7.

Datos de expertos

\begin{tabular}{ccccc}
\hline $\begin{array}{c}\text { Nombre y } \\
\text { apellido }\end{array}$ & Grado & Especialidad & Ocupación & Años de \\
& académico & profesional & & experiencia \\
\hline Alejandro Cruzata & Doctor en & Licenciado en & Director Académico de & 28 años \\
Martínez & Educación & Educación & la Escuela de Postgrado & \\
& & & de la Universidad San & \\
& & & Ignacio de Loyola & \\
\hline Miriam & Doctora en & Licenciada en & Docente de la & 28 años \\
Velásquez Tejeda & Educación & Educación & Universidad San Ignacio & \\
\hline
\end{tabular}




\begin{tabular}{ccccc}
\hline & & & de Loyola \\
\hline Fernando & Doctor en & Licenciado en & Docente de la & 16 años \\
Goñi Cruz & Educación & Educación & Universidad San Ignacio & \\
& & & de Loyola & \\
& & &
\end{tabular}

Fuente: Elaboración propia a partir de documentos de elaboración de tesis USIL (2019)

\section{Valoración interna y externa}

Para la realización de la validación de las fichas internas y externas, se consideran diez criterios de valor, agregando en estos, indicadores cuantitativos y cualitativos, los criterios comprenden la puntuación correspondiente: deficiente (1 punto), bajo ( 2 puntos), regular ( 3 puntos), buena (4 puntos) y muy buena ( 5 puntos).

Tabla 8.

Tabla de valoración

\begin{tabular}{lc}
\hline Deficiente & $0-25$ \\
\hline Baja & $26-50$ \\
\hline Regular & $51-70$ \\
\hline Buena & $71-85$ \\
\hline Muy buena & $86-100$
\end{tabular}

Fuente: Documentos de elaboración de tesis USIL (2019)

Con respecto al análisis de la dimensión cualitativa, los expertos realizaron una evaluación crítica tomando en cuenta las dimensiones: positivos, negativos y sugerencias. Se presentaron dos fichas de valoración, siendo la primera ficha de valoración interna y la segunda ficha de valoración externa; ambas fichas con diversos aspectos, como se presenta a continuación. 


\section{Tabla 9.}

Criterio de validación interna de la propuesta

\begin{tabular}{|c|c|c|c|c|c|c|c|}
\hline \multirow[t]{3}{*}{ Indicadores } & \multirow{2}{*}{\multicolumn{4}{|c|}{$\begin{array}{l}\text { Escala de } \\
\text { valoración }\end{array}$}} & \multicolumn{3}{|l|}{ Aspectos } \\
\hline & & & & & Positivos & Negativos & Sugerencias \\
\hline & \begin{tabular}{l|l}
1 & 2
\end{tabular} & 3 & 4 & 5 & & & \\
\hline Factibilidad de aplicación del resultado que se presenta. & & & & & & & \\
\hline Claridad de la propuesta para ser aplicado por otros & & & & & & & \\
\hline $\begin{array}{l}\text { Posibilidad de la propuesta de extensión a otros } \\
\text { contextos semejantes }\end{array}$ & & & & & & & \\
\hline $\begin{array}{l}\text { Correspondencia con las necesidades sociales e } \\
\text { individuales actuales }\end{array}$ & & & & & & & \\
\hline $\begin{array}{l}\text { Congruencia entre el resultado propuesto y el objetivo } \\
\text { fijado. }\end{array}$ & & & & & & & \\
\hline $\begin{array}{l}\text { Novedad en el uso de conceptos y procedimientos de la } \\
\text { propuesta. }\end{array}$ & & & & & & & \\
\hline $\begin{array}{l}\text { La modelación contiene propósitos basados en los } \\
\text { fundamentos educativos, curriculares y pedagógicos. } \\
\text { detallado, preciso y efectivo }\end{array}$ & & & & & & & \\
\hline La propuesta está contextualizada a la realidad en estud & & & & & & & \\
\hline $\begin{array}{l}\text { Presenta objetivos claros, coherentes y posibles de } \\
\text { alcanzar }\end{array}$ & & & & & & & \\
\hline Contiene un plan de acción de lo general a lo particular & & & & & & & \\
\hline
\end{tabular}

Fuente: Documento de elaboración de tesis USIL (2019) 
Tabla 10.

Criterio de validación externa de la propuesta

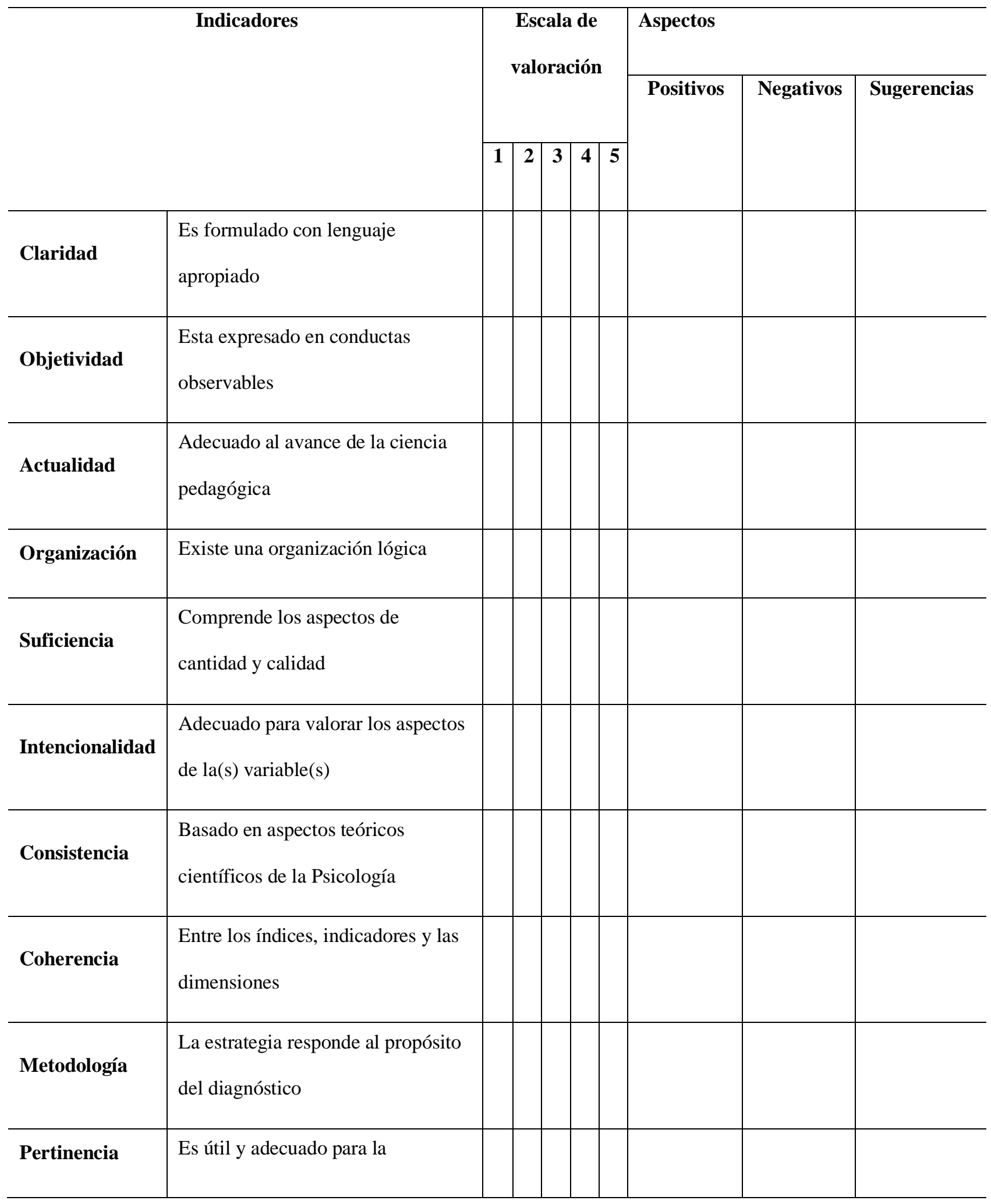




\begin{tabular}{l|l|l|l|l|l|l|l|l|l}
\hline & investigación & & & & & & & & \\
\end{tabular}

Fuente: Documento de elaboración de tesis USIL (2019)

Posteriormente a la revisión, los expertos concluyeron con las puntuaciones que se muestran a continuación.

Tabla 11.

Puntuación y promedio

\begin{tabular}{lcccc}
\hline \multicolumn{1}{c}{ Nombre } & $\begin{array}{c}\text { Grado } \\
\text { académico }\end{array}$ & $\begin{array}{c}\text { Valoración } \\
\text { interna }\end{array}$ & $\begin{array}{c}\text { Valoración } \\
\text { externa }\end{array}$ & $\begin{array}{c}\text { Valoración } \\
\text { final }\end{array}$ \\
\hline Alejandro Cruzata & Doctor & 50 & 50 & 100 \\
Martinez & & & & 94 \\
\hline Miriam Velásquez & Doctor & 45 & 49 & 84 \\
Tejada & & & & \\
\hline Fernando & Doctor & 42 & 42 & \\
Goñi Cruz & & & & \\
\hline
\end{tabular}

Fuente: Elaboración propia a partir de documento de elaboración de tesis USIL (2019) 
Resultados de la validación emitida por los expertos que participaron y las conclusiones

Tabla 12.

Resultado consolidado de la valoración interna y externa

\begin{tabular}{ccc}
\hline $\begin{array}{c}\text { Sumatoria de valoración } \\
\text { total }\end{array}$ & Promedio de valoración & Valoración \\
\hline 278 & 92.66 & Muy buena \\
\hline
\end{tabular}

Después de obtener el resultado, se pudo concluir que la propuesta obtuvo la valoración muy buena. De esta manera, se concluye que la propuesta de rúbrica pedagógica puede ser insertada en las clases impartidas en las instituciones educativas con el objetivo de mejorar el proceso de enseñanza aprendizaje con un enfoque de evaluación formativa. 


\section{Conclusiones}

Habiendo concluido con el proceso de investigación, con el planteamiento del problema, el marco teórico, el diagnóstico o trabajo de campo y la modelación, se desarrolla la propuesta de rúbrica pedagógica para la evaluación formativa en los estudiantes del segundo año de nivel Secundaria, se arriba a las siguientes conclusiones:

\section{Primera}

Se logró alcanzar el objetivo general con la modelación de la rúbrica pedagógicas para desarrollar la evaluación formativa en los estudiantes del segundo año de educación Secundaria, identificando la situación real y la situación ideal de la situación problemática, dando la propuesta de solución al problema científico de la investigación. Así, el diseño de las rúbricas pedagógicas procura desarrollar el enfoque formativo de la evaluación para que los estudiantes mejoren su aprendizaje en el aula y por ende su rendimiento escolar.

\section{Segunda}

Se pudo comprobar las necesidades y limitaciones que presentan los sujetos de investigación con respecto al uso de la evaluación formativa en el aula de los estudiantes de segundo año de educación Secundaria. Dicha verificación, se llevó a cabo gracias al diagnóstico, el cual se pudo determinar por medio del análisis del problema en estudio, derivado del trabajo de campo, la aplicación de técnicas e instrumentos además de considerar fundamentos teóricos. Se cumplió con alcanzar la primera tarea científica.

\section{Tercera}

En base al análisis de los datos obtenidos y alcanzar la segunda tarea científica, durante el trabajo de campo además de los fundamentos teóricos, se determina que la rúbrica pedagógica que se presenta, impulsará favorablemente otra forma de evaluación donde los estudiantes y 
docentes se involucrarán activamente en el proceso de enseñanza aprendizaje en el área de comunicación y se fortalecerán las competencias específicas.

\section{Cuarta}

Se pudieron identificar las categorías emergentes por medio del análisis de datos obtenidos en la aplicación de técnicas e instrumentos y un proceso de codificación y triangulación. Dichas categorías emergentes, se utilizaron para determinar la situación ideal del sujeto y diseñar la rúbrica pedagógica para fortalecer las competencias del área de comunicación para desarrollar la evaluación formativa en los estudiantes del segundo grado de educación Secundaria. Se cumplió con la tercera tarea científica la modelación de la propuesta.

\section{Quinta}

Por último, al cumplir con la cuarta tarea científica, se establece que los resultados positivos obtenidos en la valoración de la aplicación del método de criterio de especialistas avalan que es factible la aplicación de la propuesta de rúbrica pedagógica para desarrollar la evaluación formativa en los estudiantes del segundo año de educación Secundaria de una institución educativa particular en el distrito de San Miguel. 


\section{Recomendaciones}

\section{Primera}

La evaluación formativa es una práctica centrada en el aprendizaje de los estudiantes que realimenta oportunamente respecto a los logros alcanzados en los progresos; esta permite diagnosticar, retroalimentar y posibilitar acciones para el aprendizaje de los estudiantes. La evaluación con este nuevo enfoque formativo hace que se alimenten los conocimientos, se formen competencias, se promuevan aptitudes y actitudes en los estudiantes.

\section{Segunda}

Para el fortalecimiento de los aprendizajes, se recomienda que los docentes evalúen formativamente durante el proceso de enseñanza - aprendizaje, retroalimentando los trabajos constantemente y siempre teniendo una meta u objetivo que el estudiante conozca desde el inicio de las actividades; por ello también se debe trabajar la autoevaluación, coevaluación y heteroevaluación de las actividades, siendo fundamentales para que este tome conciencia de su avance, del resultado de sus esfuerzos y de su evolución a lo largo de las actividades.

\section{Tercera}

Es importante que los profesores se capaciten constantemente, actualicen sus conocimientos y apliquen en el aula esta nueva forma de evaluación, ya que trabajándola se fortalecerá en los estudiantes sus aprendizajes y por ende el logro de competencias.

\section{Cuarta}

Insertar en el trabajo docente el uso de instrumentos como la que proponemos en la investigación referente a las rúbricas pedagógicas para la mejora del rendimiento escolar. Estas rúbricas también se pueden trabajar en todas las áreas escolares para el desarrollo cognitivo, procedimental y actitudinal, adaptándolas a las necesidades de los estudiantes y a los logros de 
objetivos y metas para desarrollar mediante una serie de actividades y estrategias en el aula la evaluación formativa. 


\section{REFERENCIAS}

Alsina y otros (2013). Rúbricas para la evaluación de competencias. Universidad de Barcelona. España.

Andrade, H. (2005). Teaching with rubrics. College Teaching. 53 pp.27.30.

Ausubel, D. P. (1976). Psicología educativa. Un punto de vista cognoscitivo. Ed. Trillas. México.

Ausubel, Novacky Hanesian, H. (1995). Psicología educativa. México: Trillas.

Bernad, J. A. (1999). Estrategias de Aprendizaje. Como Aprender y Enseñar Estratégicamente en la Escuela. Madrid: Bruño.

Bernal, C. (2010). Metodología de la Investigación. (3raed.).Colombia

Blanco (2008). Las rúbricas: Un instrumento útil para la evaluación de competencias.

Casanova, M. (2012). El diseño curricular como factor de calidad educativa. REICE. Revista Iberoamericana sobre Calidad, Eficacia y Cambio en Educación, 10(4), 6-20.

Castillo, S. y Cabrerizo, D. (2009). Evaluación educativa de aprendizajes y competencias. Pearson Education. España.

Cerezal, J. y Fiallo, J. (2016). Métodos científicos de la Investigaciones Pedagógicas. Cuba: Colectivo Pedagógico.

Cruz, M. (2008). La evaluación formativa y la autorregulación. Universidad San Francisco de Quito. Ecuador.

D. D. Stevens, A. J. Levi. (2005). Introduction to Rubrics. Canadá.

Delgado, A., y Oliver, R. (2006). La evaluación continua en un nuevo escenario docente. Revista de Universidad y Sociedad del Conocimiento, III (1), 1-13.

Díaz, F. y Hernández, G. (2007). Estrategias docentes para un aprendizaje significativo. México: McGraw-Hill.

Díaz, F., y De la Cruz, G. (2011). Rúbricas en la evaluación de competencias y aprendizaje complejo. Universidad Nacional Autónoma de México. 
Dörnyei, Zoltán (2008). Estrategias de motivación en el aula de lenguas. Barcelona. Editorial UOC.

Flavell, J. (1996). El desarrollo cognitivo. España: Prentice Hall.

Fraile, J., López, N., Valdes, M., (2016). Formación de competencias en el aula - Guía didáctica - Formación de competencias en el aula. Educación, México.

Freire, P. (2012). Pedagogía de la autonomía. Saberes necesarios para la práctica educativa. Siglo XXI. México.

Frola, P. y Velasquez, J. (2011). Competencias docentes para la evaluación cualitativa del aprendizaje. Centro de Investigación Educativa y Capacitación Institucional S.C. México D.F.

García, A. (2011). Estrategias de evaluación formativa en el aula. Editorial Educación XXI.

García, S. (2010). Guía para la elaboración del anteproyecto de investigación. Costa Rica.

Gobierno Federal (2012). El enfoque formativo de la evaluación. Serie: Herramientas para la evaluación en educación básica. México.

Guajardo, B. ( 2011 ). La Evaluación Formativa: Práctica de Evaluación del aprendizaje por hacía el aprendizaje y evaluación de competencias. México: Pearson.

Hernández, J., Mosqueda, Tobón, S. y Guerrero, G. ( 2016) Hacia una evaluación integral del desempeño: las rúbricas socioformativas. Sistema de Información Científica Red de Revistas Científicas de América Latina y el Caribe, España y Portugal - 2016 p. 237.

Innova Schools (2018). Rúbricas del curso de comunicación, nivel secundario. Perú.

Lamas (2018). La evaluación formativa de los aprendizajes en el segundo ciclo de la Educación Básica Regular en una institución educativa estatal de Ate. PUCP. Perú. 
Lliguaipuma A, M. (2016). “Guía didáctica de rúbricas de evaluación para el bloque uno de números y funciones”. Cuenca. Ecuador.

López, A. A. (2008b). The role of language testing in the classroom. Documento procedente de las Memorias del Fourth Language Forum, Valledupar, Colombia.

López, M. (2007). Innovación educativa. Guía básica para la elaboración de rúbricas. Universidad Iberoamericana Puebla. México.

Marchese, Agustina (2013). La era constructivista: los nuevos modelos de evaluación. Editorial Troquel.

Melquisedec, A. (2015). Evaluación formativa aplicada por los docentes del área de ciencia, tecnología y ambiente. Arequipa. Perú

Minedu (2012). Marco del Buen Desempeño Docente. Perú.

Minedu (2013). Mapas del progreso del aprendizaje, área de comunicación. Perú.

Minedu (2017). Diseño Curricular Básico Nacional. Perú.

Ministerio de Educación del Perú (2007). La metacognición y la comunicación. En Pedagogía Fascículo 7. Serie 1 Perú.

Ministerio de Educación Pública (2013). La evaluación formativa. Dirección de desarrollo curricular. Departamento de evaluación de los aprendizajes. Editoral EUNED. Costa Rica.

Moffett, J., \& Wagner, B. J. (1992). Student-centered language arts, K-12. Portsmouth, NH: Boynton/Cook Publishers Heinemann.

Montalvan, D. (2017). Características asociadas a la evaluación formativa y su relación con el aprendizaje de habilidades matemáticas en estudiantes de la Carrera Profesional de Administración de Empresas de la Universidad Privada SISE. Lima - Perú.

Murillo, W. (2008). La investigación científica. Consultado el 18 de abril de 2008 de http//www.monografias.com/trabajos15/invest-científica/investcientífica.shtm 
Ninabanda, R. (2014). La rúbrica como herramienta pedagógica de evaluación. Universidad Estatal de Bolívar. Guanujo. Ecuador.

Parra, M. (2016). Evaluación formativa y rúbrica de evaluación. Universidad de Santander Facultad de educación. Bogotá.

Patton, M. (2002). Qualitative research and evaluation methods. 3a. Ed. Thousand Oaks: Sage Publications.

Popham, W.J. (Coord.) (2013) Evaluación trans-formativa. El poder transformador de la evaluación formativa. Madrid : Narcea

Puente, A. (2005). Cognición y aprendizaje fundamentos psicológicos. Madrid: Pirámide.

Resnick y Klopfer(1997) . Currículo y Cognición. Buenos Aires: Aiqué

Roblyer, M.D. \& Wiencke, W.R. (2003). Design and use of a rubric to assess and encourage interactive qualities in distance courses. The American Journal of Distance Education, 17 (2), 77-97.

Rodríguez, D. (2017). La Filosofía de la educación y la evaluación. Ediciones Universales.

Ruiz, M. I. (2009). La evaluación basada en competencias. 1-22. Recuperado de http://www.cca.org.mx/profesores/congreso_recursos/descargas/mag_competencias.pdf

Ruiz, R. (2014). Análisis de rúbricas para la evaluación oral y escrita en estudiantes de grado de magisterio de educación primaria. Universidad Nacional de Educación a distancia. UNED. España.

Schuster, A. et al. (2013). Revista Electrónica Iberoamericana de Educación en Ciencias y Tecnología - Volumen 4, Número 2. Argentina.

Shepard, L. A. (2001). The role of classroom assessment in teaching and learning. En V. Richardson (Ed.). Handbook of research on teaching (4a ed., pp. 1066-1101). Washington: American Educational Research Association.

Siccha (2015). La rúbrica para evaluar competencias en el área de historia, geografía y economía. Universidad San Ignacio de Loyola. Lima- Perú.

Simon, M. y Forgette, R. (2001) . A rubric for scoring postsecondary academic skills. Practical Assessment, Research \& Evaluation, 7. 
Sironi, R. (2014). Evaluación formativa para el aprendizaje escolar de un idioma. Jalisco. México.

Stevens, D. y Levi, A. (2012). Introducción a las rúbricas: Una herramienta de evaluación para ahorrar tiempo de clasificación, transmitir efectiva retroalimentación, y promover el aprendizaje de los estudiantes. Sterling, VA: Stylus Publishers.

Tarazona (2011). Influencia de la evaluación formativa en el rendimiento académico de los estudiantes de la Escuela Profesional de Educación de la Universidad Nacional Santiago Antúnez de Mayolo. Huaraz -Perú.

Tobón, S. (2007). El enfoque complejo de las competencias y el diseño curricular por ciclos propedéuticos. Editorial Magisterio.

Tobón, S. (2009). Formación basada en competencias: pensamiento complejo. ECOE ediciones.

Tobón, S. (2013). Formación integral y competencias. ECOE ediciones. Cuarta edición. Colombia.

Tobón, S., García, J., \& López, N. (2010). Currículo, didáctica. Editorial Trillas.

Tobón, S., Pimienta, J. \& García, J. (2010). Secuencias didácticas. Pearson Educación.

Tobón, S., \& García, J. (2009). Estrategias didácticas para la formación. ECOE ediciones.

Torres, J \& Perera V. (2010). Rúbricas para la orientación y evaluación del aprendizaje. España.

Torres, J.\& Perea, V. (2010). La rúbrica como instrumento pedagógico para la tutorización y evaluación de los aprendizajes en el foro online en educación superior. Universidad de Sevilla. España pp. 141-149.

Torres, T. (2016). Reflexiones en torno a la Lógica en la investigación científica, Editorial Academia Española, Deutschlan.

Trahtemberg, L. (2006). Minedu debe de reemplantear un cambio. Revista Perú 21. Lima, Perú.

Unesco (2015). Replantear la educación ¿Hacia un bien común mundial?. Organización de las Naciones Unidas para la Educación, la Ciencia y la Cultura 7, Place de Fontenoy, 75352 PARÍS 07 SP, Francia. 
Urrutia, E. (2015). Aplicación de rúbricas para evaluar aprendizajes significativos bajo el enfoque por competencias del área de matemática en los estudiantes del primer grado sección " $A$ " del nivel secundaria de I.E. 'La Salle' - Abancay. Arequipa - Perú.

Valverde, J., Ciudad, A. (2014). El uso de e-rúbricas para la evaluación de competencias en estudiantes universitarios. Estudio sobre fiabilidad del instrumento. Universidad de Extremadura, España.

Zazueta, M. y Herrera, L (2008) .Rúbrica o matriz de valoración, herramienta de evaluación formativa y sumativa. Universidad de Campeche - México.

Zulma, M. (2006). Aprendizaje autorregulado: el lugar de la cognición, la metacognición y la motivación. Estudios pedagógicos, 2, 121-132. Extraído el 18 junio 2011. 
ANEXOS 
Anexo I

MATRIZ METODOLÓGOGICA

\begin{tabular}{|c|c|c|c|c|c|c|c|c|}
\hline $\begin{array}{l}\text { Problema de } \\
\text { investigación }\end{array}$ & Preguntas científicas & Objetivo general & $\begin{array}{c}\text { Objetivos } \\
\text { específicos }\end{array}$ & Categorías & Sub-categorías & Técnicas & Instrumentos & Unidad de análisis \\
\hline \multirow[t]{3}{*}{$\begin{array}{l}\text { ¿Cómo desarrollar } \\
\text { la evaluación } \\
\text { formativa en los } \\
\text { estudiantes del } \\
\text { nivel secundaria } \\
\text { de una institución } \\
\text { educativa privada } \\
\text { en el distrito de } \\
\text { San Miguel? }\end{array}$} & $\begin{array}{lrr}\text { ¿Cuál es el } & \text { estado } \\
\text { actual de la evaluación } \\
\text { formativa } & \text { en } & \text { los } \\
\text { estudiantes } & \text { del } & \text { nivel } \\
\text { secundaria } & \text { de } & \text { una } \\
\text { institución educativa } \\
\text { privada en el distrito de } \\
\text { San Miguel? }\end{array}$ & \multirow[t]{3}{*}{$\begin{array}{c}\text { Proponer una rúbrica } \\
\text { pedagógica para } \\
\text { desarrollar la } \\
\text { evaluación formativa } \\
\text { en los estudiantes del } \\
\text { nivel secundario de } \\
\text { una institución } \\
\text { educativa privada en } \\
\text { el distrito de San } \\
\text { Miguel. }\end{array}$} & $\begin{array}{l}\text { Diagnosticar el } \\
\text { estado actual de la } \\
\text { rúbrica pedagógica } \\
\text { de los estudiantes } \\
\text { del nivel } \\
\text { secundario de una } \\
\text { institución } \\
\text { educativa privada } \\
\text { en el distrito de } \\
\text { San Miguel }\end{array}$ & \multirow{3}{*}{$\begin{array}{l}\text { Evaluación } \\
\text { formativa }\end{array}$} & $\begin{array}{l}\text { Dimensión } \\
\text { cognitiva }\end{array}$ & Observación & Guía de observación & Estudiantes \\
\hline & \begin{tabular}{lrr} 
¿Cuáles & son & los \\
fundamentos & teóricos \\
de una & rúbrica \\
pedagógica & para \\
contribuir al & desarrollo \\
de la evaluación \\
formativa en & los \\
estudiantes & del & nivel \\
secundario & de & una \\
institución educativa \\
privada en el distrito de \\
\multicolumn{3}{l}{ San Miguel? }
\end{tabular} & & $\begin{array}{l}\text { Sistematizar los } \\
\text { fundamentos } \\
\text { teóricos de una } \\
\text { rúbrica pedagógica } \\
\text { para el desarrollo } \\
\text { de la evaluación } \\
\text { formativa de los } \\
\text { estudiantes del } \\
\text { nivel secundario } \\
\text { de una institución } \\
\text { educativa privada } \\
\text { en el distrito de } \\
\text { San Miguel. }\end{array}$ & & $\begin{array}{l}\text { Dimensión } \\
\text { procedimental }\end{array}$ & Encuesta & Cuestionario & Estudiantes \\
\hline & $\begin{array}{l}\text { ¿Qué criterios se } \\
\text { tendrán en cuenta en la } \\
\text { modelación de la } \\
\text { propuesta de una } \\
\text { rúbrica pedagógica } \\
\text { para contribuir al } \\
\text { desarrollo de la } \\
\text { evaluación formativa } \\
\text { en los estudiantes del } \\
\text { nivel secundario de una } \\
\text { institución educativa } \\
\text { privada en el distrito de } \\
\text { San Miguel? }\end{array}$ & & $\begin{array}{l}\text { Determinar los } \\
\text { criterios teóricos y } \\
\text { metodológicos } \\
\text { para la modelación } \\
\text { de la propuesta de } \\
\text { una rábrica } \\
\text { pedagógica para } \\
\text { desarrollar ra la } \\
\text { evaluación } \\
\text { formativa en los } \\
\text { estudiantes del } \\
\text { nivel secundario } \\
\text { de una institución } \\
\text { educativa privada } \\
\text { en el distrito de }\end{array}$ & & $\begin{array}{l}\text { Dimensión } \\
\text { actitudinal }\end{array}$ & Observación & Guía de observación & Estudiantes y docentes \\
\hline
\end{tabular}




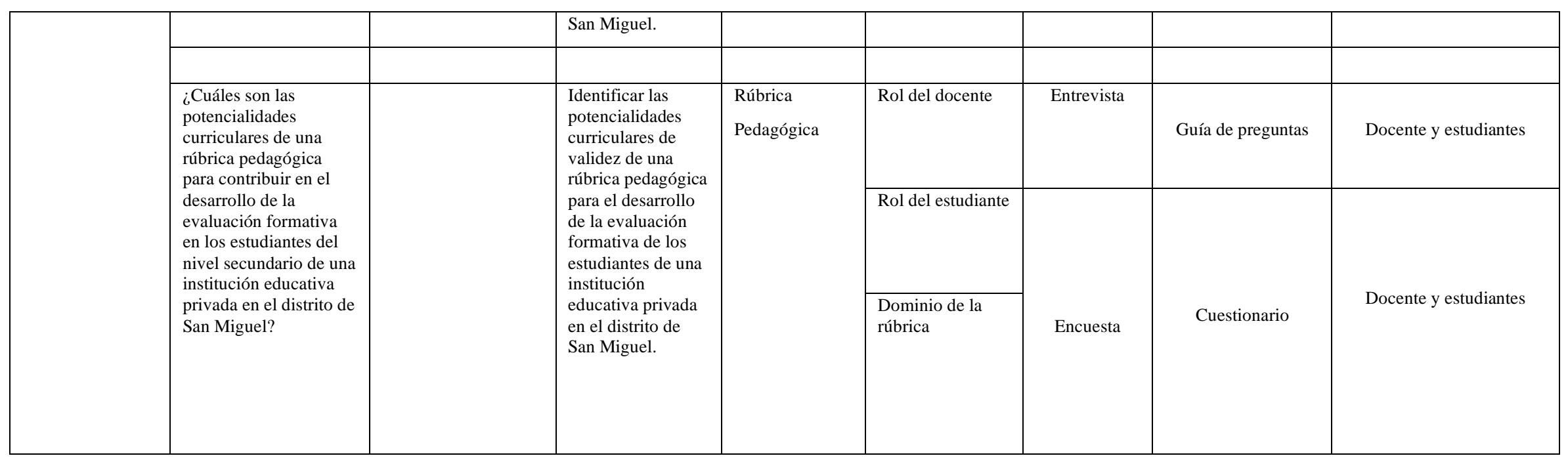




\section{Anexo 3}

\section{Validación de instrumentos}

PROGRAMA ACADÉMICO DR MAESTRIA EN EDUCACIÓN EN MENCIÓY GESTIÓN EDUCATIVA CARTA DE PRESENTACIÓN

La Molina, 22 de febrero del 201

Señor:

Mg. GAFANELO ESCOBAR RONAL RODOLFO

Presente:

Asunto: Validación de instrumento, por criterio de especialista

De mi especial consideración:

Es grato dirigirme a Usted, para expresarle un sludo cordial e informarle que como parte del desarrollo de la tesis del Programa Académico de Maestria en Educación con mención en Gestión de la Educación estoy desarrollando el avance de mi tesis titulada "Ríhrica para desarrollar la evaluación formativa en los estudiantes de educación secundaria de una institución privada de San Miguel'?

Motivo por el cual se hizo necesario la elaboración de una matriz de categorización, construecióa del instrumento y ficha de validación.

Por lo expuesto, con la finalidad de darle riggor cientifico necesario, se requiere la validación de dichos instrumentos a través de la evaluación de Juicio de Experios. Es por ello, que me permito solicitarle su participación como juez, spelando sa trayectoria y reconocimiento como docente universitario y profesional.

Agradeciendo por anticipado su colaboración y aporte en la presente me despido de ustod, no sin antes expresarle los sentimientos de consideración y estima personal. Atentamente;

of

Rosa Mariel Ascurra Lozad

PD. Se adjunta

se recolección de la información

- Ficha de validación de instrumento.

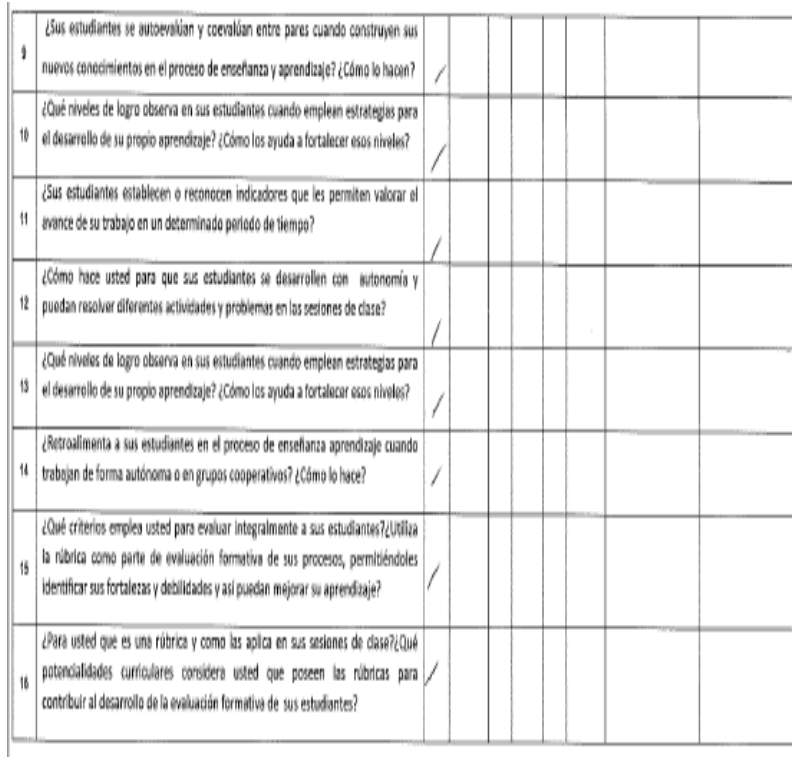

CERTIFICADO DE VALIDEZ DE CONTENDO DE LA ENTREVISTA A DOCENTES

\begin{tabular}{|c|c|c|c|c|c|c|c|}
\hline \multirow[t]{2}{*}{ v } & \multirow[t]{2}{*}{ Pormulación del ittem } & \multicolumn{3}{|c|}{ 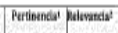 } & \multirow{2}{*}{ 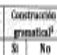 } & \multirow[t]{2}{*}{ Otachaciotem } & \multirow[t]{2}{*}{ Sugmencitas } \\
\hline & & 8 & w & \begin{tabular}{|l|l|}
8 & $K_{0}$ \\
\end{tabular} & & & \\
\hline 1 & 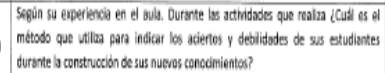 & 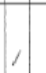 & & & & & \\
\hline 2 & 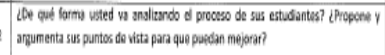 & & & & & & \\
\hline 2 & 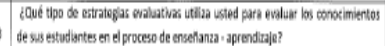 & 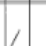 & & & & & \\
\hline 4 & 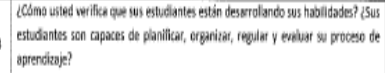 & / & & & & & \\
\hline$s$ & 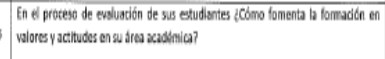 & 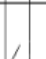 & & & & & \\
\hline 6 & 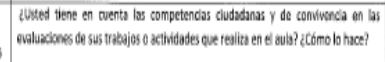 & & & & & & \\
\hline , & 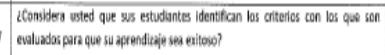 & / & & & & & \\
\hline 1 & 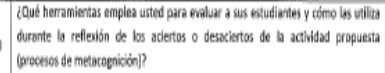 & & & & & & \\
\hline
\end{tabular}

OPNONOE APLCABLLDAD DE LA ENREEVISTA:

Obsenaciones /precisar si hay suficioncla): APCl cedsice

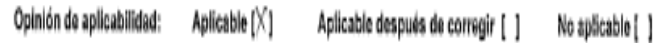

\begin{tabular}{|c|c|c|c|}
\hline Nerbow y doullias & 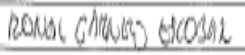 & DNN & 0664510 \\
\hline Drowing dimilinit & & Tellian/Ceditit & \\
\hline 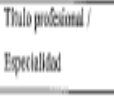 & 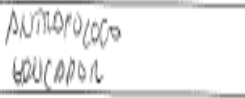 & \multirow[t]{2}{*}{ fim } & \\
\hline Cond Aodetivio & & & \\
\hline Mowdiligo lentition & noropoloks & Liquryutil & 1000 os $800 \%$ \\
\hline
\end{tabular}

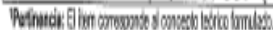

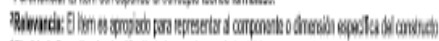

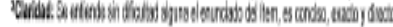

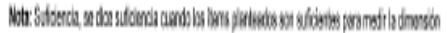


CERTIFICADO DE VALIDEZ DE CONTENDO DEL CUESTIONARIO TOMADO A ESTUDIANTES

\begin{tabular}{|c|c|c|c|c|c|c|c|}
\hline \multirow[t]{2}{*}{$N$} & \multirow[t]{2}{*}{ Formulacion del intem } & \multicolumn{2}{|c|}{ Pertiention' } & Therancta' & 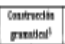 & \multirow[t]{2}{*}{ Obtenvalomen } & \multirow[t]{2}{*}{ Sigatenciat } \\
\hline & & 81 & in & \begin{tabular}{l|l}
51 & 10
\end{tabular} & \begin{tabular}{|l|l|}
51 & \\
10
\end{tabular} & & \\
\hline 1 & 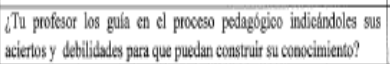 & , & & & & & \\
\hline 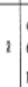 & 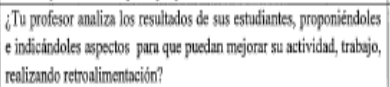 & , & & & & & \\
\hline 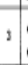 & $\begin{array}{l}\text { ¿Tu profesor uiliza instrumentoo y les iddica cómo utilizallos para } \\
\text { que puedan evaluar gis apreadizajes? }\end{array}$ & , & & & & & \\
\hline 4 & 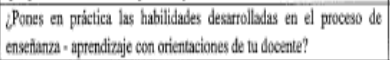 & / & & & & & \\
\hline 1 & $\begin{array}{l}\text { ¿Tu profesor fonetia en ustedes la fomación en valores, buenas } \\
\text { actitudes en su arra académica los losaláa en este aspecto? }\end{array}$ & 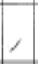 & & & & & \\
\hline , & $\begin{array}{l}\text { ¿Tu profesor toma en cuenta las competencias ciudadanas y de } \\
\text { convivencia en las evaluaciones de los trabajos de sus estudiantes } \\
\text { fortaleciendo su sigratura? }\end{array}$ & 1 & & & & & \\
\hline 1 & $\begin{array}{l}\text { ¿Usted como esudiante conoce y analiza los criterios o pautas para } \\
\text { alcanzzar el exito de sus trabjojos en clase? }\end{array}$ & $/$ & & & & & \\
\hline , & 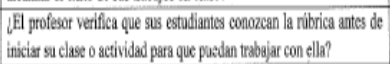 & / & & & & & \\
\hline 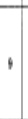 & 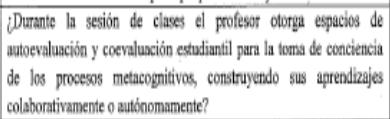 & , & & & & & \\
\hline
\end{tabular}

\section{OPMONON OE APLCABBLLDAD DEL CUESTONARIO:}

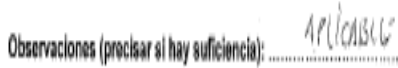

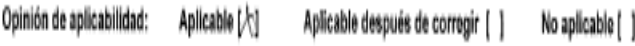

\begin{tabular}{|c|c|c|c|}
\hline Nentrei Applitidien & 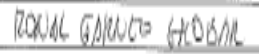 & DWIN & 0664951. \\
\hline Dirmein bancilin & & Teklam /Ceditr & \\
\hline 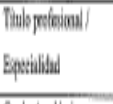 & 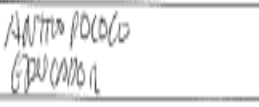 & \multirow[t]{2}{*}{ Fimi } & \\
\hline 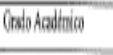 & & & \\
\hline Nonollowinatilio & Motoproalces & Lpry yidin & 60103000402015 \\
\hline
\end{tabular}

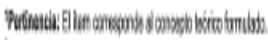

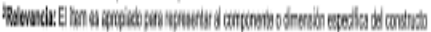

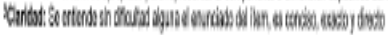

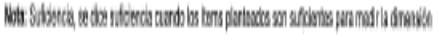

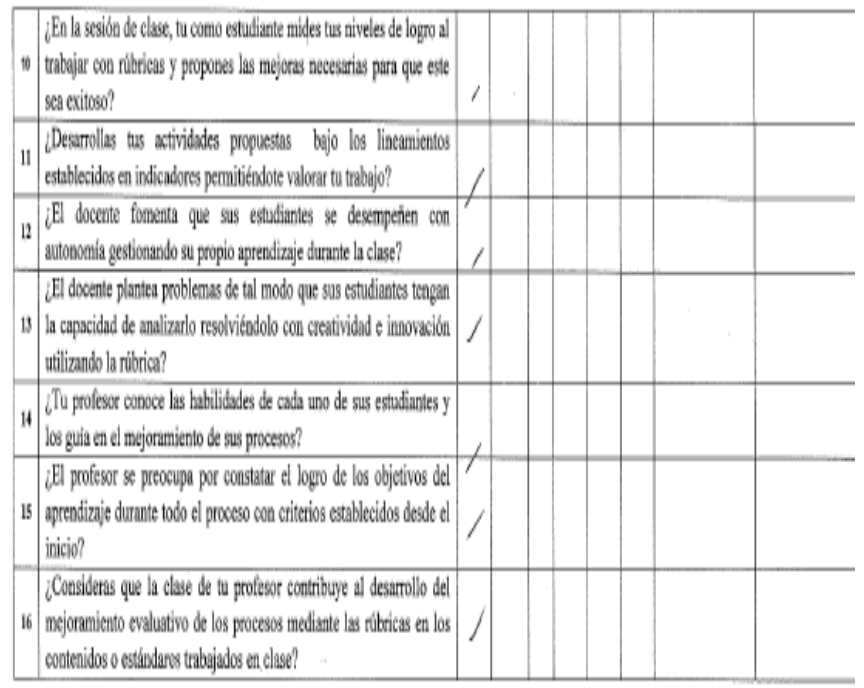

CERTIFICADO DE VALIDEZ DE CONTENDO DE LA GUIA DE OBSERVACIÓN

\begin{tabular}{|c|c|c|c|c|c|c|c|}
\hline \multirow[t]{2}{*}{$m$} & \multirow[t]{2}{*}{ Formulación del ittem } & \multicolumn{3}{|c|}{ 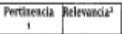 } & 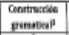 & \multirow[t]{2}{*}{ Cesaraconons } & \multirow[t]{2}{*}{ Sugromaian } \\
\hline & & si & Ko & \begin{tabular}{|l|l|}
$\&$ & $K_{0}$ \\
\end{tabular} & \begin{tabular}{l|l|}
8 & No \\
\end{tabular} & & \\
\hline 1 & $\begin{array}{l}\text { El docente toma en cuenta las nociones, conceptos, saberes previas de sus } \\
\text { estudiantes dentro de la construcción de las aprendizajes. }\end{array}$ & 1 & & & & & \\
\hline 2 & $\begin{array}{l}\text { El docente propicla y construpe con sus estudiantes competenclas } \\
\text { ciudadanas y de convivencia, fomentando un clima de aprendizaje basado } \\
\text { en vabres demostrondolob en el proceso de enserianta aprendizaje. }\end{array}$ & I & & & & & \\
\hline 3 & $\begin{array}{l}\text { Los estudiantes ponen en practica sus habilidades desarrolladeas en el } \\
\text { proceso de aprendizaje. }\end{array}$ & 1 & & & & & \\
\hline 4 & $\begin{array}{l}\text { El estudiante demuestra autonomía gestionando sus proyectos, actividades } \\
\text { o trabajos realizados en la sesión de clases. }\end{array}$ & 1 & & & & & \\
\hline$s$ & $\begin{array}{l}\text { El docentec conoce bas habilidades de sus estudiantes y plantea la mejora de } \\
\text { sus procasos, rotroalimentandolo durante la sesion de clases. }\end{array}$ & 1 & & & & & \\
\hline 1 & 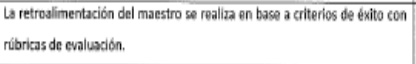 & / & & & & & \\
\hline , & $\begin{array}{l}\text { El docente enseía la utilizodión de la rúbrica como herramienta midiendo } \\
\text { las acciones de su alumnado respecto a su tarea o actividad realizada para } \\
\text { obtener un resultado y poder realizar las mejoras nocesarias con sus } \\
\text { estudiantes respectio a su trabajo. }\end{array}$ & 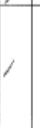 & & & & & \\
\hline 1 & $\begin{array}{l}\text { El estudiante participa en clase araficando su proceso de aprendizaje } \\
\text { proponiendo y arevimentando us diferentes puntos de vista en el aula para }\end{array}$ & & & & & & \\
\hline
\end{tabular}




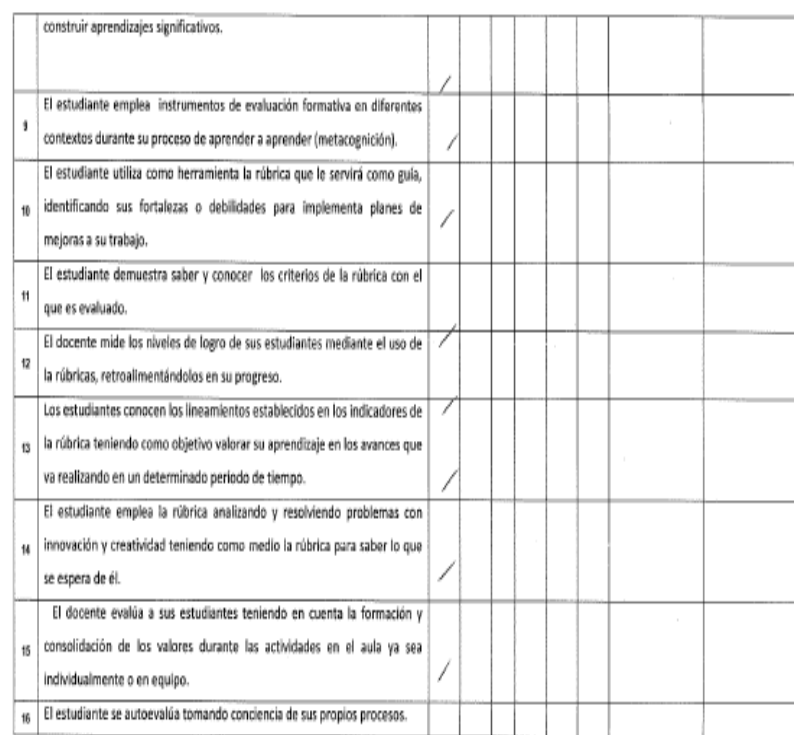

PROGRAMA ACADÉMICO DE MAESTRIA EN EDUCACIÓN EN MENCIÓN GESTIÓN EDUCATIVA

CARTA DE PRESENTACIÓN

La Molina, 22 de febrero del 2019

Senier:

Dr. Goñ Cruz, Féba

Presente:

Asunto: Validación de instrumento, por criterio de especialista

De mi especial cansideración:

Es grato dirigirme a Usted, para expressarle un saludo cordial $\mathrm{e}$ informarte que como parte de desarrollo de la tesis del Programa Académico de Maestria en Educación con mencicin en Gestión de la Educación estoy desarrollando el avance de mi tesis títulada "Rúbrica para desarrollar la evaluación formativa en los estadiantes de oducación secundaria de una institación privada de San Miguel"

Mocivo por el cual se hizo noseserio la elaboración de una matrix de categorización, construcción del instrumento y fiecha de validacicion.

Poe lo expuesto, con la finalidad de dartle rigor cientifico necesario, se requiere la validación de dichos instrumentus a través de la evaluación de Juicio de Expertas. Es por ello, que me permito solicitarle su participacion cesmo juez, apelando su trayectaria y reconocimiento como docente universitario y professional.

Agradeciendo por anticipado su colaboración y aporte en la presente me despido de usted, no sin untes expresarle las sentimientos de consideración y estima personal.

Atentamente;

Rosa Mariel Ascura Lozada

PD. Se adjunta:

- Matriz de categorización

- Instrumentos de recoleccióa de la información

- Ficha de validación de instrumento

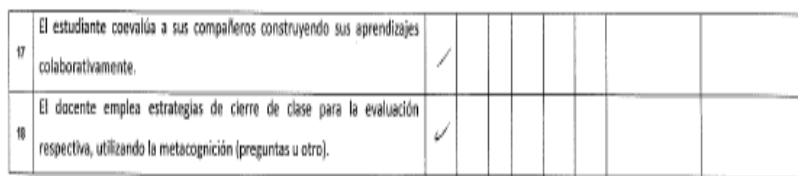

OPINION DE APLICABILLIDAD DE LA GUIA DE OBSERVACIÓN:

\begin{tabular}{|c|c|c|}
\hline Opinión de aplicabilidad: & Aplicable IX] & Aplicable después de corrogir ( ) \\
\hline
\end{tabular}

\begin{tabular}{|c|c|c|c|}
\hline Nentres y Apelilis & RONAL GARNEL ESCOAA & DNIN & $0 6 \longdiv { 6 4 5 1 2 }$ \\
\hline 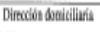 & & Telotion/Cauly & \\
\hline $\begin{array}{l}\text { Thibh forlaixal! } \\
\text { Esposidalal }\end{array}$ & $\begin{array}{l}\text { AuTlopocolo } \\
\text { entechoon. }\end{array}$ & \multirow[t]{2}{*}{ Fima } & \multirow[t]{2}{*}{ Armpo } \\
\hline 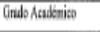 & & & \\
\hline 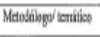 & notolocolas & Lupery fecha & $400403 \mathrm{mw} 201 \mathrm{~s}$ \\
\hline
\end{tabular}

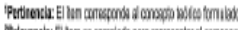

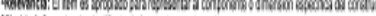

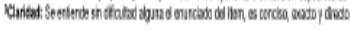

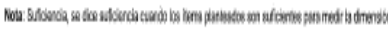

CERTIFICADO DE VALIDEZ DE CONTENDO DE LA GUIA DE OBSERVACIÓN

\begin{tabular}{|c|c|c|c|c|c|c|c|c|}
\hline \multirow[t]{2}{*}{$v$} & \multirow[t]{2}{*}{ Formulación del ittem } & \multicolumn{2}{|c|}{ Pertimasaia } & Raterenosiat & \multicolumn{2}{|c|}{$\begin{array}{l}\text { Comitrocim } \\
\text { graatiaf }\end{array}$} & \multirow[t]{2}{*}{ Obsurwaines } & \multirow[t]{2}{*}{ Sugenentios } \\
\hline & & S & $\mathrm{B}_{0}$ & \begin{tabular}{l|l}
5 & $\mathrm{~N}_{0}$
\end{tabular} & 5 & $K_{0}$ & & \\
\hline 1 & $\begin{array}{l}\text { El docente toma en cuenta las nociones, conceptos, saberes previos de sus } \\
\text { estudezantes dentro de la construcción de los aprendirajes. }\end{array}$ & I & & $/$ & $/$ & & & \\
\hline 2 & 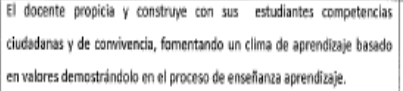 & I & & / & 1 & & & \\
\hline 3 & $\begin{array}{l}\text { Los estudiantes ponen en príctica sus habiliddades desamoladidas en el } \\
\text { proceso de aprendlaje. }\end{array}$ & I & & ( & $<$ & & & \\
\hline 4 & $\begin{array}{l}\text { El estudiante demuestra autonomla gustionando sus proyectos, activitades } \\
\text { o trabales reallzados en la sesión de chses. }\end{array}$ & / & & 1 & l & & & \\
\hline 3 & $\begin{array}{l}\text { El docente coroce las habilidades de sus estudiantos y plantea la mejor de } \\
\text { sus procesos, retroalimentindolo durante la sesion de clases. }\end{array}$ & / & & / & / & & & \\
\hline 6 & 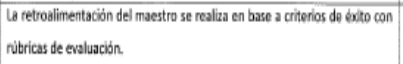 & / & & 1 & I & & & \\
\hline$T$ & 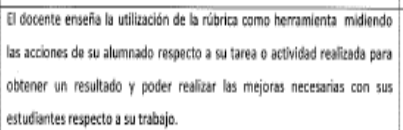 & & & / & 1 & & & \\
\hline 1 & 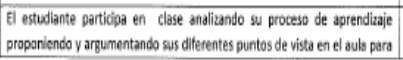 & t & & 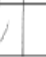 & 1 & & & \\
\hline
\end{tabular}




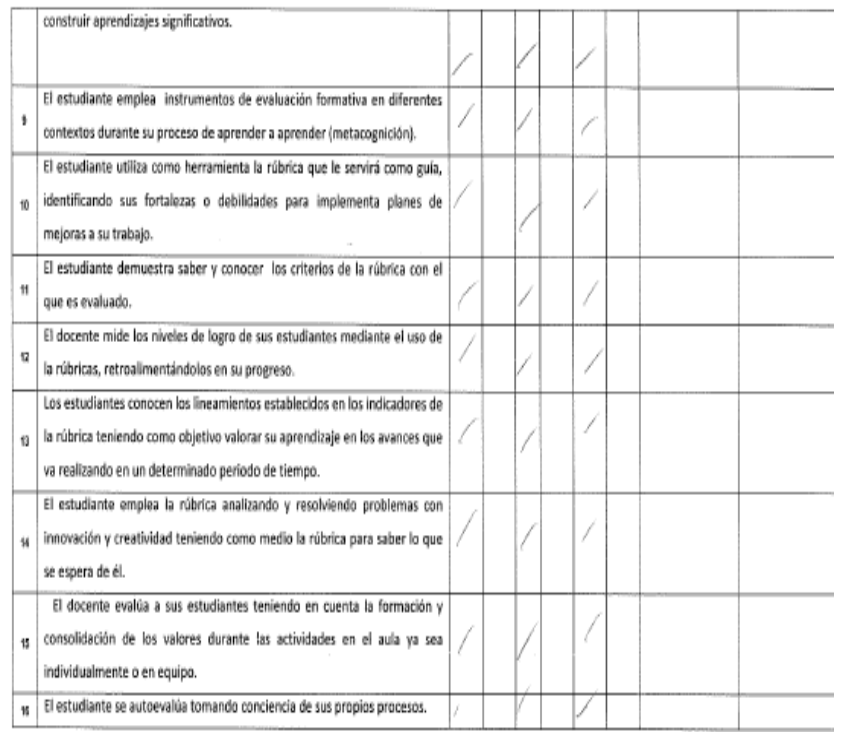

CERTIFCADO DE VALIDEZ DE CONTENDO DEL CUESTIONARIO TOMADO A ESTUDIANTES

\begin{tabular}{|c|c|c|c|c|c|c|c|c|c|}
\hline w & Fomulation del Item & & andar & Vitiean: & & $\begin{array}{l}\text { Geatron } \\
\text { gaxis }\end{array}$ & & Otourvicines & Sugurentau \\
\hline & & $\pi$ & $k_{0}$ & iा & $\mathrm{No}$ & 8 & No & & \\
\hline 1 & $\begin{array}{l}\text { ¿Tu profesor los guia en el proceso pedagdgico indicandoles sus } \\
\text { aciettos y decilidades para que puedan construir su contocimiento? }\end{array}$ & 1 & & $\gamma$ & & / & & & \\
\hline 8 & $\begin{array}{l}\text { ¿Tu profesor analiza los resulados de sus estudiantes, proporiéndoles } \\
\text { o indiciandoles spectos para que puedan męjorar suactividad, trabajo, } \\
\text { realizando retroalimentación? }\end{array}$ & / & & 1 & & 1 & & & \\
\hline 1 & $\begin{array}{l}\text { ¿Tu profesor utiliza instrumentos y les indica cómo utilizartos para } \\
\text { que pudan evaluar sus apreadizajes? }\end{array}$ & 1 & & 1 & & 1 & & & \\
\hline 4 & $\begin{array}{l}\text { ¿Pones en prictica las habilidades desarollandas en el proceso ide } \\
\text { enselanza - aprendizaje con orientaciones de tu docente? }\end{array}$ & 1 & & 1 & & 1 & & & \\
\hline 1 & $\begin{array}{l}\text { ¿Tu profesor fomenta en ustedes la formación en valores, buenas } \\
\text { actitudes en su área acadénica y los evalua en este aspecto? }\end{array}$ & / & & 1 & & I & & & \\
\hline 1 & $\begin{array}{l}\text { ¿Tu profesor toma en cuenta las conpectencias ciudedanas y de } \\
\text { convivencia en las evaluacioates de los trabujos de sus estudiantes } \\
\text { fortaleciendo su asignatura? }\end{array}$ & / & & / & & 1 & & & \\
\hline 1 & $\begin{array}{l}\text { ¿Usted como estudiante coococe y analiza los criterios op pattas para } \\
\text { alcanzar el éxito de as trabajos en clase? }\end{array}$ & $/$ & & V & & 1 & & & \\
\hline 1 & $\begin{array}{l}\text { JEl profeser veifica que sus estudiantes conozzan la rubrica antes de } \\
\text { iniciar su class o actividad para que puedan trabajar con ella? }\end{array}$ & 1 & & ) & & l & & & \\
\hline 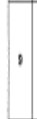 & 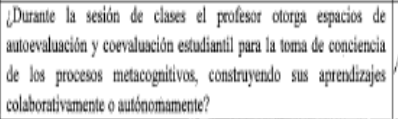 & & & & & i & & & \\
\hline
\end{tabular}

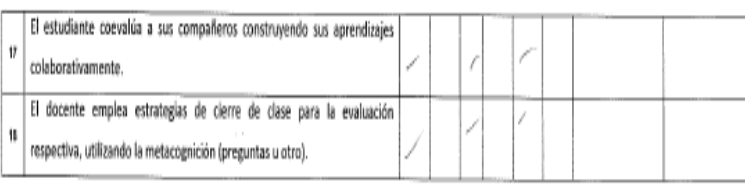

OPNONON DE APLCABBLIDAD DE LA GUAA DE OBSERVACIONN;

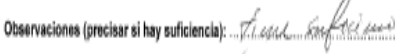

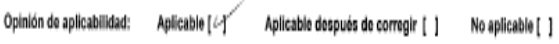

\begin{tabular}{|c|c|c|c|}
\hline 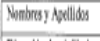 & Fernoudo fodrit Cor & DNIN & $09406 / 5$ \\
\hline 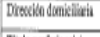 & If cunders sit linse & 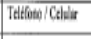 & 98546010 \\
\hline 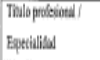 & 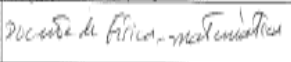 & Fima & \\
\hline Crabli doultinia) & 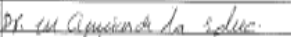 & & \\
\hline 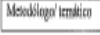 & Nesedow & Lüry & \\
\hline
\end{tabular}

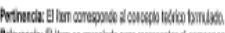

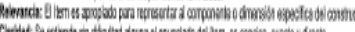

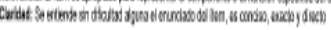

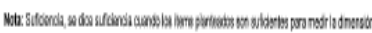

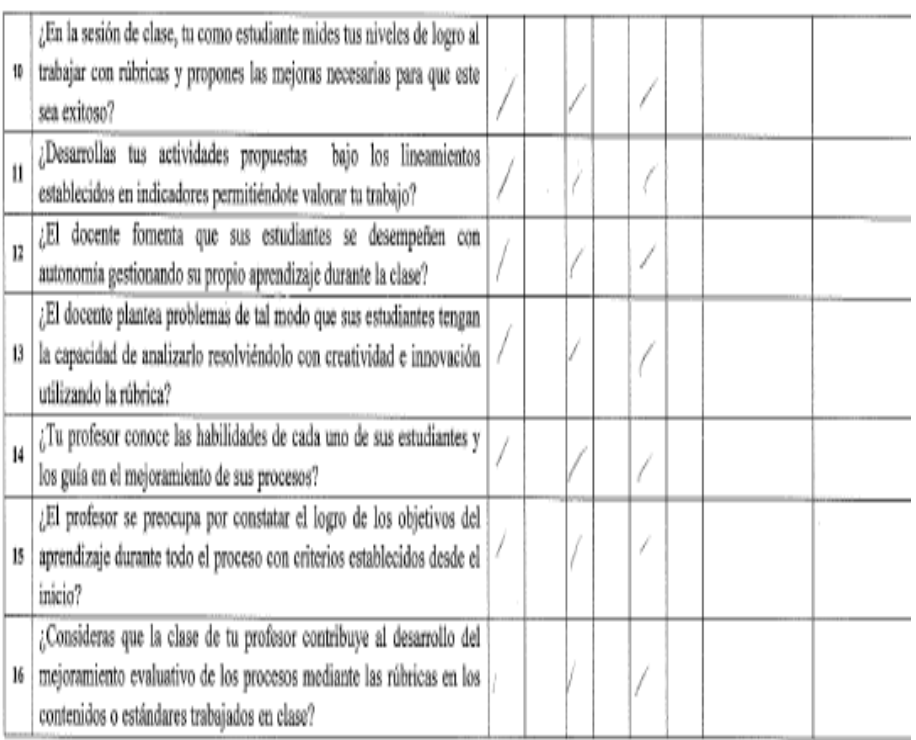


CERTIFICADO DE VALLDEZ DE CONTENDO DE LA ENTREVISTA A DOCENTES

OPINIÓN DE APLICABILIDAD DEL CUESTIONARIO:

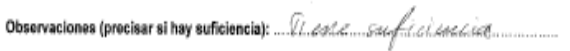

Opinión de aplicabilidad: Aplicable [ 4 Aplicable despuós de corrogir [ ] No aplicablo [ ]

\begin{tabular}{|c|c|c|c|}
\hline Nantikes y Applilides & Farnondo Gon̈i & DNN" & oquUsess \\
\hline Direcolon dorrictiliaria & Tr coñsiasc7 limes & Telefono/Cesilar & 785418510 \\
\hline 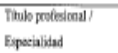 & Docante de firica-Nateminticat & \multirow[t]{2}{*}{$\mathrm{Fim}$} & \\
\hline Orado Aradenico & 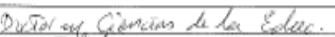 & & \\
\hline Moobology/ teulitico & Madibes & Lagery f frch & le Malua, of $207-18$ \\
\hline
\end{tabular}

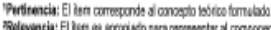

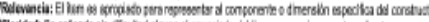

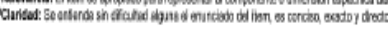

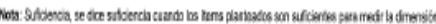

\begin{tabular}{|c|c|c|c|c|c|c|c|}
\hline \multirow[t]{2}{*}{ N } & \multirow[t]{2}{*}{ Formulación del iltem } & \multicolumn{3}{|c|}{ 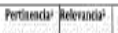 } & 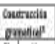 & \multirow[t]{2}{*}{ Otwnetents } & \multirow[t]{2}{*}{ Bupantican } \\
\hline & & \begin{tabular}{l|l}
51 & 10 \\
\end{tabular} & s| $\mathrm{k}$ & 4) 5 & hio & & \\
\hline & 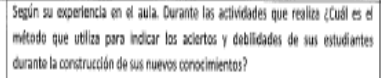 & & / & / & & & \\
\hline 2 & 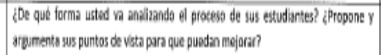 & 1 & / & / & & & \\
\hline 8 & 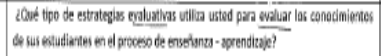 & 1 & $/$ & & 2 & & 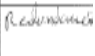 \\
\hline 4 & 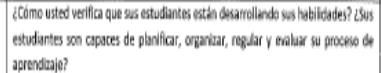 & / & l & 1 & & & \\
\hline 6 & 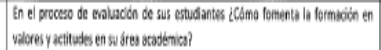 & $/$ & / & $/$ & & & \\
\hline 4 & 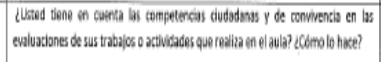 & & / & 1 & & & \\
\hline 1 & 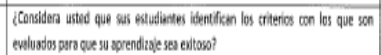 & 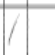 & / & 1 & & & \\
\hline 8 & 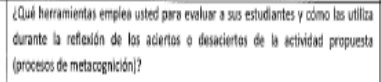 & 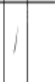 & 1 & 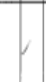 & & & " \\
\hline
\end{tabular}

OPNONONDE APLCABBLIDAD DELAENTREVISTA:

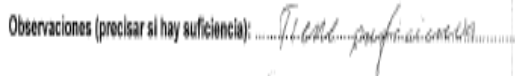

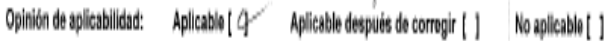

\begin{tabular}{|c|c|c|c|}
\hline Nonitrey Aptilider & 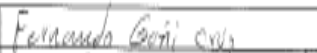 & DNN & 09446915 \\
\hline 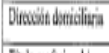 & 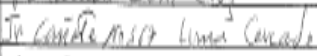 & Tetkimo/Côin & 983410010 \\
\hline $\begin{array}{l}\text { Filub propinal } \\
\text { Epscalidal }\end{array}$ & 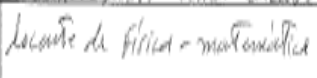 & firis & \\
\hline Oralo haderito & 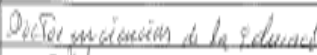 & & \\
\hline Netodolow innitho & ofodolon & Lapy fath & Wa Meho \\
\hline
\end{tabular}

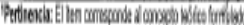

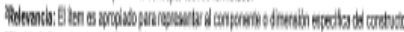

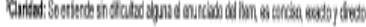

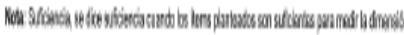


PROGRAMA ACADÉMICO DE MAESTRA EN
EDUCACTON EN MIENCION GESTION EDUCATIVA

CARTA DE PRESENTACIÓN

La Molina, 22 de febrero del 2019

ME. MONTES DE OCA SERPA, JESUS HUGO

Presentez
Asurta: Validación de instrumento, por criterio de especialista

De mi espocial consideración

Es grato dírigirme a Usted, para expresarle un saludo condial e informarle que como parte del desarrollo de ln tesis del Programa Acedémico de Maestria en Educsación con mención en Gestión de la Educacíán estoy desarrollando el avance de mi tesis títulada "Röbrica para desarrollar ta evaluación formativa en los estudiantes de educación secundarin de una institución privada de San Migue!

Motivo por el cual se hizo nocesartio la etaboraciún de una matriz de categorizaciòion. construcción dé instremento y hecha de validación.

Por lo expuesto, con la finsaldad de darle rigor cientifico necesario, se requiere ta validación

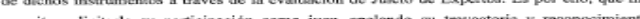

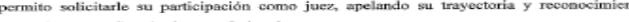

sin antes expresale los sentimientos de consideración y eatima personal.

Alentemente:

Ros Marie

PD. Se adjunta:

: Instrumentoste de recolecónión de la información

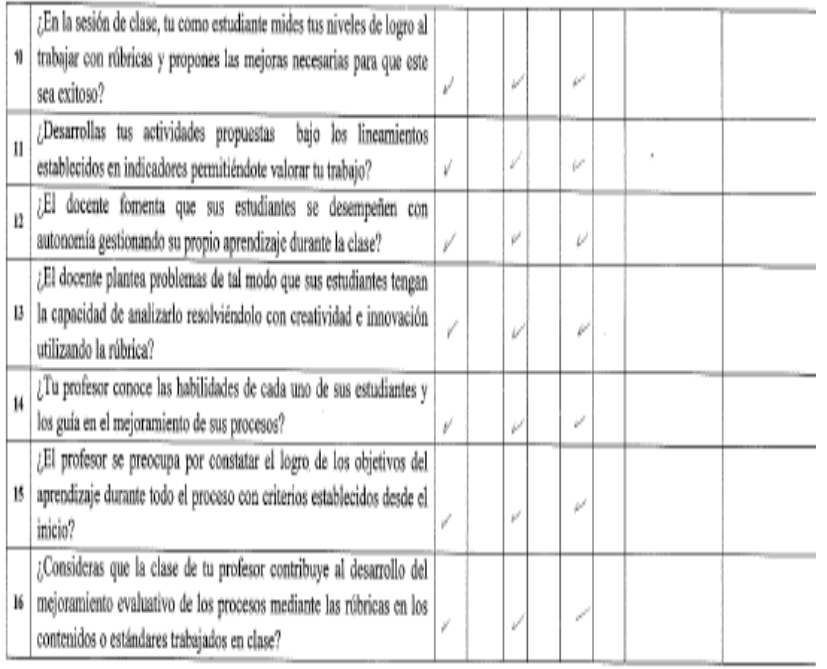

CERTIFICADO DE VALIDEZ DE CONTENDO DEL CUESTIONARIO TOMADO A ESTUDIANTES

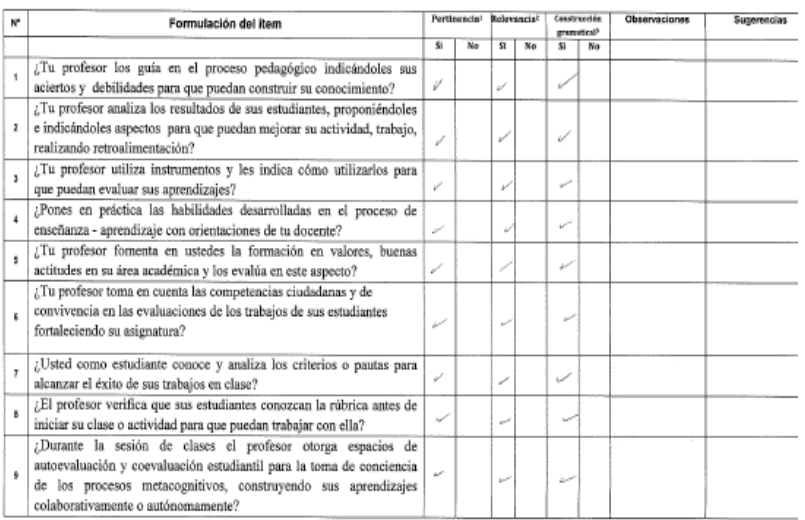

OPINION DE APUICABILIDAD DEL CUESTIONARIO:

Observacionos (procisar si hay guficiencia):

Opinión de applicabilidad: Aplicablo [/] Aplicable después de corregir [ ] No aplicable [ ]

\begin{tabular}{|c|c|c|c|}
\hline Nonbres y Apetilíai & 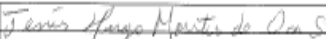 & DNIN & $0660 / 494$ \\
\hline Droscépin demicliarin & Ty- Sebillo isk & Tekfino/ Cenlutar & 999902792 \\
\hline 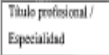 & Lic. ou & $\mathrm{Fmm}$ & \\
\hline Oralo Aradinico & $D_{7} \quad P_{S}$ & & \\
\hline Metobology tunitise & -7 and $z^{2}$ & Lager fictu & 2. \\
\hline
\end{tabular}

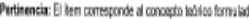

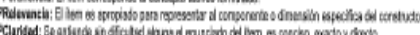

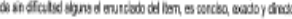

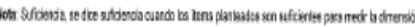


CERTIFICADO DE VALIDEZ DE CONTENDO DE LA ENTREVISTA A DOCENTES

\begin{tabular}{|c|c|c|c|c|c|c|c|}
\hline \multirow[t]{2}{*}{ * } & \multirow[t]{2}{*}{ Formulaclón del it tem } & \multicolumn{2}{|c|}{ 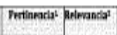 } & \multicolumn{2}{|c|}{ 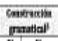 } & \multirow[t]{2}{*}{ Othenandions } & \multirow[t]{2}{*}{ sipentends } \\
\hline & & \begin{tabular}{l|l}
1 & $x_{0}$
\end{tabular} & 511 & 50 & $n^{n}$ & & \\
\hline 1 & 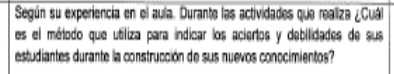 & & r & $v$ & & & \\
\hline 2 & 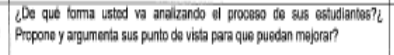 & v & $v$ & v & & & \\
\hline , & 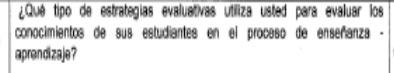 & V & V & V & & & \\
\hline 4 & 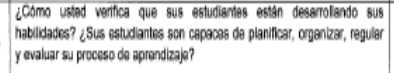 & V & v & $\gamma$ & & & \\
\hline : & 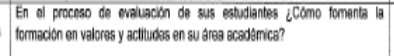 & v & $\checkmark$ & $\sqrt{ }$ & & & \\
\hline 4 & 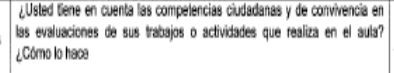 & V & V & v & & & \\
\hline 1 & 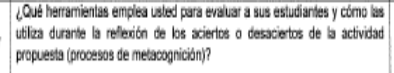 & $\checkmark$ & v & v & & & \\
\hline ' & 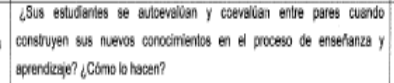 & v & $v$ & $r$ & & & \\
\hline
\end{tabular}

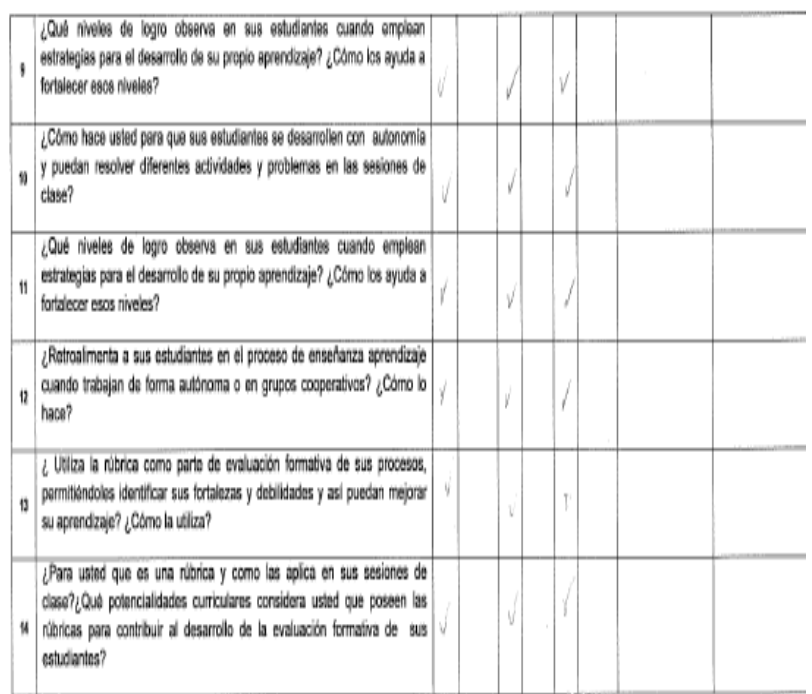

\begin{tabular}{|c|c|c|c|c|c|c|c|}
\hline \multirow[t]{2}{*}{ if } & \multirow[t]{2}{*}{ Formulación del ittem } & \multicolumn{3}{|c|}{ 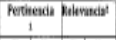 } & 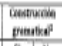 & \multirow[t]{2}{*}{ Comracionen } & \multirow[t]{2}{*}{ Suppromisu } \\
\hline & & s & $\mathrm{N}_{0}$ & $\begin{array}{ll}\mathrm{K} \\
\mathrm{K}\end{array}$ & & & \\
\hline 1 & 1 Il docente toma en cuenta las nociones, concepptos, saberes previos de aus & $r$ & & $r$ & $r$ & & \\
\hline 1 & 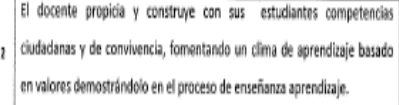 & $r$ & & $r$ & v & & \\
\hline 1 & 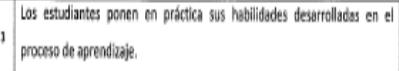 & , & & $r$ & 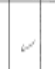 & & \\
\hline 1 & 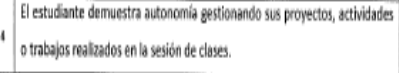 & , & & $\sigma$ & $r$ & & \\
\hline 4 & 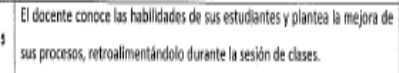 & r & & $r$ & $r$ & & \\
\hline 1 & 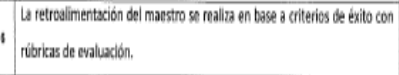 & , & & $r$ & r & & \\
\hline 1 & 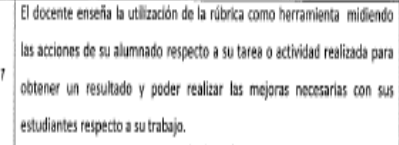 & ' & & $r$ & 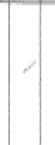 & & \\
\hline & 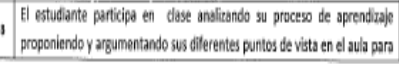 & . & & 4 & $r$ & & \\
\hline
\end{tabular}

\section{CERTIFICADO DE VALLIDEZ DE CONTENDO DE LA GUIA DE OBSERVACIÓN}

\section{OPNONONE APLLCABLDADODE LAENTREVIST:}

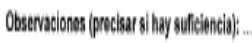

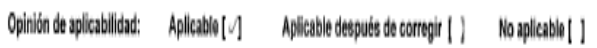

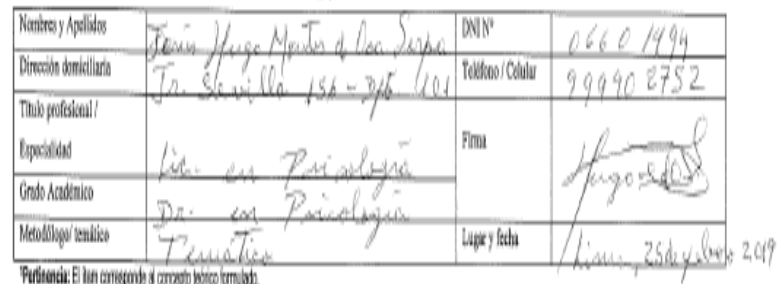

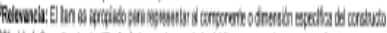

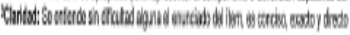

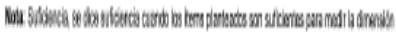




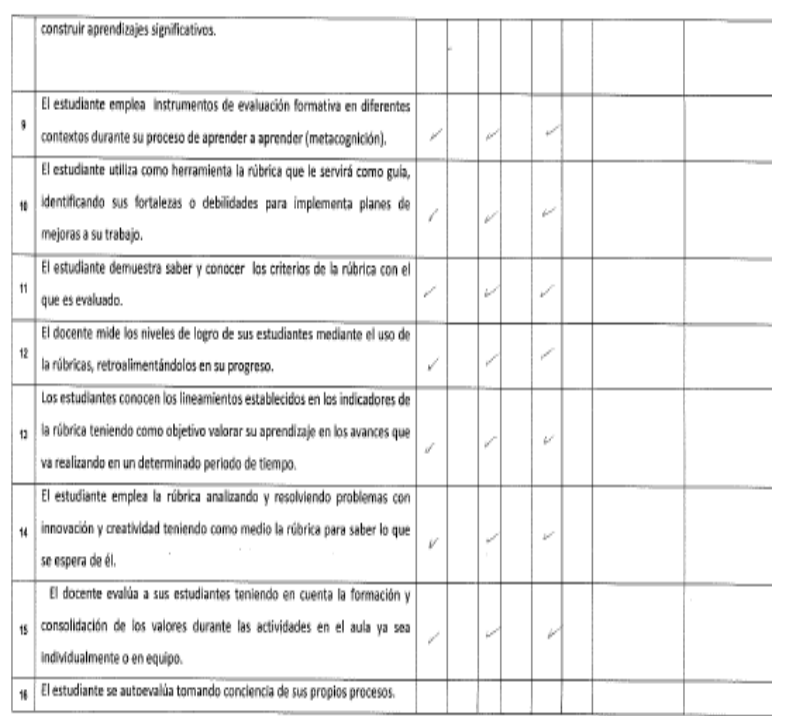

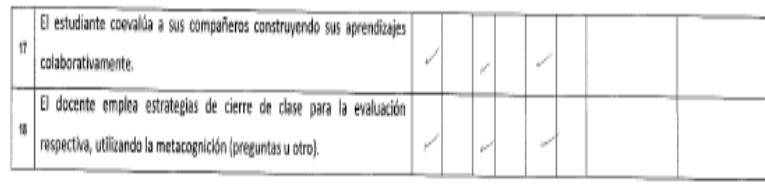

OPNOON DE APLICABLLDAD DE LA GUIA DE OBSERVACION:

Obsarvaciones (procisar si hay sufliencia):

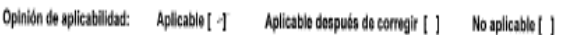

\begin{tabular}{|c|c|c|c|}
\hline 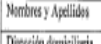 & 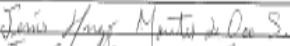 & DNIN & 06001494 \\
\hline Diesctin dunikilini & Tn Sbille is6 sumer & 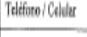 & 499402752 \\
\hline 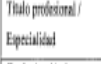 & $P S$ & Fim & \\
\hline Ginto holittrial & $7 x+P_{0}$ & & 78 \\
\hline Masulowi ierbicico & Tenúfies & Lepryfumi & \\
\hline
\end{tabular}

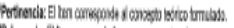

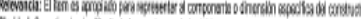

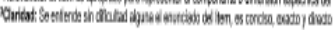

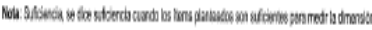




\section{Anexo 4}

\section{GUIA DE ENTREVISTA SEMI-ESTRUCTURADA}

\section{Datos Informativos:}

Entrevistador :

Lugar y Fecha:

Duración :

Entrevistado :

Objetivo: Conocer la experiencia docente en el proceso de enseñanza aprendizaje en el desarrollo de la evaluación formativa en sus estudiantes.

Querido docente: Un gusto saludarlo, la presente entrevista es para conocer su experiencia en aula en el desarrollo de la evaluación formativa en sus estudiantes.

1.- Según su experiencia en el aula. Durante las actividades que realiza ¿Cuál es el método que utiliza para indicar los aciertos y debilidades de sus estudiantes durante la construcción de sus nuevos conocimientos?

2.- ¿De qué forma usted va analizando los procesos cognitivos de sus estudiantes en clases? ¿Propone y argumenta sus puntos de vista para que ellos puedan mejorar?

3.-¿Qué tipo de estrategias evaluativas utiliza usted para evaluar los conocimientos de sus estudiantes en el proceso de enseñanza - aprendizaje?

4.- ¿Cómo usted verifica que sus estudiantes están desarrollando sus habilidades? ¿Sus estudiantes son capaces de planificar, organizar, regular y evaluar su proceso de aprendizaje?

5.- En el proceso de evaluación de sus estudiantes ¿Cómo fomenta la formación en valores y actitudes en su área académica?

6.- ¿Usted tiene en cuenta las competencias ciudadanas y de convivencia en las evaluaciones de sus trabajos o actividades que realiza en el aula? ¿Cómo lo hace?

7.-¿Qué herramientas emplea usted para evaluar a sus estudiantes y cómo las utiliza durante la reflexión de los aciertos o desaciertos de la actividad propuesta (procesos de metacognición)?

8.- ¿Sus estudiantes se autoevalúan y coevalúan entre pares cuando construyen sus nuevos conocimientos en el proceso de enseñanza y aprendizaje? ¿Cómo lo hacen? 
9. ¿Qué niveles de logro observa en sus estudiantes cuando emplean estrategias para el desarrollo de su propio aprendizaje? ¿Cómo los ayuda a fortalecer esos niveles?

10. ¿Cómo hace usted para que sus estudiantes se desarrollen con autonomía y puedan resolver diferentes actividades y problemas en las sesiones de clase?

11.¿Qué niveles de logro observa en sus estudiantes cuando emplean estrategias para el desarrollo de su propio aprendizaje? ¿Cómo los ayuda a fortalecer esos niveles?

12. ¿Retroalimenta a sus estudiantes en el proceso de enseñanza aprendizaje cuando trabajan de forma autónoma o en grupos cooperativos? ¿Cómo lo hace?

13. ¿Utiliza la rúbrica como parte de evaluación formativa de sus procesos, permitiéndoles identificar sus fortalezas y debilidades y así puedan mejorar su aprendizaje? ¿Cómo las utiliza?

14. ¿Para usted que es una rúbrica y como las aplica en sus sesiones de clase?¿Qué potencialidades curriculares considera usted que poseen las rúbricas para contribuir al desarrollo de la evaluación formativa en sus estudiantes?

Muchas gracias por su participación, su aporte ha sido muy valioso. 
Anexo 5

CUESTIONARIO A LOS ESTUDIANTES

\section{Datos Informativos}

Nombre y Apellido :

Institución Educativa :

Grado / Sección : _ Fecha:

\section{Objetivo:}

Determinar si el docente promueve la evaluación formativa en sus estudiantes en el desarrollo de sus sesiones de enseñanza - aprendizaje.

Estimado estudiante, la información que nos proveas en el siguiente cuestionario nos ayudará a mejorar el proceso de enseñanza aprendizaje, por lo que te pedimos que tus respuestas sean lo más sinceras posibles. Marca solo una de las alternativas de acuerdo a la tabla adjunta. Tienes 30 minutos.

\begin{tabular}{|c|c|c|c|c|}
\hline NUNCA & CASI NUNCA & A VECES & CASI SIEMPRE & SIEMPRE \\
\hline 1 & 2 & 3 & 4 & 5 \\
\hline
\end{tabular}

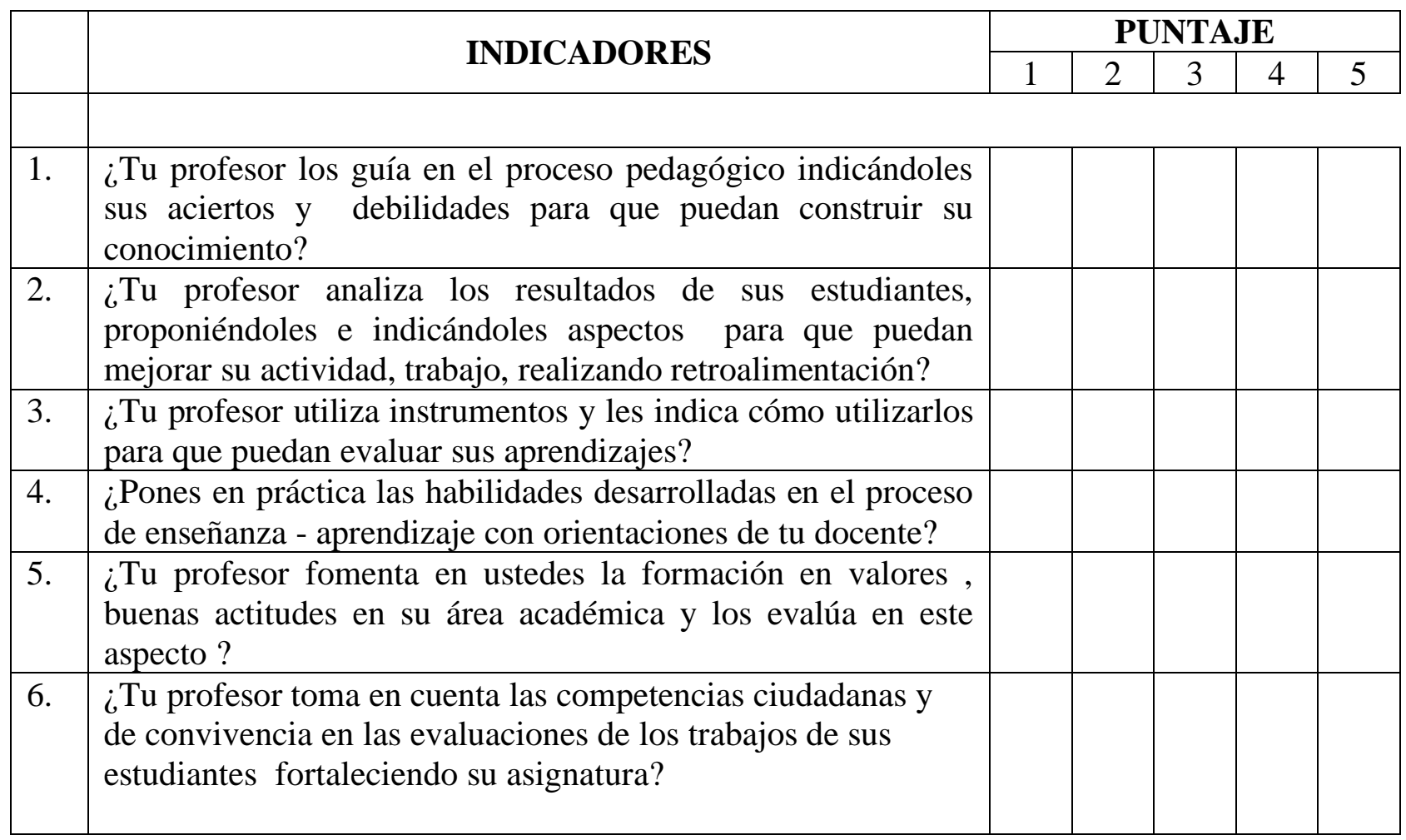




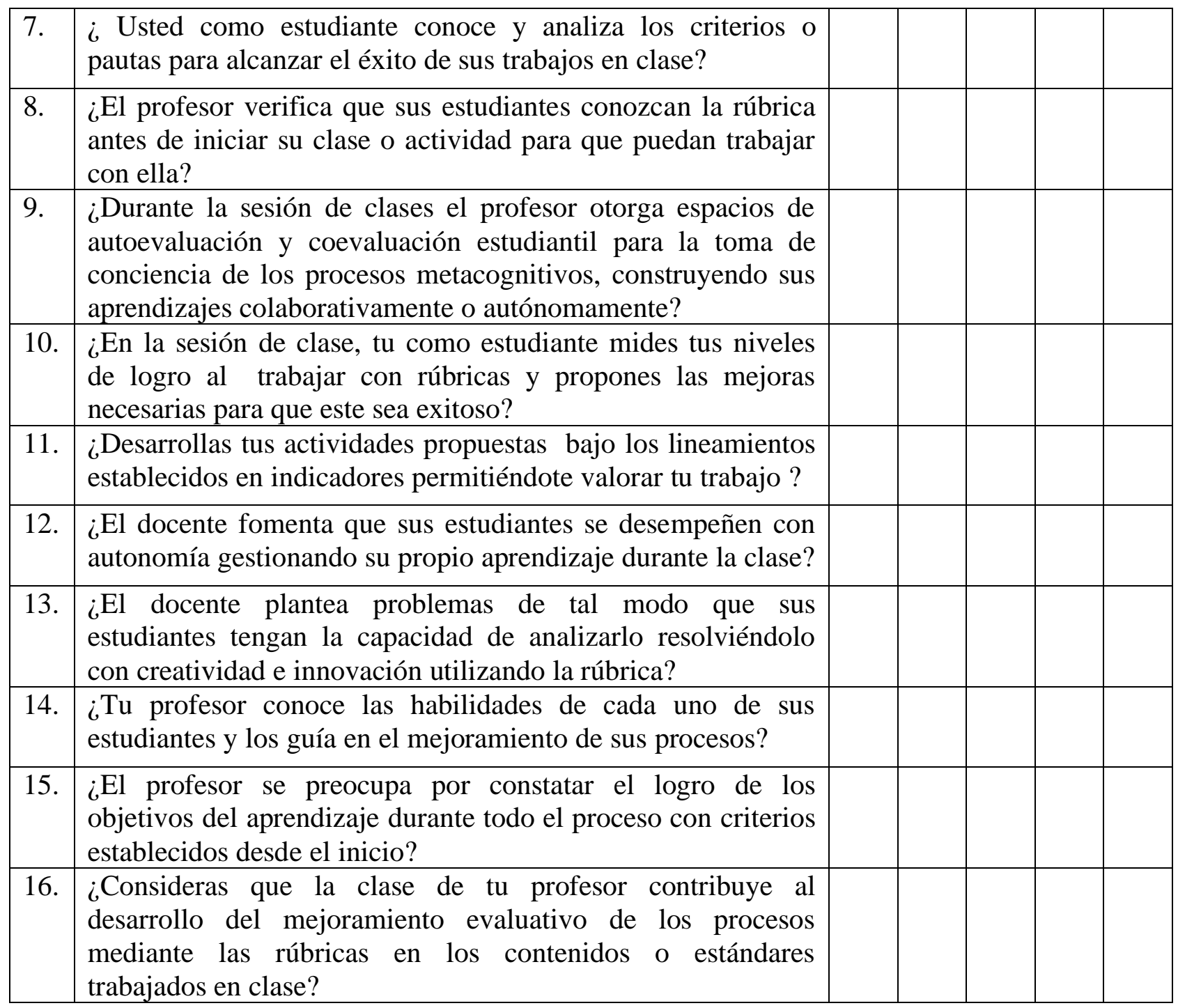

Muchas gracias por tu colaboración... 


\section{Anexo 6}

Guía de observación de sesión de clase

\section{Datos Informativos:}

- Lugar y Fecha de observación:

- Curso:

- Título de la sesión:

- Duración:

- Grado y sección:

- $\mathrm{N}^{\circ}$ de estudiantes:

- Nombre del docente observado:

Objetivo: Identificar si el docente utiliza las rúbricas pedagógicas para desarrollar la evaluación formativa en sus estudiantes.

\section{Iniciación de la actividad:}

\begin{tabular}{|l|l|l|l|}
\hline Indicadores & SI & NO & OBSERVACIONES \\
\hline 1. El docente toma en cuenta las nociones, & & & \\
conceptos, saberes previos de sus & & & \\
estudiantes dentro de la construcción de los \\
aprendizajes.
\end{tabular}

\section{Desarrollo de la actividad:}

\begin{tabular}{|c|c|c|c|}
\hline Indicadores & SI & $\mathrm{NO}$ & OBSERVACIONES \\
\hline $\begin{array}{l}\text { 3. Los estudiantes ponen en práctica sus habilidades, } \\
\text { siendo capaces de organizar, planificar, regular y } \\
\text { evaluar su aprendizaje. }\end{array}$ & & & \\
\hline
\end{tabular}




\begin{tabular}{|l|l|l|l|}
\hline $\begin{array}{l}\text { El estudiante demuestra autonomía gestionando } \\
\text { sus proyectos, actividades o trabajos realizados en } \\
\text { la sesión de clases. }\end{array}$ & & & \\
\hline $\begin{array}{l}\text { El docente conoce las habilidades de sus } \\
\text { estudiantes y plantea la mejora de sus procesos, } \\
\text { retroalimentándolo durante la sesión de clases. }\end{array}$ & & & \\
\hline $\begin{array}{l}\text { La retroalimentación del maestro se realiza en } \\
\text { base a criterios de éxito con rúbricas de } \\
\text { evaluación. }\end{array}$ & & \\
\hline 7. El docente enseña la utilización de la rúbrica como \\
herramienta midiendo las acciones de su \\
alumnado respecto a su tarea o actividad realizada \\
para obtener un resultado y poder implementar las \\
mejoras necesarias con sus estudiantes respecto a \\
su trabajo.
\end{tabular}




\begin{tabular}{|l|l|l|l|}
\hline & & & \\
\hline $\begin{array}{l}\text { 14. El estudiante emplea la rúbrica analizando y } \\
\text { resolviendo problemas con innovación y }\end{array}$ & & & \\
creatividad teniendo como medio la rúbrica para & & & \\
saber lo que se espera de él. & & \\
\hline $\begin{array}{l}\text { 15. El docente evalúa a sus estudiantes teniendo en } \\
\text { cuenta la formación y consolidación de los valores } \\
\text { durante las actividades en el aula ya sea } \\
\text { individualmente o en equipo. }\end{array}$ & & & \\
\hline
\end{tabular}

\section{Cierre de la actividad:}

\begin{tabular}{|c|l|l|l|}
\hline Indicadores & SI & NO & \\
\hline $\begin{array}{l}\text { 16. El estudiante se autoevalúa tomando conciencia } \\
\text { de sus propios procesos. }\end{array}$ & & & \\
\hline $\begin{array}{l}\text { 17. El estudiante coevalúa a sus compañeros } \\
\text { construyendo aprendizajes } \\
\text { colaborativamente. sus }\end{array}$ & & & \\
\hline $\begin{array}{l}\text { 18. El docente emplea estrategias de cierre de clase } \\
\text { para la evaluación respectiva, utilizando la } \\
\text { metacognición (preguntas u otro). }\end{array}$ & & & \\
\hline
\end{tabular}


Anexo 11

\section{Validación de la propuesta}
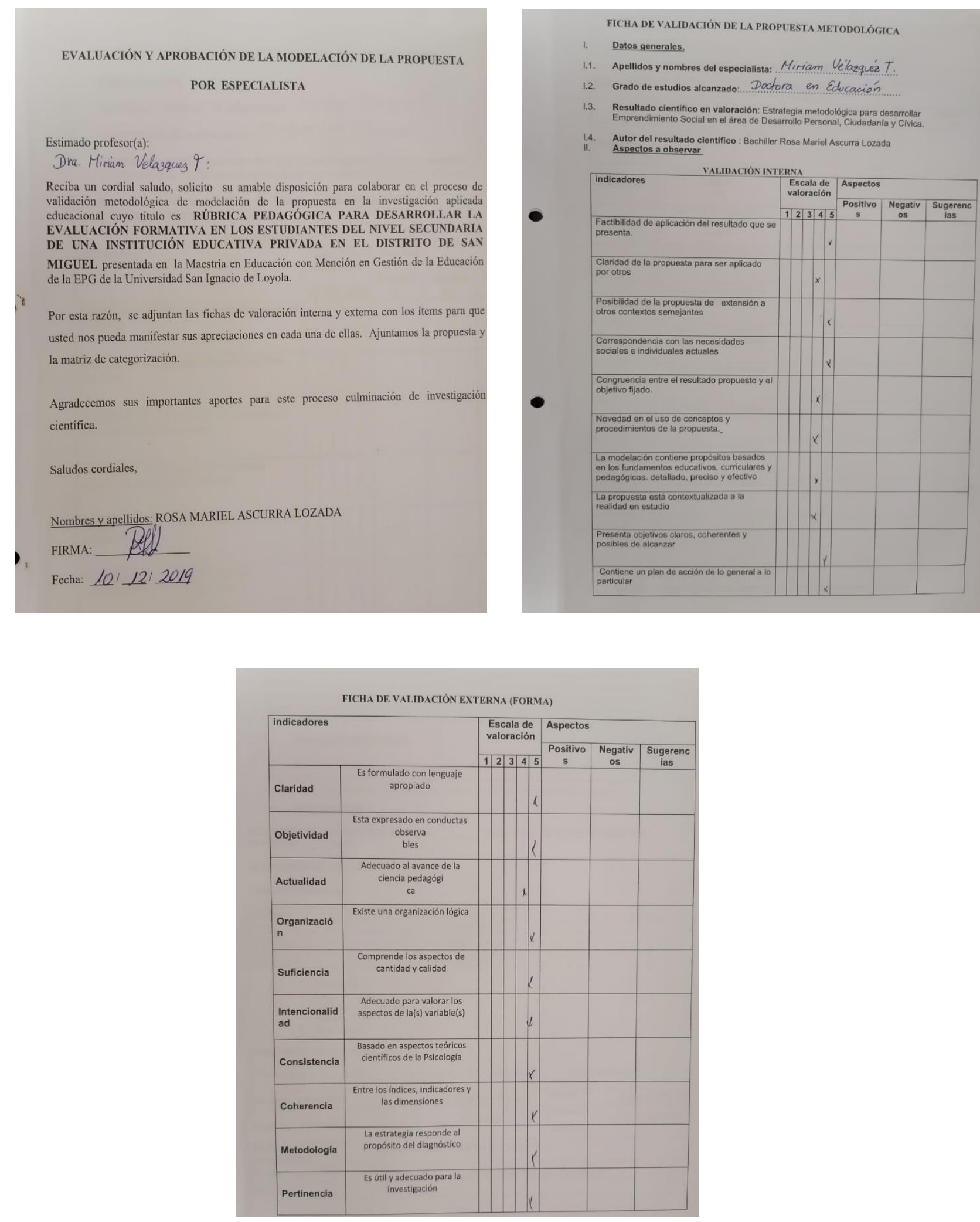
EVALUACIÓN Y APROBACIÓN DE LA MODELACIÓN DE LA PROPUESTA POR ESPECIALISTA

Estimado profesor(a):

Dr. Alejaindro bruzata M.:

Reciba un cordial saludo, solicito su amable disposición para colaborar en el proceso de validación metodológica de modelación de la propuesta en la investigación aplicada cducacional cuyo titulo es RUBRICA PEDAGOGICA PARA DIVEL SECLNDARIA EVALUACION FORMATIVA EN LOS ESTUDIANTES DEL NIVELPITO DE SAN DE UNA INSTITUCIÓN EDUCATTVA PRIVA MIGUEL presentada en la Maestria en Educación con Mención en Gestión de la Educación de la EPG de la Universidad San Ignacio de Loyol.

Por esta razón, se adjuntan las fichas de valoración interna y exterma con los items para que usted nos pueda manifestar sus apreciaciones en cada una de ellas. Ajuntamos la propuesta y la matriz de categorización.

Agradecemos sus importantes aportes para este proceso culminación de investigación cientifica.

Saludos cordiales,

Nombres y apellidos: ROSA MARIEL ASCURRA LOZADA

FIRMA: Reft.

Fecha: $10,12,2019$
FICHA DE VALIDACIÓN DE LA PROPUESTA METODOLÓGICA

1. Datos generales.

1.1. Apellidos y nombres del especialista: ... Alejandro Cruzata

1.2. Grado de estudios alcanzado:.....Pootor en Pedaggía

3esultado cientifico en valoración: Estrategia metodológica para desarrollar

1.4. Autor del resultado cientifico : Bachiller Rosa Mariel Ascurra Lozada

II. Aspectos a observar

\begin{tabular}{|c|c|c|c|c|}
\hline \multirow[t]{2}{*}{ indicadores } & $\begin{array}{l}\text { Escala de } \\
\text { valoración }\end{array}$ & \multicolumn{3}{|l|}{ Aspectos } \\
\hline & \begin{tabular}{l|l|l|l}
1 & 2 & 3 & 4 \\
\end{tabular} & \begin{tabular}{|c|c|} 
Positivo \\
$\mathrm{s}$
\end{tabular} & $\begin{array}{l}\text { Negativ } \\
\text { os }\end{array}$ & $\begin{array}{c}\text { Sugerenc } \\
\text { ias }\end{array}$ \\
\hline $\begin{array}{l}\text { Factibilidad de aplicación del resultado que se } \\
\text { presenta. }\end{array}$ & & & & \\
\hline $\begin{array}{l}\text { Claridad de la propuesta para ser aplicado } \\
\text { por otros }\end{array}$ & & & & \\
\hline $\begin{array}{l}\text { Posibilidad de la propuesta de extensión a } \\
\text { otros contextos semejantes }\end{array}$ & & V & & \\
\hline $\begin{array}{l}\text { Correspondencia con las necesidades } \\
\text { sociales e individuales actuales }\end{array}$ & & & & \\
\hline $\begin{array}{l}\text { Congruencia entre el resultado propuesto y el } \\
\text { objetivo fijado. }\end{array}$ & & & & \\
\hline $\begin{array}{l}\text { Novedad en el uso de conceptos y } \\
\text { procedimientos de la propuesta.- }\end{array}$ & & $V$ & & \\
\hline $\begin{array}{l}\text { La modelación contiene propósitos basados } \\
\text { en los fundamentos educativos, curriculares y } \\
\text { pedagógicos. detallado, preciso y efectivo }\end{array}$ & & $r$ & & \\
\hline $\begin{array}{l}\text { La propuesta está contextualizada a la } \\
\text { realidad en estudio }\end{array}$ & & 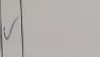 & & \\
\hline $\begin{array}{l}\text { Presenta objetivos claros, coherentes y } \\
\text { posibles de alcanzar }\end{array}$ & & $V$ & & \\
\hline $\begin{array}{l}\text { Contiene un plan de acción de lo general a lo } \\
\text { particular }\end{array}$ & & $V$ & & \\
\hline
\end{tabular}

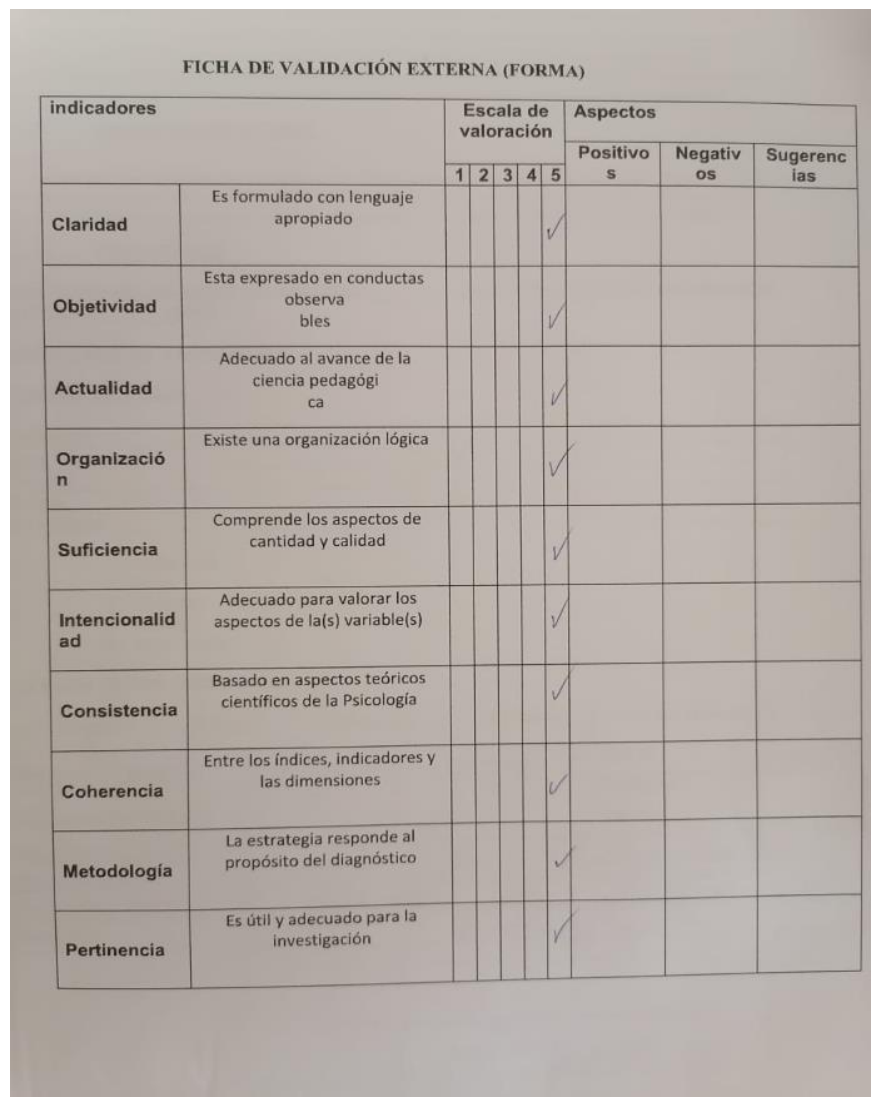




\section{EVALUACIÓN Y APROBACIÓN DE LA MODELACIÓN DE LA PROPUESTA}

\section{POR ESPECIALISTA}

Estimado profesor(a):

Dr. Felix Goni C.

Reciba un cordial saludo, solicito su amable disposición para colaborar en el proceso de lija un en la investigación aplicada validacion metodologica de TÍ educacional cuyo titulo es RUBICA PEDAGOG EVALUACION FORMATIVA EN LOS ESTUDIANTES DEL DISTRITO DE SAN

DE UNA INSTITUCIÓN EDUCATIVA PRIVADA EN EL DISTRITO DE MIGUEL presentada en la Maestria en Edacacion con

Por esta razón, se adjuntan las fichas de valoración interna y externa con los items para que nos pueda manifestar sus apreciaciones en cada una de ellas. Ajuntamos la propuesta y la matriz de categorización.

Agradecemos sus importantes aportes para este proceso culminación de investigació cientifica.

Saludos cordiales,

Nombres y apellidos: ROSA MARIEL ASCURRA LOZADA

FIRMA: Reft)

Fecha: $10,12,2019$

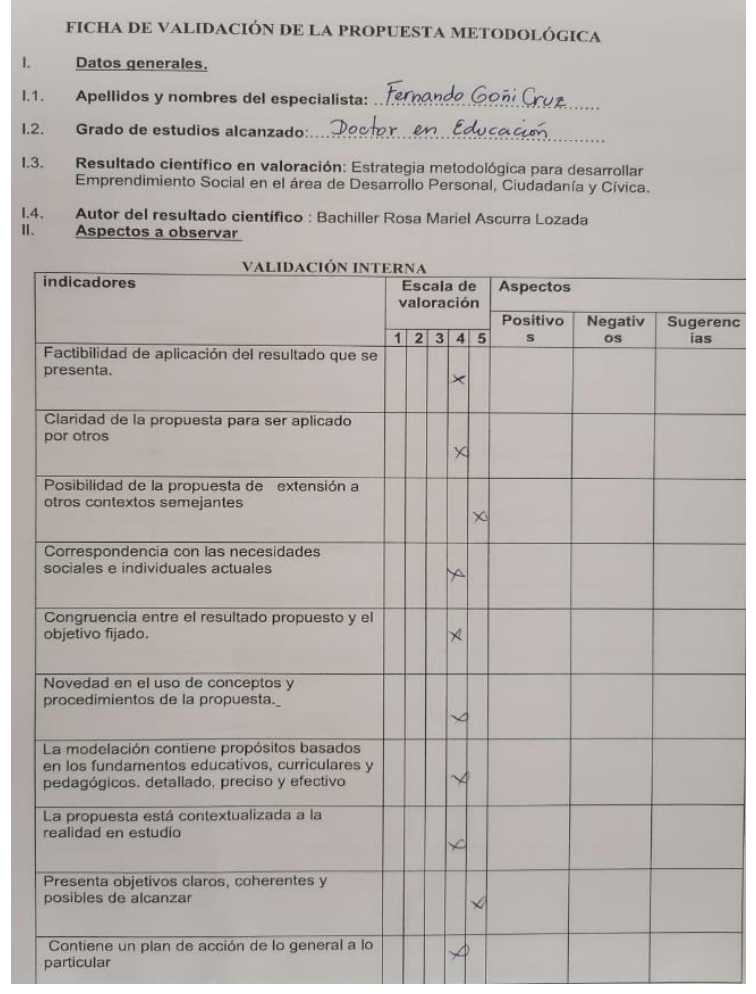

\begin{tabular}{|c|c|c|c|c|c|c|c|}
\hline \multicolumn{8}{|c|}{ FICHA DE VALIDACIÓN EXTERNA (FORMA) } \\
\hline \multirow[t]{2}{*}{ indicadores } & & \multicolumn{3}{|c|}{$\begin{array}{l}\text { Escala de } \\
\text { valoración }\end{array}$} & \multicolumn{3}{|l|}{ Aspectos } \\
\hline & & \begin{tabular}{l|l|}
1 & 2 \\
\end{tabular} & \begin{tabular}{|l|l|}
3 & 4 \\
\end{tabular} & & \multirow[t]{2}{*}{$\begin{array}{c}\text { Positivo } \\
\text { s }\end{array}$} & $\begin{array}{c}\text { Negativ } \\
\text { os }\end{array}$ & \multirow[t]{2}{*}{$\begin{array}{c}\text { Sugerenc } \\
\text { ias }\end{array}$} \\
\hline Claridad & $\begin{array}{c}\text { Es formulado con lenguaje } \\
\text { apropiado }\end{array}$ & & $\phi$ & & & & \\
\hline Objetividad & $\begin{array}{c}\text { Esta expresado en conductas } \\
\text { observa } \\
\text { bles }\end{array}$ & & $x$ & & & & \\
\hline Actualidad & $\begin{array}{l}\text { Adecuado al avance de la } \\
\text { ciencia pedagógi } \\
\text { ca }\end{array}$ & & $x$ & & & & \\
\hline $\begin{array}{l}\text { Organizació } \\
\text { n }\end{array}$ & Existe una organización lógica & & $x$ & & & & \\
\hline Suficiencia & $\begin{array}{l}\text { Comprende los aspectos de } \\
\text { cantidad y calidad }\end{array}$ & & & $x$ & & & \\
\hline $\begin{array}{l}\text { Intencionalid } \\
\text { ad }\end{array}$ & $\begin{array}{l}\text { Adecuado para valorar los } \\
\text { aspectos de la(s) variable(s) }\end{array}$ & & & $x$ & & & \\
\hline Consistencia & $\begin{array}{l}\text { Basado en aspectos teóricos } \\
\text { científicos de la Psicología }\end{array}$ & & $x$ & & & & \\
\hline Coherencia & $\begin{array}{l}\text { Entre los indices, indicadores y } \\
\text { las dimensiones }\end{array}$ & & $x$ & & & & \\
\hline Metodologia & $\begin{array}{l}\text { La estrategia responde al } \\
\text { propósito del diagnóstico }\end{array}$ & & $x$ & & & & \\
\hline Pertinencia & $\begin{array}{l}\text { Es útil y adecuado para la } \\
\text { investigación }\end{array}$ & & $x$ & & & & \\
\hline
\end{tabular}


OPINION DE APLICABILIDAD:

a) Deticiente (, b) Baja (, c) Regular ( ) d) Buera ( ) e) Mur Buena (X)

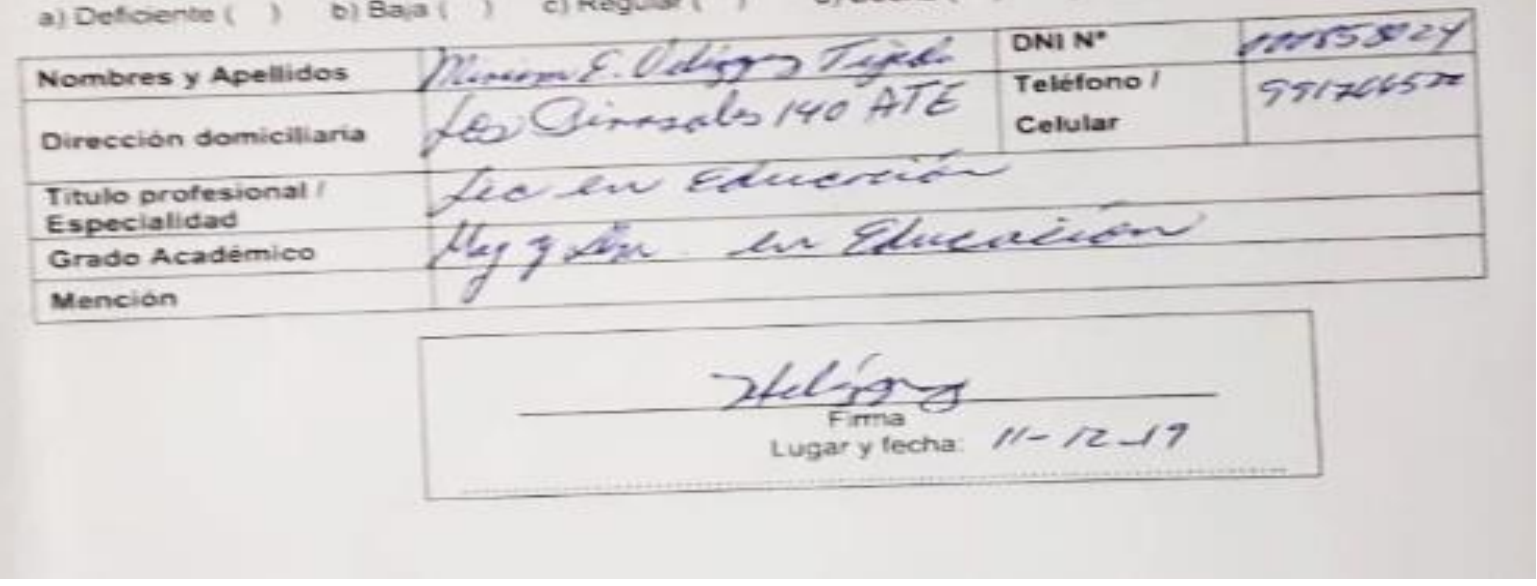

OPINION DE APLICABILIDAD:

a) Deficiente ( ) b) Baja ( ) c)Regular ( , d) Buena ( ) e) Muy Buena ( $)$

Nombres y Apellidos
$\begin{aligned} & \text { Dirección domiciliaria } \\ & \text { Titulo profesional I } \\ & \text { Especialidad } \\ & \text { Grado Académico } \\ & \text { Mención }\end{aligned}$

OPINION DE APLICABILIDAD:
a) Deficiente ( )
b) Baja ( )
c) Regular ( )
d) Buena ( S
e) Muy Buena ( )

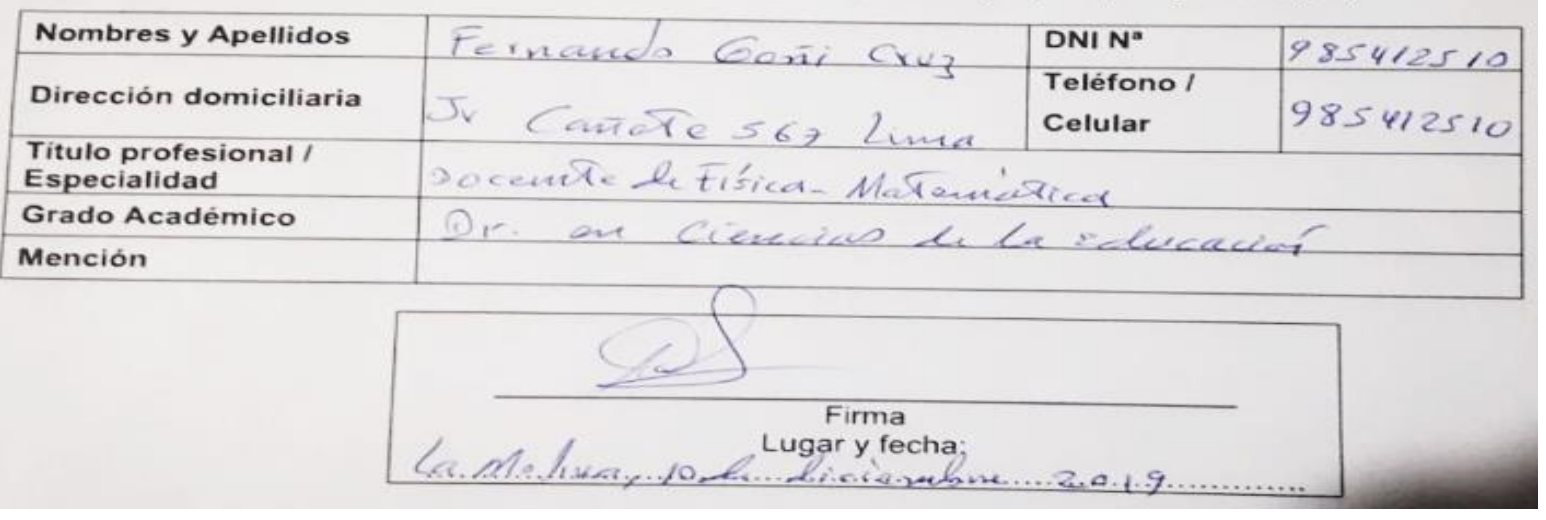


